NBER WORKING PAPER SERIES

\title{
MISALLOCATION IN THE MARKET FOR INPUTS: ENFORCEMENT AND THE ORGANIZATION OF PRODUCTION
}

Johannes Boehm

Ezra Oberfield

Working Paper 24937

http://www.nber.org/papers/w24937

\author{
NATIONAL BUREAU OF ECONOMIC RESEARCH \\ 1050 Massachusetts Avenue \\ Cambridge, MA 02138 \\ August 2018
}

We are grateful to David Baqaee, Hugo Hopenhayn, Sam Kortum, Eduardo Morales, Steve Redding, Matt Rognlie, Meredith Startz, Felix Tintelnot, Gustavo Ventura, Chris Woodruff, and various seminar participants for helpful suggestions. Anusha Guha, Helene Maghin, and Juan Manuel Castro provided excellent research assistance. We are grateful to Daksh India for sharing data, and to CEPR/PEDL and the Sciences Po/Princeton partnership for financial support. Boehm thanks the International Economics Section at Princeton for hospitality during the later stages of the project. This document is an output from the research initiative "Private Enterprise Development in Low-Income Countries" (PEDL), a programme funded jointly by the by the Centre for Economic Policy Research (CEPR) and the Department for International Development (DFID), contract reference PEDL_LOA_4006_Boehm. The views expressed are not necessarily those of CEPR or DFID. All mistakes are our own. The views expressed herein are those of the authors and do not necessarily reflect the views of the National Bureau of Economic Research.

NBER working papers are circulated for discussion and comment purposes. They have not been peer-reviewed or been subject to the review by the NBER Board of Directors that accompanies official NBER publications.

(C) 2018 by Johannes Boehm and Ezra Oberfield. All rights reserved. Short sections of text, not to exceed two paragraphs, may be quoted without explicit permission provided that full credit, including $\odot$ notice, is given to the source. 
Misallocation in the Market for Inputs: Enforcement and the Organization of Production Johannes Boehm and Ezra Oberfield

NBER Working Paper No. 24937

August 2018

JEL No. E23,F12,O11

\begin{abstract}
$\underline{\text { ABSTRACT }}$
The strength of contract enforcement determines how firms source inputs and organize production. Using microdata on Indian manufacturing plants, we show that production and sourcing decisions appear systematically distorted in states with weaker enforcement. Specifically, we document that in industries that tend to rely more heavily on relationshipspecific intermediate inputs, plants in states with more congested courts shift their expenditures away from intermediate inputs and appear to be more vertically integrated. To quantify the impact of these distortions on aggregate productivity, we construct a model in which plants have several ways of producing, each with different bundles of inputs. Weak enforcement exacerbates a holdup problem that arises when using inputs that require customization, distorting both the intensive and extensive margins of input use. The equilibrium organization of production and the network structure of input-output linkages arise endogenously from the producers' simultaneous cost minimization decisions. We identify the structural parameters that govern enforcement frictions from cross-state variation in the first moments of producers' cost shares. A set of counterfactuals show that enforcement frictions lower aggregate productivity to an extent that is relevant on the macro scale.
\end{abstract}

Johannes Boehm

Departement d'Economie

Sciences Po

28 Rue des Saints-Peres

75007 Paris

France

johannes.boehm@sciencespo.fr

Ezra Oberfield

Department of Economics

Princeton University

Julis Romo Rabinowitz Building

Princeton, NJ 08544

and NBER

edo@princeton.edu 


\section{Introduction}

Weak contract enforcement hinders firm-to-firm trade and distorts production decisions. For example, a manager who cannot rely on courts for timely and cheap enforcement may need to purchase low-quality substitutes from her cousin, vertically integrate the production process, or switch to a different technique altogether that avoids the bottleneck input. Regardless of the chosen alternative she will find herself producing at a higher cost. Collectively, the micro distortions induced by weak enforcement alter the equilibrium network structure of production and reduce aggregate productivity.

This paper studies theoretically and empirically how weak legal institutions - more precisely, slow contract enforcement due to congestion of the courts - shapes the organization of production. We develop a framework that allows us to use detailed micro production data to quantify the impact of these frictions on aggregate productivity.

We study contract enforcement frictions in the context of the Indian manufacturing sector. India is a country with infamously slow and congested courts: the World Bank (2016) currently ranks India 172nd (out of 190) when it comes to the enforcement of contracts, behind countries such as the Democratic Republic of Congo (171st) and Zimbabwe (165th). Around $6 \mathrm{~m}$ of the $22 \mathrm{~m}$ pending cases are older than five years, and while India's Law Commission has been advocating vast reforms for several decades, these reforms have not been implemented, and pendency ratios have not decreased. At the same time, India's liberalization and growth has spurred demand for timely enforcement of contracts.

Using plant-level data from India's Annual Survey of Industries, we document several facts about how court congestion alters plants' input choices. While there is an enormous amount of heterogeneity in the input bundles plants use even within narrowly defined (5-digit) industries, ${ }^{1}$ the bundles differ in systematic ways related to the quality of courts. To focus on these differences, we differentiate between inputs that are relatively homogeneous and standardized from those that require customization or are relationship specific, using the classification from Rauch (1999). Users (or potential users) of relationship-specific inputs are most likely to benefit from better formal enforcement of supplier contracts.

Our first fact is that in states where courts are more congested, plants in industries that typically rely on relationship-specific intermediate inputs systematically shift production away from intermediate inputs. This is consistent with slow courts raising the effective cost of relationshipspecific inputs. Second, we show that, where courts are slower, plants in all industries shift the composition of their intermediate input bundles toward homogenous inputs. Third, we construct a new measure of vertical integration and show that, where courts are more congested, plants in industries that typically rely on relationship-specific inputs tend to be more vertically integrated.

\footnotetext{
${ }^{1}$ Some of this heterogeneity reflects different organizational and technological choices. As an example, a plant that produces frozen chicken may purchase live chicken and slaughter and freeze them; or it may purchase chicken feed, and raise, slaughter, and freeze the chicken on the same vertically integrated plant. Other examples indicate horizontal technological choices, e.g., the chicken producer could use a sophisticated machine that mechanically packages the chicken or use more basic implements.
} 
To alleviate concerns that higher court quality might arise endogenously from higher demand for formal contract enforcement, we use an instrumental variable strategy that exploits the historical origins and structure of the Indian judiciary.

To interpret these facts and to quantitatively evaluate their ramifications for aggregate productivity and for the organization of production, we construct a multi-industry general-equilibrium model of heterogeneous firms and intermediate input linkages that form between them. Firms face a menu of technology/organizational choices ("recipes") and draw suppliers along with match-specific productivities. Both primary inputs and relationship-specific inputs are subject to distortions that reflect weak contract enforcement. Each firm chooses the production technique and suppliers that minimize cost. The effective cost of an input depends on the match-specific productivity, the supplier's marginal cost, and the distortion. We model the enforcement distortion for each supplier as randomly drawn to reflect the idea that formal enforcement may only sometimes be relevant at the margin. For example, formal enforcement may not be necessary if the buyer and supplier are engaged in a long-term relationship, are related, or share other social ties.

In our model, distortions alter production choices and build up along entire supply chains. Weak enforcement has a direct impact on producers that use inputs that require contract enforcement, but may also lead firms to switch to suppliers with a higher cost or to an entirely different production technique with a different set of inputs. We think of vertical integration as one such option.

To make quantitative statements, we structurally estimate technological parameters and distributions of wedges that distort the use of relationship-specific intermediate inputs and of primary inputs that are specific to each state. Our identification strategy exploits the idea that the quality of courts should have no impact on the effective cost of homogeneous inputs (which is, if anything, conservative). The identified wedges on relationship-specific intermediate inputs are correlated with the observed speed of the regional courts, in line with the motivating reduced-form regressions.

Our results suggest that courts may be important in shaping aggregate productivity. For each state we ask how much aggregate productivity of the manufacturing sector would rise if congestion were reduced to be in line with the least congested state. On average across states, the boost to productivity is roughly $5 \%$, and the gains for the states with the most congested courts are roughly $10 \%$.

Our model builds on recent models of firm linkages in general equilibrium that include Oberfield (2018), Eaton, Kortum and Kramarz (2015), Lim (2017), Lu, Mariscal and Mejia (2013), Chaney (2014), Acemoglu and Azar (2017), Taschereau-Dumouchel (2017), and Tintelnot et al. (2017)2 and uses aggregation techniques pioneered by Houthakker (1955) and Jones (2005). We model the technology choice and choice of organization concurrently with the sourcing decision, motivated by evidence that increased access to intermediate inputs has a productivity-enhancing effect (e.g. Pavcnik (2002), Khandelwal and Topalova (2011), Goldberg et al. (2010), Bas and Strauss-Kahn (2015)). As in Grossman and Helpman (2002), one producer's choice of organization depends on

\footnotetext{
${ }^{2}$ These are also closely related to models of global value chains and global sourcing such as Costinot, Vogel and Wang (2012), Fally and Hillberry (2015), Antràs and de Gortari (2017), Antras, Fort and Tintelnot (2017).
} 
the industry environment and the choices of other producers.

Our paper is also closely related to the literature on misallocation in developing countries (see Hopenhayn (2014) for a survey). Several papers have extended the work of Hsieh and Klenow (2009) to settings in which distortions affect the use of intermediate inputs, e.g., Jones (2013), Bartelme and Gorodnichenko (2014), Fadinger, Ghiglino and Teteryatnikova (2016), Bigio and La'O (2016), Caprettini and Ciccone (2015), Liu (2017), Caliendo, Parro and Tsyvinski (2017), Osotimehin and Popov (2017), and Baqaee and Farhi (2017). These papers typically posit industry-level production functions and use industry-level data. Our approach of identifying wedges from factor shares (in our case, intermediate input expenditure shares) extends the work of Hsieh and Klenow (2009) along three key dimensions. First, we relate the estimated wedges to the quality of Indian statelevel institutions, which allows us draw policy conclusions from our exercise. Second, we confront the fact that firms produce in very different ways even in narrowly defined industries by explicitly modeling this heterogeneity; we allow firms to choose among several types of technologies (recipes) in the theory and identify these recipes in the data through the application of techniques from statistics/data mining. Third, we identify wedges from systematic differences in first moments, which helps to alleviate concerns about mismeasurement being interpreted as misallocation. ${ }^{3}$ In fact, our model predicts that, even in the absence of distortions, firms that use the same broad technology would use inputs with varying intensities.

The paper is related to the literatures on legal institutions and economic development (La Porta et al. (1997), Djankov et al. (2003), Acemoglu and Johnson (2005), Nunn (2007), Levchenko (2007), Acemoglu, Antràs and Helpman (2007), Laeven and Woodruff (2007) among many others). Ponticelli and Alencar (2016) and Chemin (2012) argue that better courts reduce financial frictions. Amirapu (2017) shows that where district courts in India are more congested, firms in industries that relied on relationship-specific inputs grew faster. Johnson, McMillan and Woodruff (2002) provide survey evidence that reduced trust in courts makes firms that rely on relationship-specific inputs less likely to switch suppliers. By embedding a contracting friction into a general equilibrium model, we explore its quantitative importance for aggregate outcomes. Boehm (2016) characterizes the impact of weak enforcement on aggregate productivity, using cross-country differences in inputoutput tables to show that weak legal institutions have a larger impact on industry pairs that are more vulnerable to holdup problems.

\section{Input Use among Indian Manufacturing Plants}

\subsection{Intermediate Input Use}

We use data from the 2000/01 to 2012/13 rounds of the Annual Survey of Industry (ASI), the official annual survey of India's formal manufacturing sector. The ASI is a panel that covers all establishments with more than 100 employees, and, every year, a fifth of all establishments with more than 20 employees (or more than 10 if they use power). The ASI's unique feature is that

\footnotetext{
${ }^{3}$ See Bils, Klenow and Ruane (2017) and Rotemberg and White (2017).
} 


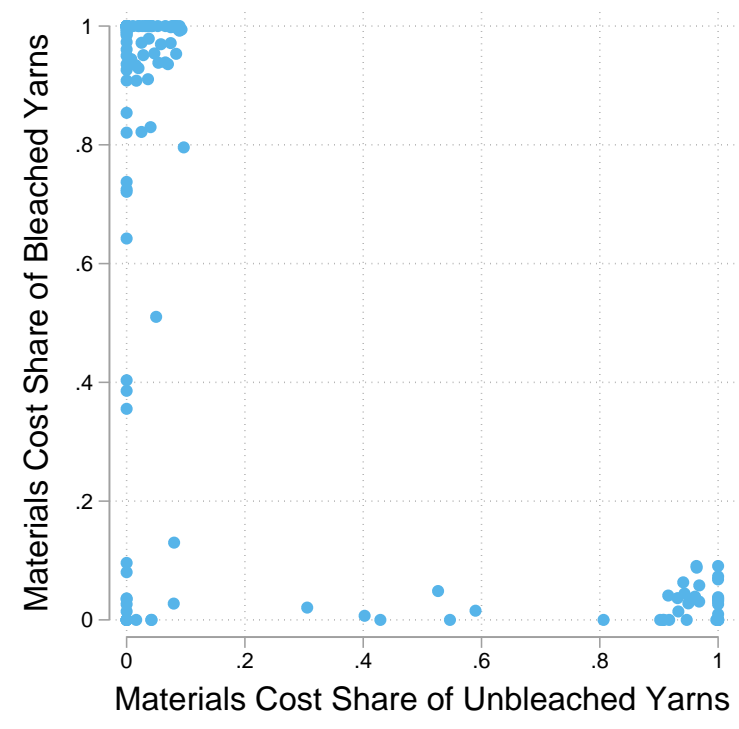

(a) Input mixes for Bleached Cotton Cloth (63303)

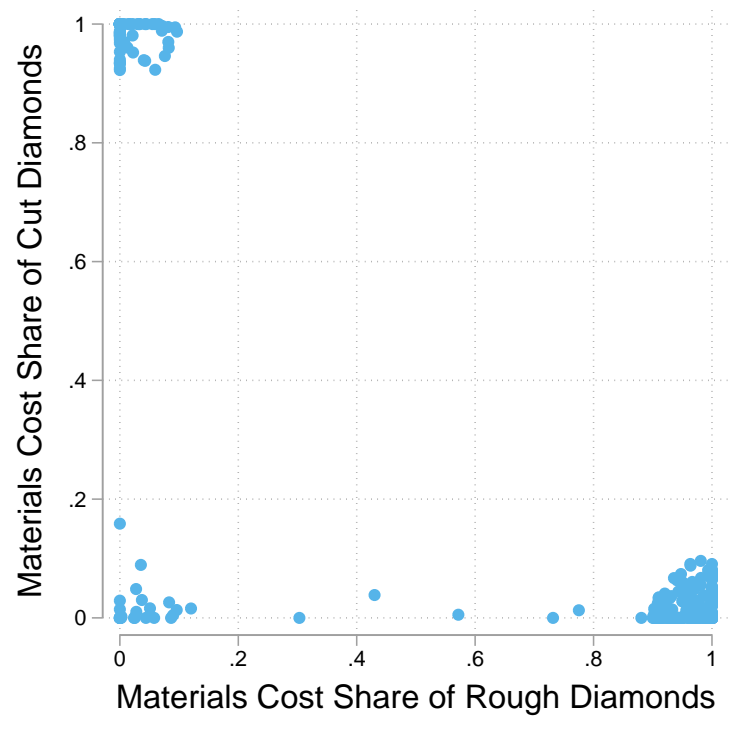

(b) Input mixes for Polished Diamonds (92104)

Figure 1 Heterogeneity in input mixes within narrow industries

In the left panel, "bleached yarns" refer to yarns that have been bleached or dyed. Each dot refers to a plant-year observation. We include only single-product plants. Observations on the bottom left mostly produce their output from unbleached cloth (left panel) or industrial diamonds (right panel). Points have been jittered to improve readability.

it contains detailed product-level information on each plant's intermediate inputs and outputs. Products codes are at the 5-digit level, of which there are around 5,200 codes in their classification. The product classification remains largely unchanged during the years 2000/01 to 2009/10. The rounds 2010/11 to 2012/13 use a different (albeit similar) product classification, and we bring product-level data to the classification of the earlier years using the official concordance table published by the Ministry of Statistics. Appendix A contains more details on the data and a description of our sample.

One striking feature of the data is that even in narrowly defined industries, plants produce using very different input bundles. Figure 1 shows two examples that are particularly clear. Among respective producers of bleached cotton cloth and polished diamonds, output is made using different sets of inputs. While we believe that much of the heterogeneity in organization and input bundles is not associated with inefficiencies and would arise naturally, Section 2.3 below shows that some of the differences are systematically related to court congestion.

Intermediate inputs vary in their degree to which buyers and sellers are subject to hold-up problems. Producers of goods that are tailored to a particular buyer ("relationship-specific") may find that buyers refuse to pay for the supplied good, knowing that they are useless to anyone but themselves (Iyer and Schoar (2008)). We use the Rauch (1999) classification that divides goods into homogeneous goods (those that are traded on organized exchanges or for which a reference price exists), and relationship-specific goods (the remainder). Holdup problems are more likely to arise 
with relationship-specific inputs. Firms may rely more heavily on judicial institutions to enforce supplier contracts when trading goods belonging to the latter category (Johnson, McMillan and Woodruff (2002)).

\subsection{Court Congestion in India}

Among all ills of the Indian judicial system, its slowness is perhaps the most apparent one. As of 2017, about nine percent of pending cases in district courts and six percent of pending cases in High Courts are older than ten years. ${ }^{4}$ Some cases make international headlines, such as in 2010, when the Bhopal District Court convicted eight executives for death by negligence during the 1984 Bhopal gas leak which killed thousands of people. The conviction took place some 25 years after the disaster; one of the eight executives had already passed away, and the remaining seven appealed the conviction. ${ }^{5}$

The slowness of the Indian courts is at least partly due to the uneven distribution of workload across its three tiers. ${ }^{6}$ The lowest tier is the Subordinate (District) Courts, which have courthouses in district capitals and major cities. ${ }^{7}$ The next tier are the High Courts, of which there generally exists one for each state, and which have both appellate and original jurisdiction over cases originating from their state (and sometimes an adjacent union territory). High Courts also administer subordinate courts in their jurisdiction. The highest tier is the Supreme Court of India. All three tiers are heavily congested, with district courts facing the additional problems that judges are often inexperienced and make erroneous decisions. While contract cases between firms should, in principle, be filed at the district level, litigants typically bypass this step by claiming an infringement of their fundamental rights or appealing to the constitution of India, in which case they are permitted to file the claim directly at a high court. ${ }^{8}$ High Court judges, often taking a dim view of the subordinate judiciary, tend to accommodate this practice. The result is that the Indian judiciary is relatively heavy in its upper levels, with only the simplest cases being dealt with in the subordinate courts. ${ }^{9}$ For better or worse, it is the quality of the higher judiciary that determines whether and how contracts can be enforced.

We construct a measure of court quality from microdata on pending civil cases in High Courts, which the Indian NGO Daksh collects from causelists and other court records (Narasappa and Vidyasagar (2016)). These records show the status and age of pending and recently disposed cases,

\footnotetext{
${ }^{4}$ Figures for district courts are from the National Judicial Data Grid (2017). Figures for High Courts are based on authors' calculations from the Daksh data (see below).

5 "Painfully slow justice over Bhopal", Financial Times, June 7, 2010.

${ }^{6}$ See Robinson (2016) for an overview of the Indian judiciary. Hazra and Debroy (2007) discuss its problems in relation to economic development.

${ }^{7}$ Districts are the administrative divisions below states. Between 2001 and 2010 there were around 620 districts and 28 states in India. Union territories are small administrative divisions (typically cities or islands) that are under the rule of the federal government, as opposed to states, which have their own government.

${ }^{8}$ Some High Courts, such as the High Courts of Bombay, Calcutta, Madras, and Delhi, even allow civil cases to be filed directly whenever the claim exceeds a certain value.

${ }^{9}$ Between 2010 and 2012, about $40 \%$ of all disposed cases in subordinate courts were related to traffic tickets, another seven percent related to bounced cheques (Law Commission of India (2014)).
} 
along with characteristics of the case, such as the act under which the claim was filed or a case type categorization. Our measure of high court quality is the average age of pending civil cases in each court, at the end of the calendar year 2016. Whenever a high court has jurisdiction over two states and a separate bench in each of them (such as the Bombay High Court, which has jurisdiction over Maharashtra and Goa), we construct the statistic by state. We prefer this measure over existing measures of the speed of enforcement, such as pendency ratios published by the High Courts, which suffer from the problem that different high courts measure pendencies in vastly different ways (as recently emphasized by the Law Commission of India (2014)).

The average age of pending civil cases varies substantially across high courts - from less than one year in Goa and Sikkim, to about four and a half years in Uttar Pradesh and West Bengal. The cross-state average is two and a half years. These differences can be seen in Figure 2.

The problems of the Indian judiciary are not a recent phenomenon, and have not gone unnoticed. Throughout the modern history of India as an independent nation, the Law Commission of India has pointed out the enormous backlogs and arrears of cases (14th report, 1958, 79th report, 1979, 120th report, 1987, and 245th report, 2014), and suggested a plethora of policies to alleviate the situation. The vast majority of these proposals have not been adopted, and the few exceptions seem to have had little impact. Overall, the backlogs have slowly but continually accumulated.

The main explanation for why court speed varies so much across states lies in the history of India's political subdivisions. The first high courts (Madras, Bombay, and Calcutta) were set up by the British in the 1861 Indian High Courts Act, and served as the precursor for India's post-independence high courts. Upon independence, India was divided into a number of federated states, with the Constitution of India (1947) mandating a high court for each state. Throughout the twentieth century and beyond, India has frequently subdivided its states, often because of ethno-nationalist movements. These subdivisions were often accompanied with new high courts being set up, which then start without any existing backlog of cases. ${ }^{10}$ The age of the high court is hence a strong determinant of its speed of enforcement (see Figure 2). We will later use the age of high courts as an instrument for its quality.

\subsection{Motivating Facts}

We first turn to documenting the correlation between court quality and plants' intermediate input use. For the sake of preciseness we restrict our attention here to single-product plants. ${ }^{11}$

Fact 1 In states with worse formal contract enforcement, cost shares of intermediate inputs are relatively lower in industries that tend to rely more on relationship-specific intermediate inputs.

Table I shows regressions of the plants' materials cost share on an interaction of court quality (as measured by the average age of pending cases in the state's high court) and the industry's reliance

\footnotetext{
${ }^{10}$ Table VII in the data appendix summarizes the reasons for the high court being set up, or the state being formed.

${ }^{11}$ One difficulty that arises when studying multi-product plants is that we do not observe which inputs are used to produce each product. Nevertheless, the results in this section are quantitatively similar when we include multiproduct plants and assign the plant to the category of its highest-revenue product.
} 


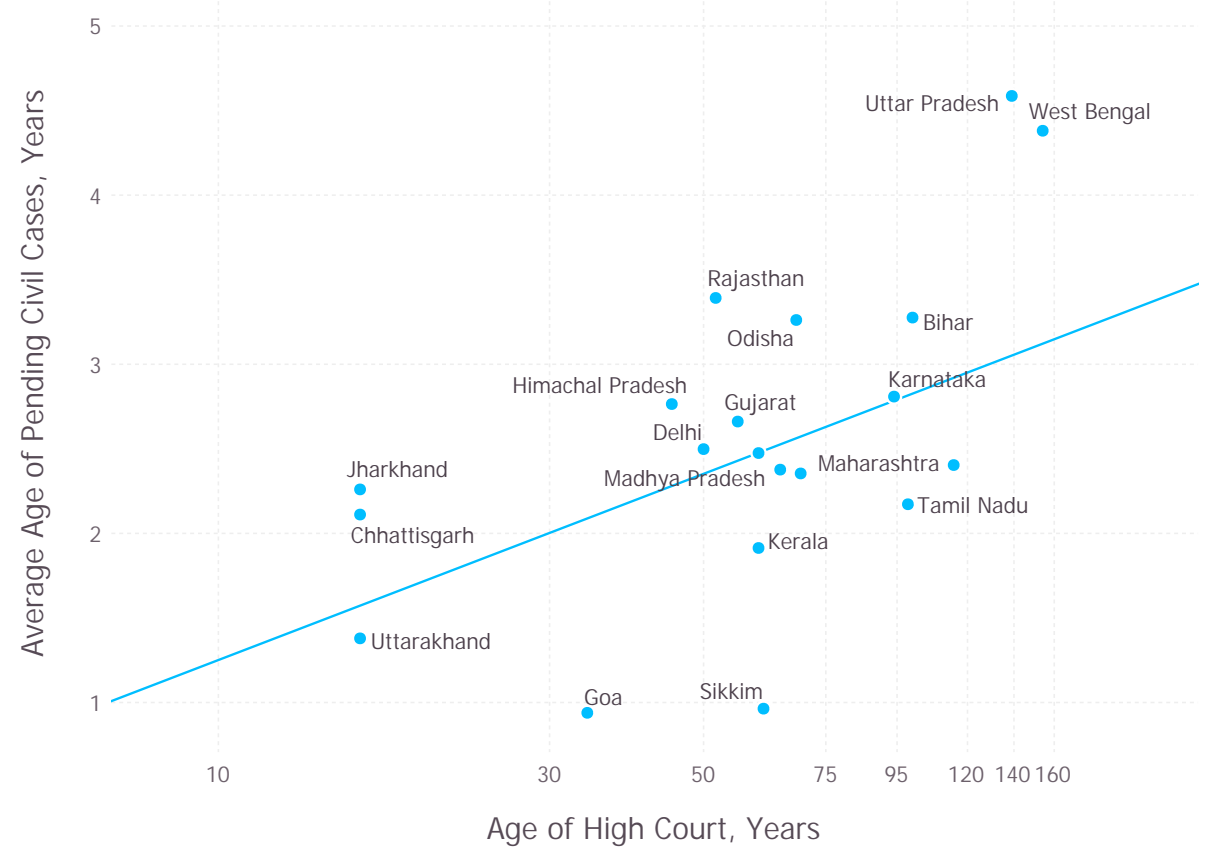

Figure 2 Age of the High Court and Speed of Enforcement

on relationship-specific inputs. ${ }^{12}$ The interaction term has a negative and significant coefficient, showing that, within industries, in states where courts are slow, materials cost shares are relatively lower in industries that depend heavily on relationship-specific inputs. ${ }^{13}$ The magnitude in column (1) indicates that for each additional year of court congestion, plants' materials share of cost declines by 1.67 percentage points more in industries that rely on relationship-specific inputs than in industries that rely on standardized inputs.

A primary concern in this specification is that court congestion is standing in for the level of development, or that the level of development is correlated with the relative productivity of industries that rely on relationship-specific inputs. Column (1) includes district fixed effects . Column (2) controls for the interaction of relationship specificity with district income per capita and column (3) adds controls for the interaction of relationship specificity with a variety of state characteristics including measures of trust, corruption, linguistic fragmentation, and fragmentation by caste. While the coefficients (reported in Appendix C) suggest that ethnolinguistic homogeneity facilitates the use of relationship-specific inputs, this appears to be orthogonal to court congestion. Finally, columns (4) to (6) employ an instrumental variables strategy that we discuss below in Section 2.4 .

\footnotetext{
${ }^{12}$ We measure an industry's reliance on relationship-specific inputs at the national level by computing the fraction of intermediate input expenditures spent on relationship-specific inputs across all plants in the industry. See Appendix A.1 for details.

${ }^{13}$ In principle firms may file claims in the courts of any state - it is then up to the court to decide whether it has jurisdiction over the contract. Our results suggest that plants typically find it costly to use courts outside their state.
} 
Table I Materials Shares and Court Quality (Fact 1)

\begin{tabular}{|c|c|c|c|c|c|c|}
\hline & \multicolumn{6}{|c|}{ Dependent variable: Materials Expenditure in Total Cost } \\
\hline & $(1)$ & $(2)$ & $(3)$ & (4) & $(5)$ & (6) \\
\hline Avg Age Of Civil Cases * Rel. Spec. & $\begin{array}{c}-0.0167^{* *} \\
(0.0046)\end{array}$ & $\begin{array}{c}-0.0129^{*} \\
(0.0051)\end{array}$ & $\begin{array}{c}-0.0118^{*} \\
(0.0053)\end{array}$ & $\begin{array}{c}-0.0156^{+} \\
(0.0085)\end{array}$ & $\begin{array}{c}-0.0201^{*} \\
(0.0082)\end{array}$ & $\begin{array}{c}-0.0212^{* *} \\
(0.0078)\end{array}$ \\
\hline LogGDPC * Rel. Spec. & & $\begin{array}{c}0.0114 \\
(0.0086)\end{array}$ & $\begin{array}{c}0.0102 \\
(0.0091)\end{array}$ & & $\begin{array}{c}0.00710 \\
(0.0095)\end{array}$ & $\begin{array}{l}0.00556 \\
(0.0096)\end{array}$ \\
\hline Rel. Spec. $\times$ State Controls & & & Yes & & & Yes \\
\hline 5-digit Industry FE & Yes & Yes & Yes & Yes & Yes & Yes \\
\hline District FE & Yes & Yes & Yes & Yes & Yes & Yes \\
\hline Estimator & OLS & OLS & OLS & IV & IV & IV \\
\hline$R^{2}$ & 0.480 & 0.482 & 0.484 & 0.480 & 0.482 & 0.484 \\
\hline Observations & 208527 & 199544 & 196748 & 208527 & 199544 & 196748 \\
\hline
\end{tabular}

Fact 2 In states with worse formal contract enforcement, intermediate input bundles are tilted towards standardized intermediate inputs.

Our first fact related court quality to how plants divided their expenditures between intermediate and primary inputs. We next study how the composition of plants' intermediate input baskets covaries with court quality. Table II shows that in states where courts are faster, plants' intermediate input baskets are tilted towards relationship-specific intermediate inputs. This correlation remains statistically significant when controlling for district income per capita and other state characteristics.

Table II Input Mix and Court Quality (Fact 2)

\begin{tabular}{|c|c|c|c|c|c|c|}
\hline & \multicolumn{6}{|c|}{ Dependent variable: $X_{j}^{R} /\left(X_{j}^{R}+X_{j}^{H}\right)$} \\
\hline & $(1)$ & $(2)$ & $(3)$ & $(4)$ & $(5)$ & (6) \\
\hline Avg age of Civil $\mathrm{HC}$ cases & $\begin{array}{c}-0.00547^{*} \\
(0.0022)\end{array}$ & $\begin{array}{c}-0.00621^{* *} \\
(0.0023)\end{array}$ & $\begin{array}{c}-0.00530^{*} \\
(0.0024)\end{array}$ & $\begin{array}{c}-0.0144^{* *} \\
(0.0044)\end{array}$ & $\begin{array}{c}-0.0146^{* *} \\
(0.0044)\end{array}$ & $\begin{array}{c}-0.0167^{* *} \\
(0.0045)\end{array}$ \\
\hline Log district GDP/capita & & $\begin{array}{r}-0.00389 \\
(0.0045) \\
\end{array}$ & $\begin{array}{c}-0.00384 \\
(0.0046) \\
\end{array}$ & & $\begin{array}{c}-0.00912^{+} \\
(0.0051)\end{array}$ & $\begin{array}{c}-0.00980^{+} \\
(0.0051)\end{array}$ \\
\hline State Controls & & & Yes & & & Yes \\
\hline 5-digit Industry FE & Yes & Yes & Yes & Yes & Yes & Yes \\
\hline Estimator & OLS & OLS & OLS & IV & IV & IV \\
\hline$R^{2}$ & 0.441 & 0.446 & 0.449 & 0.441 & 0.446 & 0.449 \\
\hline Observations & 225590 & 204031 & 199339 & 225590 & 204031 & 199339 \\
\hline
\end{tabular}


Fact 3 In states with worse formal contract enforcement, plants in industries that tend to rely more on relationship-specific intermediate inputs are more vertically integrated.

A low materials share suggests that a plant may be doing more of production in-house, i.e., be more vertically integrated. For example, a car producer that assembles components may also manufacture those components in the same facility. The regressions in Table III show how court quality is related to a measure vertical integration. We first construct a measure of the "vertical distance" between an output good $\omega$ to an input $\omega^{\prime}$. This is intended to capture the typical number of "steps" between the use of $\omega^{\prime}$ and the production of $\omega$, where we define a step to be the activity performed by a single plant. ${ }^{14}$ Finally, for each plant, our measure of vertical integration is the expenditure weighted average of the distance to its intermediate inputs. A higher number indicates that the plant uses inputs that are typically more distant, and suggests that the plant is performing more "steps" in-house. Table III shows that, in industries that rely more heavily on relationship-specific inputs, plants tend to be more vertically integrated in states with worse courts.

Table III Vertical Integration of Plants and Court Quality (Fact 3)

\begin{tabular}{|c|c|c|c|c|c|c|}
\hline & \multicolumn{6}{|c|}{ Dependent variable: Vertical Integration } \\
\hline & $(1)$ & $(2)$ & $(3)$ & (4) & (5) & (6) \\
\hline Avg Age Of Civil Cases * Rel. Spec. & $\begin{array}{c}0.0195^{+} \\
(0.011)\end{array}$ & $\begin{array}{c}0.0269^{*} \\
(0.012)\end{array}$ & $\begin{array}{c}0.0280^{*} \\
(0.012)\end{array}$ & $\begin{array}{c}0.0292 \\
(0.019)\end{array}$ & $\begin{array}{c}0.0314^{+} \\
(0.018)\end{array}$ & $\begin{array}{c}0.0368^{*} \\
(0.018)\end{array}$ \\
\hline LogGDPC * Rel. Spec. & & $\begin{array}{c}0.0464^{*} \\
(0.022)\end{array}$ & $\begin{array}{c}0.0288 \\
(0.024)\end{array}$ & & $\begin{array}{c}0.0491^{*} \\
(0.023)\end{array}$ & $\begin{array}{c}0.0330 \\
(0.024)\end{array}$ \\
\hline Rel. Spec. $\times$ State Controls & & & Yes & & & Yes \\
\hline 5-digit Industry FE & Yes & Yes & Yes & Yes & Yes & Yes \\
\hline District FE & Yes & Yes & Yes & Yes & Yes & Yes \\
\hline Estimator & OLS & OLS & OLS & IV & IV & IV \\
\hline$R^{2}$ & 0.443 & 0.451 & 0.453 & 0.443 & 0.451 & 0.453 \\
\hline Observations & 163334 & 156191 & 154021 & 163334 & 156191 & 154021 \\
\hline
\end{tabular}

\subsection{Endogeneity, and the Historical Determinants of Indian Court Efficiency}

The main caveat in the above regressions is the concern that there are unobserved covariates of court quality that may also affect the cost of plants' inputs, and thereby their input shares. The simplest version is reverse causality. In principle, the bias from reverse causality could be positive or negative. Suppose that a state had, for exogenous reasons, many plants that produced using relationshipspecific inputs. The disputes that arise may cause the courts to be congested. Or alternatively, the

\footnotetext{
${ }^{14}$ We construct national input-output tables using our plant-level data. For each output good $\omega$ and input good $\omega^{\prime}$, we take a weighted average of the number of steps along any path from $\omega^{\prime}$ to $\omega$, weighted by the product of the input-output shares along that path, excluding any path which cycles. This measure is similar to Upstreamness $s_{i j}$ of Alfaro et al. (2015). Appendix B gives the precise mathematical definition of vertical distance.
} 
state may respond to the disputes that arise by spending resources to reduce congestion. Either of these would be problematic for interpreting the regressions as a causal relationship.

While we believe reverse causality is unlikely to arise - the fraction of cases related to firm-tofirm trade is relatively low $^{15}$ - it is difficult to rule out other factors that may influence both court congestion and usage of relationship-specific inputs.

We therefore employ an instrumental variables strategy that uses the historical determinants of congestion. As discussed in Section 2.2, courts have been continually accumulating backlogs throughout the 20th century. At certain points in time, however, states were split or reorganized, mostly in response to ethno-nationalist movements. In the course of these reorganizations, new high courts were set up, which initially started with a clean slate but were, like existing courts, understaffed and started accumulating backlogs. The time since their founding - the court's age - is therefore a strong predictor for the current backlog, which in turn determines the present-day speed of enforcement. Our instrumental variable for the speed of enforcement is hence the (log) age of the high court, and the instrument for an interaction of an industry-level variable with court speed is the interaction of the industry-level variable with the log age of the court. Figure 2 in Section 2.2 shows the strong correlation between court age and speed of enforcement.

Columns (4) to (6) of Tables I, II, and III repeat the regressions while instrumenting for the speed of enforcement. The point estimates of the coefficient of the interaction term is usually slightly larger than the OLS estimates.

There are a few reasons that the exclusion restriction may be violated. We argue that two candidates would lead us to conclude that the true relationships are stronger than reported in the IV regressions. First, new states tend to be relatively poor and have low state capacity. Thus the usual concern that a high level of development causes firms to use more sophisticated technologies that use relationship-specific inputs would cause the newer states to have higher use of homogeneous inputs. Alternatively, it may be that when a state splits, many firms lose their suppliers and must switch. It may be easy to find a new supplier of homogeneous inputs, whereas it might be harder to find a supplier of relationship-specific inputs. This channel would also cause newer states to be more intensive in homogeneous inputs. In either case, the true relationship would be stronger than reported. A third reason that the exclusion restriction might be violated is that newly formed states might be more ethnically homogenous, so that newer courts might be correlated with better informal enforcement. This is a particular concern here because ethno-nationalist conflicts are a primary reason that states split. Nevertheless, we can control for states' ethnic fragmentation - or more specifically the interaction of relationship-specificity with various measures of ethnic-fragmentation - as we do in columns (3) and (6) of Tables I, II, and III. Controlling for these has little impact on the main coefficients of interest.

A final concern is that an industry's reliance on relationship-specific inputs is correlated with other industry characteristics such as capital intensity, skill intensity, upstreamness, or tradability.

\footnotetext{
${ }^{15}$ The fraction of cases that is related to the enforcement of supplier contracts is hard to pinpoint exactly because courts classify cases very broadly, and in different ways across states. We know, however, that they account for less than $5 \%, 14 \%$, and $7 \%$ of the pending cases in the High Courts of Allahabad, Mumbai, and Kolkata, respectively.
} 
In Appendix C.1 we show that the estimates are robust to controlling for the respective interactions of court congestion with each of these industry characteristics. More broadly, in Appendix C we show a number of additional results about the relationship between court quality and establishment characteristics (age, size, number of products, and import ratios), and more robustness checks. We also provide additional suggestive evidence from two instances in which high courts set up new benches in remote areas during our sample period.

\section{Model}

The previous section showed that imperfect contract enforcement alters the production decisions of manufacturing firms in India in systematic ways. We next aim to quantify the impact of weak enforcement on the productivity of the manufacturing sector. Our main identifying assumption is that imperfect contract enforcement distorts the use of relationship-specific inputs and of labor, but not the use of homogeneous inputs. Motivated by the reduced-form evidence, we will ultimately identify the impact of the distortions by studying how patterns of plants' expenditure shares differ across states.

Several factors complicate the tasks of measuring distortions and assessing their impact. First, there are many ways to avoid contracting frictions. Suppose a firm needed to use an input that required customization and gave rise to a holdup problem. In the face of weak formal contract enforcement, the firm might buy the intermediate input from a cousin or rely on the repeated interactions of a long-term relationship. Such decisions, however, may come at a cost. A family member may not be the optimal supplier of an intermediate input, and if a firm is in a long-term relationship, it may pass up using new, more cost-effective inputs in order to remain in that longterm relationship. ${ }^{16}$ Such a firm's production cost is higher than it would be with better contract enforcement. Nevertheless, since the firm avoids the holdup problem, its expenditure shares will not be distorted. The higher production cost is an indirect consequence of weak formal enforcement. We can infer this indirect cost by incorporating this type of decision in the model, and using the structure of the model.

Second, as discussed in Section 2.1, even in narrowly defined industries, firms produce in qualitatively different ways. As a simple example, consider two plants that both produce tires, one that buys rubber and another that harvests rubber itself. It may well be the case that the latter's decision to vertically integrate was a consequence of a distortion. But simply comparing the two plants' expenditure shares won't give a direct measure of the size of the distortion. Similarly, some shoe producers make the shoes by hand and others using sophisticated technologies. Fortunately the ASI provides an extremely detailed characterization of plants' input bundles. As a result, we can model firm's choices over these alternative modes of production (which we label recipes) and

\footnotetext{
${ }^{16} \operatorname{Lim}$ (2017) documents that in each year, firms switch roughly 40\% of suppliers, and Lu, Mariscal and Mejia (2013) document that ubiquitous switching of imported inputs among importers, suggesting gains from taking advantage of new opportunities that arise. Johnson, McMillan and Woodruff (2002) show that those who distrust courts are less likely to switch suppliers, suggesting that weak enforcement inhibits this.
} 
use the rich data to help distinguish between heterogeneity and misallocation.

In the model, using relationship-specific inputs gives rise to a holdup problem that can be alleviated with good contract enforcement. The model incorporates two ways that weak enforcement might cause firms to alter their production decisions. A firm might change the intensities with which it uses specific inputs, or it might switch methods of production altogether. There is a tremendous amount of heterogeneity across firms in the number, types, and cost shares of inputs used, even within extremely narrowly defined industries. Our model takes the stand that much of this heterogeneity is natural and would arise even in the absence of distortions, due to realizations of match-specific productivity differences.

\subsection{The Environment}

There is a set of industries $\Omega$. For industry $\omega \in \Omega$, there is a mass of firms with measure $J_{\omega}$ that produce differentiated varieties. There is a representative household that inelastically provides a mass of labor with measure $L$ and has nested CES preferences over all varieties in each industry, maximizing consumption of the bundle $U$ defined as

$$
\begin{aligned}
U & =\left[\sum_{\omega \in \Omega} v_{\omega}^{\frac{1}{\eta}} U_{\omega}^{\frac{\eta-1}{\eta}}\right]^{\frac{\eta}{\eta-1}} \\
U_{\omega} & =\left[\int_{0}^{J_{\omega}} u_{\omega j}^{\frac{\varepsilon-1}{\varepsilon}} d j\right]^{\frac{\varepsilon}{\varepsilon-1}}
\end{aligned}
$$

where $u_{\omega j}$ is consumption of variety $j$ in industry $\omega, v_{\omega}$ reflects the household's taste for goods in industry $\omega, \eta$ is the elasticity of substitution across industries, and $\varepsilon$ is the elasticity of substitution across varieties within each industry.

There are many ways to produce a good using different combinations of inputs. ${ }^{17}$ These different ways correspond to different production functions, which we call recipes. Denote the set of recipes to produce a good $\omega$ by $\varrho_{\omega}$. Each recipe $\rho \in \varrho_{\omega}$ describes a production function $G_{\omega \rho}(\cdot)$ that can be used by any firm in industry $\omega$ to produce its good using labor $l$ and a particular bundle of inputs $\hat{\Omega}^{\rho}$. The only restrictions we place on the production function $G_{\omega \rho}$ are that it exhibits constant returns to scale and that all inputs are complements. Note that the different $G_{\omega \rho}$ may differ in their shape and their factor intensities, and that they need not be Leontief.

Assumption 1 For any recipe $\rho \in \varrho_{\omega}$, the production function $G_{\omega \rho}$ exhibits constant returns and all inputs $\left(l, \hat{\Omega}^{\rho}\right)$ are complements.

Firm $j$ in industry $\omega$ has random sets of productivity and supplier draws $\Phi_{j \rho}$ for each recipe $\rho \in \varrho_{\omega}$. We call these draws techniques. Each technique $\phi \in \Phi_{j \rho}$ is characterized by (i) a set of potential suppliers for each intermediate input, $\left\{S_{\hat{\omega}}(\phi)\right\}_{\hat{\omega} \in \hat{\Omega}^{\rho}}$, (ii) for each of those suppliers

\footnotetext{
${ }^{17}$ For example, some electricity producers use coal as an intermediate input while others use natural gas. Some producers of frozen chicken use chickens as an intermediate input while others use chicken feed.
} 
$s \in S_{\hat{\omega}}(\phi)$ an input-augmenting productivity, and (iii) a labor-augmenting productivity $b_{l}(\phi)$. The input-augmenting productivity for supplier $s \in S_{\hat{\omega}}(\phi)$ consists of a match-specific component $z_{s}$ that is specific to the supplier and a component $b_{\hat{\omega}}(\phi)$ that is common to all suppliers of input $\hat{\omega}$ in the set $S_{\hat{\omega}}(\phi)$.

Suppose that $j$ produced its good using a technique of recipe $\rho$ which used labor and intermediate inputs $\hat{\Omega}^{\rho}=\left\{\hat{\omega}_{1}, \ldots, \hat{\omega}_{n}\right\}$. If it chose to employ $l$ units of labor and purchase $\left\{x_{s_{1}}, \ldots, x_{s_{n}}\right\}$ units of intermediate inputs from respective suppliers $s_{1} \in S_{\hat{\omega}_{1}}, \ldots, s_{n} \in S_{\hat{\omega}_{n}}$, its output would be

$$
y_{j}=G_{\omega \rho}\left(b_{l} l, b_{\hat{\omega}_{1}} z_{s_{1}} x_{s_{1}}, \ldots, b_{\hat{\omega}_{n}} z_{s_{n}} x_{s_{n}}\right)
$$

Each technique is specific to the firm producing the output (the "buyer") and the potential suppliers that might provide the intermediate inputs. Techniques within a particular recipe may differ in how intensively the particular inputs are used, as this depends on the input-augmenting productivities and the prices charged by the suppliers. In equilibrium, the firm produces using the combination of production function and suppliers that is most cost-effective.

Terms of trade among firms determine their choices of inputs, productions decisions, and productivity. We also assume that sales of goods for intermediate use are priced at the supplier's marginal cost. ${ }^{18}$ Firms engage in monopolistic competition when selling to the representative household, and remit all profit to the household.

First, nature chooses the sets of techniques available to all firms $\left\{\left\{\Phi_{j \rho}\right\}_{\rho \in \varrho_{\omega}}\right\}_{j \in J_{\omega, \omega} \in \Omega}$. Then all firms simultaneously set prices and make their production decisions (i.e. choices of technique $\phi \in \bigcup_{\rho \in \varrho_{\omega}} \Phi_{j \rho}$, suppliers, and inputs $\left.l, x_{s_{1}}, \ldots, x_{s_{n}}\right)$ to minimize cost, taking into account the decisions of others. All firms have perfect information about the economy's production possibilities and about other firms' choices. The probability distribution governing the set of techniques with which firm $j$ can produce $\left(\left\{\Phi_{j \rho}\right\}_{\rho \in \varrho_{\omega}}\right)$ will be described below.

\subsection{Contracting Enforcement}

Enforcement of contracts facilitates the use of inputs that require customization and the use of labor. Imperfect enforcement introduces wedges between the effective cost to the buyer and the payment to the supplier and between the time supplied by workers and the efficiency units of labor available to the firm. The wedges take the form of tax paid using labor that is a fixed fraction of the value of the transaction. ${ }^{19}$ Appendix D.4 provides one microfoundation for modeling imperfect

\footnotetext{
${ }^{18}$ One interpretation of this assumption is that in firm-to-firm trade, buyers have all of the bargaining power. For example, in a simpler environment, Oberfield (2018) characterizes an alternative market structure in which firm-tofirm trade is governed by bilateral trading contracts specifying a buyer, a supplier, a quantity of the supplier's good to be sold to the buyer and a payment. Given a contracting arrangement, each entrepreneur makes her remaining production decisions to maximize profit. The economy is in equilibrium when the arrangement is such that no countable coalition of entrepreneurs would find it mutually beneficial to deviate by altering terms of trade among members of the coalition and/or dropping contracts with those not in the coalition. The terms of trade described here are one particular equilibrium in which buyers have all of the bargaining power.

${ }^{19}$ This wedge on relationship-specific inputs is, in some ways, similar to an iceberg cost. However, since the tax is paid in units of labor and is proportional to the value of the transaction, there is scope for industrial policy to
} 
enforcement in this way, although there are other microfoundations that are equally plausible. We briefly describe the microfoundation here and refer the reader to Appendix D.4 for details.

If an input requires customization, the supplier can shirk and provide a good that is imperfectly customized to the buyer. If this happens, the buyer needs to use extra labor to correct the defect. This is wasteful because the supplier has a comparative advantage in performing the customization. Similarly, workers can shirk, but time spent shirking is valued less by the worker than pure leisure. Buyers, suppliers, and workers can write contracts that require perfect customization or prohibit shirking, but imperfect enforcement of these contracts implies that some of this misbehavior will occur in equilibrium. While all parties anticipate equilibrium behavior and build this into prices, the behavior leads to a wedge that wastes resources.

For each potential supplier of a relationship-specific intermediate input $\hat{\omega}$, there is a random input wedge $t_{x} \in[1, \infty)$ that distorts the use of that input, drawn from a distribution with CDF $T\left(t_{x}\right)$. If the supplier's price is $p_{s}$ and input-augmenting productivity is $b_{\hat{\omega}} z_{s}$, the effective cost to the buyer is $\frac{p_{s} t_{x}}{b_{\hat{\omega}} z_{s}}$.

The distribution $T\left(t_{x}\right)$ summarizes the quality of enforcement. Perfect enforcement of contracts would imply that $t_{x}=1$ for all suppliers. We interpret worse enforcement as a first-order stochastically-dominating shift in distribution of distortions.

Similarly, if production is subject to the labor wedge $t_{l}$, then the firm needs to hire $t_{l}$ workers to obtain one efficiency unit of labor, so that effective cost of labor to the firm is $w t_{l}$. For simplicity we assume that $t_{l}$ is the same across all firms. ${ }^{20}$

\subsection{Discussion of Assumptions}

Before analyzing the equilibrium outcomes, we pause to discuss some of the modeling choices we have made and how we interpret some of the assumptions. First, as discussed earlier, courts are not the only way to enforce contracts; contracts could be enforced informally through social punishments or reputation. $t_{x}$ and $t_{l}$ should be interpreted as the wedges that prevail after all forms of enforcement are exhausted. For example, if formal enforcement would leave the wedge $t_{x}^{\text {formal }}$ while informal enforcement would leave the wedge $t_{x}^{\text {informal }}$, then the parties would use whichever form of enforcement is better, i.e., $t_{x}=\min \left\{t_{x}^{\text {formal }}, t_{x}^{\text {informal }}\right\}$ (and similarly for $t_{l}$ ). ${ }^{21}$ Improving the quality of courts would reduce the wedges $t_{x}^{\text {formal }}$ but would not change $t_{x}^{\text {informal }}$.

Second, we model the wedges as random and specific to a supplier. As discussed earlier, for some suppliers (e.g., family members, those with whom the buyer is in a long-term relationship) the possibility of informal enforcement may mitigate any hold-up problem. For others, the hold-up problem may be more severe.

increase output by manipulating relative prices. In contrast, if the distortion took the form of an iceberg cost, there would be no such possibility. See Liu (2017) for a good discussion of these issues. The wedge on labor is an iceberg cost.

${ }^{20}$ Our counterfactuals focus on changes in the distribution of distortions that impede the use of relationship-specific intermediate inputs $(T)$. Our identification strategy does not recover the labor wedges $\left(t_{l}\right)$.

${ }^{21}$ Of course, the argument extends in the obvious way if there are multiple ways of enforcing contracts informally. 
Third, we model the wedges as wasting resources rather than as an implicit tax or subsidy as in Hsieh and Klenow (2009) which does not waste resources. An implicit tax may stand in for rationing or a Lagrange multiplier on a collateral constraint, and would raise the buyer's shadow cost of an input relative to the supplier's price without using up resources.

The facts presented in Section 2 are not sufficient to distinguish whether the wedges use up resources. However, there is at least one observable dimension that we can use to distinguish between the two types of frictions. With implicit taxes, those subject to larger wedges should have higher ratios of revenue to cost. If wedges use up resources they should lead to weakly lower ratios of revenue to cost. ${ }^{22}$ In Appendix E.1 we ask whether those firms that we believe are subject to larger wedges - those in industries that tend to use relationship-specific inputs in states with congested courts - have higher or lower revenue-cost ratios. Our findings are consistent with wedges wasting resources: larger distortions are associated with lower revenue-cost ratios.

\subsection{Production Decisions}

For each technique, firm $j$ draws a set of potential suppliers to provide each input. Each potential supplier $s \in S_{\hat{\omega}}(\phi)$ comes with an input-augmenting productivity draw and a wedge, so that the effective cost of using that supplier would be $\frac{t_{x s} p_{s}}{b_{\hat{\omega}}(\phi) z_{s}}$. $j$ 's effective cost of input $\hat{\omega}$ for technique $\phi$ is the minimum across all potential suppliers:

$$
\lambda_{\hat{\omega}}(\phi)=\min _{s \in S_{\hat{\omega}}(\phi)} \frac{t_{x s} p_{s}}{b_{\hat{\omega}}(\phi) z_{s}} .
$$

Similarly, the effective cost of labor when using technique $\phi$ is $\lambda_{l}(\phi)=\frac{t_{l} w}{b_{l}(\phi)}$. For the remainder, we normalize the wage to unity, $w=1$.

The unit cost delivered by a technique depends on the effective cost of each input. Let $\mathcal{C}_{\omega \rho}(\cdot)$ be the unit cost function that is the dual of the production function $G_{\omega \rho}$, so that $j$ 's cost of producing one unit of output using technique $\phi$ would be $\mathcal{C}_{\omega \rho}\left(\lambda_{l}(\phi),\left\{\lambda_{\hat{\omega}}(\phi)\right\}_{\hat{\omega} \in \hat{\Omega}^{\rho}}\right)$. Minimizing cost across all techniques, $j$ 's unit cost is

$$
\min _{\rho \in \varrho(\omega)} \min _{\phi \in \Phi_{\omega j \rho}} \mathcal{C}_{\omega \rho}\left(\lambda_{l}(\phi),\left\{\lambda_{\hat{\omega}}(\phi)\right\}_{\hat{\omega} \in \hat{\Omega}^{\rho}}\right)
$$

In words, firm $j$ 's unit cost equals that of the technique that delivers the lowest cost across all techniques of all recipes.

In this section, we specialize to particular functional form assumptions that prove tractable. The set of techniques available to each firm is random and governed by the following assumptions about the distributions of input-augmenting productivities.

\section{Assumption 2 For a firm in industry $\omega$,}

\footnotetext{
${ }^{22}$ Whether the wedges would lead to no change or lower ratios of revenue to cost depends on the demand system. With Dixit-Stiglitz demand, the ratio of revenue to cost would be invariant with respect to wedge, whereas if the demand system features imperfect pass-through, a larger wedge would lower the ratio of revenue to cost.
} 
a. Each supplier in the set $S_{\hat{\omega}}(\phi)$ is uniformly drawn from all firms that produce $\hat{\omega}$.

b. For each technique $\phi$ that uses input $\hat{\omega}$, the number of suppliers in $S_{\hat{\omega}}(\phi)$ for whom the matchspecific component of productivity is greater than $z$ follows a Poisson distribution with mean

$$
z^{-\zeta_{\hat{\omega}}}, \text { with } \zeta_{\hat{\omega}}= \begin{cases}\zeta_{R}, & \hat{\omega} \in \hat{\Omega}_{R}^{\rho} \\ \zeta_{H}, & \hat{\omega} \in \hat{\Omega}_{H}^{\rho}\end{cases}
$$

c. Consider recipe $\rho \in \varrho_{\omega}$ which uses labor and the input bundle $\hat{\Omega}^{\rho}=\left(\hat{\omega}_{1}, \ldots, \hat{\omega}_{n}\right)$. For each plant, The number of techniques to produce using that recipe for which the common components of inputaugmenting productivities strictly dominate ${ }^{23} b_{l}, b_{\hat{\omega}_{1}}, b_{\hat{\omega}_{2}}, \ldots, b_{\hat{\omega}_{n}}$ follows a Poisson distribution with mean

$$
B_{\omega \rho} b_{l}^{-\beta_{l}^{\rho}} b_{\hat{\omega}_{1}}^{-\beta_{\hat{\omega}_{1}}^{\rho}} \ldots b_{\hat{\omega}_{n}}^{-\beta_{\hat{\omega}_{n}}^{\rho}}
$$

d. There is a constant $\gamma$ such that for each $\omega$ and each recipe $\rho \in \varrho_{\omega}, \beta_{l}^{\rho}+\beta_{\hat{\omega}_{1}}^{\rho}+\ldots+\beta_{\hat{\omega}_{n}}^{\rho}=\gamma$.

e. The following parameter restrictions hold for each $\hat{\omega}: \gamma>\varepsilon-1, \gamma>\zeta_{\hat{\omega}}>\beta_{\hat{\omega}}^{\rho}$ where $\zeta_{\hat{\omega}}$ is $\zeta_{R}$ if $\hat{\omega}$ is relationship-specific or $\zeta_{H}$ if $\hat{\omega}$ is homogeneous.

Assumption $2 \mathrm{~b}$ implies above any threshold, the match-specific components of productivity follow a power law. ${ }^{2425}$ One implication is that the industry-level elasticity of substitution across groups of suppliers of the same input is $\zeta_{\hat{\omega}}+1$. When there is more dispersion in these match-specific components of productivity (low $\zeta_{\hat{\omega}}$ ), a buyer is less likely to switch suppliers in response changes in the supplier's price because it is likely that there is a larger gap between the best and second best suppliers of an input. $\zeta_{R}$ will play a role quantitatively because it determines the likelihood that a buyer will have a close substitute if it faces a holdup problem with its best supplier of an input.

Assumption 2c says that the common components of input-augmenting productivities of a technique follow independent power laws. $B_{\omega \rho}$ summarizes the level of these productivity draws. We

\footnotetext{
${ }^{23}$ We say that a vector $\left(x_{0}, x_{1}, \ldots, x_{n}\right)$ strictly dominates the vector $\left(y_{0}, y_{1}, \ldots, y_{n}\right)$ if $x_{0}>y_{0}, x_{1}>y_{1}, \ldots, x_{n}>y_{n}$.

${ }^{24}$ This type of functional form assumption goes back to at least Houthakker (1955), and versions of it are also used by Kortum (1997), Jones (2005), Oberfield (2018), and Buera and Oberfield (2016). Note that the expected number of potential suppliers for an input is unbounded. Formally, an economy satisfying Assumption $2 \mathrm{~b}$ can be thought of as the limit of a sequence of economies that satisfy more standard assumptions. Consider an economy in which firms were restricted to use only suppliers with a match-specific productivity greater than $z$. Then the number of potential suppliers for each input of a technique would be given by a Poisson distribution with mean $\underline{z}^{-\zeta}$ and the match-specific productivity for each supplier would be drawn from a Pareto distribution with $\mathrm{CDF} 1-(z / \underline{z})^{-\zeta}$. An economy satisfying Assumption $2 \mathrm{~b}$ can be thought of as the limit of such an economy as $\underline{z} \rightarrow 0$. In this limit, the number of suppliers for each input of a technique grows arbitrarily large, but the match-specific productivity associated with any single supplier is drawn from an arbitrarily poor distribution. The limit is well behaved because the probability of drawing a supplier with match-specific productivity greater than $z$ does not change as $\underline{z} \rightarrow 0$.

${ }^{25}$ In principle, we could have allowed the level of the match-specific component of productivity draws to vary by input-output pair and recipe, or $Z_{\omega \rho \hat{\omega}} z^{-\zeta_{\omega}}$, reflecting the idea that industries are often concentrated geographically or ethnically, which may imply that a given output industry may face an unusually high number of good suppliers in the input industry relative to other output industries. However, it turns out that Assumptions $2 \mathrm{~b}$ and $2 \mathrm{c}$ imply that any variation in $\left\{Z_{\omega \rho \hat{\omega}}\right\}$ would be absorbed into the constant $B_{\omega \rho}$, so we simply normalize each $Z_{\omega \rho \hat{\omega}}$ to unity.
} 
take these to be primitives, although a deeper model might model them as resulting endogenously from directed search or from the diffusion of technologies across entrepreneurs that know each other.

Assumption $2 \mathrm{~d}$ says that for each recipe, the sum of the power law exponents is the same, equal to $\gamma$. We will show later that the industry-level elasticity of substitution across techniques is $\gamma+1 .^{26}$ The parameter restrictions are necessary to keep utility finite.

It will be useful to decompose the power law exponents into two parts. For recipe $\rho$, define

$$
\alpha_{L}^{\rho}=\frac{\beta_{l}^{\rho}}{\gamma}, \quad \alpha_{\hat{\omega}}^{\rho} \equiv \frac{\beta_{\hat{\omega}}^{\rho}}{\gamma}, \quad \hat{\omega} \in \hat{\Omega}^{\rho}
$$

Note that this implies that $\alpha_{L}^{\rho}+\sum_{\hat{\omega} \in \hat{\Omega}} \alpha_{\hat{\omega}}^{\rho}=1$. Further, for some results, it will be useful to define $\alpha_{R}^{\rho}=\sum_{\hat{\omega} \in \hat{\Omega}_{R}^{\rho}} \alpha_{\hat{\omega}}^{\rho}$ and $\alpha_{H}^{\rho}=\sum_{\hat{\omega} \in \hat{\Omega}_{H}^{\rho}} \alpha_{\hat{\omega}}^{\rho}$.

With these assumptions in hand, we now characterize the equilibrium. All proofs are contained in Appendix D

Proposition 1 Under Assumptions 1 and 2, the fraction of firms with unit cost greater than $c$ among those in industry $\omega$ is

$$
e^{-\left(c / C_{\omega}\right)^{\gamma}}
$$

where

$$
\begin{aligned}
C_{\omega} & =\left\{\sum_{\rho \in \varrho_{\omega}} \kappa_{\omega \rho} B_{\omega \rho}\left(\left(t_{x}^{*}\right)^{\alpha_{R}^{\rho}} t_{l}^{\alpha_{L}^{\rho}} \prod_{\hat{\omega} \in \hat{\Omega}^{\rho}} C_{\hat{\omega}}^{\alpha_{\hat{\omega}}^{\rho}}\right)^{-\gamma}\right\}^{-\frac{1}{\gamma}} \\
t_{x}^{*} & =\left(\int_{1}^{\infty} t_{x}^{-\zeta_{R}} d T\left(t_{x}\right)\right)^{-1 / \zeta_{R}}
\end{aligned}
$$

and $\kappa_{\omega \rho}$ is a constant that depends on technological parameters.

Proposition 1 shows that the distribution of cost among firms within each industry takes the simple form of a Weibull distribution with shape parameter $\gamma$ and scale determined by $C_{\omega}$, which we call the cost index for industry $\omega$. (1) relates industry $\omega$ 's cost index to that of the industries that provide the inputs for each recipe and to $t_{x}^{*}$ and $t_{l}$, which summarize the impact of imperfect enforcement on those that produce the inputs used in recipe $\rho . t_{x}^{*}$ accounts for both the direct impact of the wedges - the wasted resources from holdup problems - and the indirect impact: wedges might cause firms to switch to a supplier with higher cost or lower productivity, or to a different technique altogether.

(1) is a system of equations that implicitly determines each industry's cost index, $\left\{C_{\omega}\right\}_{\omega \in \Omega}$. Proposition 2 shows that these are sufficient to characterize aggregate productivity.

\footnotetext{
${ }^{26}$ It would be straightforward to allow different industries to have different values of $\gamma$. However, as we show below, our counterfactuals are insensitive to the value of $\gamma$. We therefore leave the $\gamma$ constant across industries to reduce notational clutter.
} 
Proposition 2 Under Assumptions 1 and 2, the household's aggregate consumption is

$$
U=\left\{\sum_{\omega \in \Omega} v_{\omega} J_{\omega}^{\frac{\eta-1}{\varepsilon-1}} \Gamma\left(1-\frac{\varepsilon-1}{\gamma}\right)^{\frac{\eta-1}{\varepsilon-1}} C_{\omega}^{1-\eta}\right\}^{\frac{1}{\eta-1}} L
$$

We next turn to industry-level expenditure shares. The next proposition characterizes the aggregate share of total expenditures (on both intermediate inputs and labor) that is spent on each input among all firms that use a particular recipe.

Proposition 3 Suppose that assumptions 1 and 2 hold. Among firms that, in equilibrium, produce using recipe $\rho$ :

- the average and aggregate shares of expenditures that is spent on inputs from $\hat{\omega} \in \hat{\Omega}_{R}^{\rho}$ is $\frac{\alpha_{\hat{\omega}}^{\rho}}{t_{x}}$,

- the average and aggregate shares of expenditures that is spent on inputs from $\hat{\omega} \in \hat{\Omega}_{H}^{\rho}$ is $\alpha_{\hat{\omega}}^{\rho}$,

- the average and aggregate shares of expenditures that is spent on labor is $\alpha_{L}^{\rho}+\left(1-\frac{1}{t_{x}}\right) \alpha_{R}^{\rho}$,

where $\bar{t}_{x} \equiv\left[\int_{1}^{\infty} t_{x}^{-1} d \tilde{T}\left(t_{x}\right)\right]^{-1}$ and $\tilde{T}\left(t_{x}\right) \equiv \frac{\int_{1}^{t_{x}} t^{-\zeta_{R}} d T(t)}{\int_{1}^{\infty} t^{-\zeta_{R}} d T(t)}$.

Proposition 3 provides relatively simple expressions for the average and aggregate cost shares of each input among those that choose to use a particular recipe. While there is micro-level heterogeneity in the cost shares among those using a particular recipe, the aggregate factor shares among those firms depends only on technological parameters, not on the relative prices of the inputs. Thus at the recipe level, there is a Cobb-Douglas aggregate production function. This extends the celebrated aggregation result of Houthakker (1955) who derived a similar result under the assumption that individual production functions are Leontief. ${ }^{27}$ We require only that the production function exhibits constant returns to scale and that all inputs are complements. ${ }^{28}$

Imperfect enforcement, on the other hand, reduces the expenditure share of relationship-specific inputs. The buyer's production decisions depend each input's effective cost, whereas the expenditures reflect the actual payment to each supplier. Recall that imperfect enforcement means that

\footnotetext{
${ }^{27}$ Jones (2005) builds on Houthakker (1955) but derives a different type of result. Jones first shows that if a single plant draws many Leontief production functions where factor augmenting productivities are drawn from independent Pareto distributions, then the envelope of those production functions is Cobb-Douglas. He then shows numerically that the result extends beyond Leontief to CES production functions when the factors are complements. Note that these are not aggregation results; these results apply at the level of a single firm. Lagos (2006) and Mangin (2017) also build on Houthakker (1955) incorporating labor market search, while Growiec (2013) extends the argument of Jones to microfound an aggregate CES production function.

${ }^{28}$ Why complements? When inputs are complements, when the price of an input is higher, there are two offsetting effects on the industry cost share. The higher price raises that cost share on that input for any firm that uses the input. At the same time, firms that use that input more intensively are likely to shrink or switch to a technique that uses the input less intensively. When factor-augmenting productivities are drawn from independent Pareto distributions, these offset exactly and factor shares are unchanged. If inputs were substitutes, the two effects would push in the same direction, so that if the price of an input rose, its industry cost share would fall. Mathematically, if inputs were substitutes than the constant $\kappa_{\omega \rho}$ would diverge, as the arrival rate of techniques that deliver cost lower than $c$ would be infinite for any $c$.
} 
the buyer's effective expenditure on a relationship-specific input is spent partly on payments to the supplier for the input and partly on labor to customize the good. ${ }^{29}$

\subsection{Counterfactuals}

The quality of contract enforcement can be summarized by the distribution of wedges $T$. Suppose that the quality of enforcement changed in such a way that the distribution of wedges changed from $T$ to $T^{\prime}$. How would this impact aggregate productivity? Taking $J_{\omega}$ and $B_{\omega \rho}$ as primitives, the following proposition shows how one can compute the impact of such a change. ${ }^{30}$

Let $H H_{\omega}$ be the share of the household's expenditure on goods from industry $\omega$ in the current equilibrium. Among those of type $\omega$, let $R_{\omega \rho}$ be the share of total revenue of those that use recipe $\rho$ in the current equilibrium.

Proposition 4 If the quality of enforcement changed so that the distribution of wedges changes from $T$ to $T^{\prime}$, the change in household utility would be

$$
\frac{U^{\prime}}{U}=\left(\sum_{\omega} H H_{\omega}\left(\frac{C_{\omega}^{\prime}}{C_{\omega}}\right)^{1-\eta}\right)^{\frac{1}{\eta-1}}
$$

and the change in industry efficiencies would satisfy the following system of equations

$$
\left(\frac{C_{\omega}^{\prime}}{C_{\omega}}\right)^{-\gamma}=\sum_{\rho \in \varrho_{\omega}} R_{\omega \rho}\left[\left(\frac{t_{x}^{* \prime}}{t_{x}^{*}}\right)^{\alpha_{R}^{\rho}} \prod_{\hat{\omega} \in \hat{\Omega}^{\rho}}\left(\frac{C_{\hat{\omega}}^{\prime}}{C_{\hat{\omega}}}\right)^{\alpha_{\hat{\omega}}^{\rho}}\right]^{-\gamma}
$$

The first part of the proposition states that to know how a change in court quality affects aggregate productivity, it is sufficient to know only the changes in industry cost indices, $\frac{C_{\omega}^{\prime}}{C_{\omega}}$. In turn, the change in each industry's cost index depends on the weighted average over input bundles of the change in the cost index of the industries that supply inputs along with the change $t_{x}^{*}$, the summary statistic for the industry of direct and indirect impact of the wedges that distort production using relationship-specific inputs. (2) describes a system of equations that implicitly characterizes these changes in cost indices.

While Proposition 4 describes exactly how a change in enforcement would alter welfare, it is instructive to study a perturbation of the distribution of wedges to show which features of the economy are important for determining the first-order impact of a change in the quality of enforcement.

\footnotetext{
${ }^{29}$ The wedge due to imperfect enforcement and input-augmenting productivity affect a firm's unit cost in the same way. It is important, however, to model them separately because they affect expenditure shares in different ways. Larger wedges tend to reduce the share of expenditures on that input because some of the effective cost is paid to labor; lower input-augmenting productivities do not.

${ }^{30}$ An interesting alternative exercise is asking what would happen if $\left\{J_{\omega}\right\}$ and $\left\{B_{\omega \rho}\right\}$ also responded to the change in $T$.
} 
Corollary 1 The marginal welfare impact of a change in court quality is

$$
d \log U=-\sum_{\omega \in \Omega} H H_{\omega} d \log C_{\omega}
$$

and the change in industry efficiencies can be summarized by the following system of equations

$$
d \log C_{\omega}=\sum_{\rho \in \varrho_{\omega}} R_{\omega \rho}\left[\alpha_{R}^{\rho} d \log t_{x}^{*}+\sum_{\hat{\omega} \in \hat{\Omega}^{\rho}} \alpha_{\hat{\omega}}^{\rho} d \log C_{\hat{\omega}}\right]
$$

One implication is that, to a first order, the change in utility resulting from a change in the quality of enforcement does not depend on $\gamma$ or $\eta$.

\section{Identification and Estimation}

Our main counterfactual of interest is how aggregate productivity and the organization of production would change if the quality of enforcement improved. We do this in several steps. We first parameterize the model using information from the ASI under the assumption that the quality of enforcement varies by state. We then project the implied quality of enforcement for each state on our measures of court congestion. Finally, we compute the gains from reducing congestion to the level prevailing in the least congested state.

Our most important identifying assumption is that weak enforcement may introduce a wedge in the use of inputs that require customization and in the use of labor, but not in the use of standardized inputs. Given our scheme for identification, we view this as a conservative assumption. If the use of standardized inputs were also distorted by weak contract enforcement, then all of the wedges would be larger than the ones we infer.

The following proposition shows a set of moments that we can use in a GMM procedure to estimate the model parameters

Proposition 5 Let $s_{R j}, s_{H j}, s_{L j}$ be firm j's spending on relationship-specific inputs, homogeneous inputs, and labor respectively as shares of its revenue. Under assumptions 1 and 2 , the first moments of revenue shares among firms that produce $\omega$ that, in equilibrium, use recipe $\rho$ satisfy:

$$
\begin{aligned}
\mathbb{E}\left[\bar{t}_{x} \frac{s_{R j}}{\alpha_{R}^{\rho}}-\frac{s_{H j}}{\alpha_{H}^{\rho}}\right] & =0 \\
\mathbb{E}\left[\frac{s_{L j}+s_{R j}}{\alpha_{L}^{\rho}+\alpha_{R}^{\rho}}-\frac{s_{H j}}{\alpha_{H}^{\rho}}\right] & =0
\end{aligned}
$$

Assumption 3 We impose that the following objects are the same across states: (i) the form of the production function for each recipe $\left\{G_{\omega \rho}\right\}$; (ii) the power law exponents for the input-augmenting productivity draws for techniques of each recipe $\left\{\beta_{l}^{\rho}, \beta_{\hat{\omega}_{1}}^{\rho}, \ldots, \beta_{\hat{\omega}_{n}}^{\rho}\right\}$, and (iii) the power law exponent for the match-specific productivity draws, $\zeta_{R}$ and $\zeta_{H}$. 
We allow all other features of preferences and technology to vary freely across states. This includes absolute and comparative advantages in recipes, $\left\{B_{\omega \rho}\right\}$, (ii) the measure of firms of each type $\left\{J_{\omega}\right\}$, (iii) the households tastes, $\left\{v_{\omega}\right\}$, and most importantly, (iv) the quality of contract enforcement, $T$, and $t_{l}$.

We also impose a parametric form for the stochastic wedges that a firm draws for each supplier of a relationship-specific input. In particular, the wedge is drawn from a Pareto distribution, where the shape parameter is specific to a state.

Assumption 4 The distribution of wedges in state $d$ is $T_{d}\left(t_{x}\right)=1-t_{x}^{-\tau_{d}}$ for $t_{x} \geq 1$.

Using Pareto distributions has several attractive properties. First, following the discussion in Section 3.2, contracts might be enforced formally or informally. If the probability that the formal wedge is greater than $t_{x}$ is $t_{x}^{-\tau_{d}^{\text {formal }}}$ and the probability that the informal wedge is greater than $t_{x}$ is $t_{x}^{-\tau_{d}^{\text {informal }}}$, then the probability that the effective wedge is greater than $t_{x}$ is $t_{x}^{-\tau_{d}}$, where $\tau_{d}=\tau_{d}^{\text {formal }}+\tau_{d}^{\text {informal }}{ }^{31}$ This will lead to a clean interpretation of the counterfactual of interest.

Our algorithm for identification is thus as follows:

1. Identify recipes, estimate technology parameters $\left\{\alpha_{L}^{\rho}, \alpha_{H}^{\rho}, \alpha_{R}^{\rho}\right\}_{\rho \in \varrho_{\omega}, \omega \in \Omega}$, and distortions to the cost of relationship-specific inputs for each state, $\bar{t}_{x}^{d}$. We use an iterative procedure to ensure that our recipe classification is consistent with the possibility of distortions that vary across states.

(a) Start with an initial guess of $\bar{t}_{x}^{d}$ for each state $d$.

(b) Identify recipes from plant's cost shares (see next section for details), taking out the distortion to the cost shares of relationship-specific inputs $\bar{t}_{x}^{d}$.

(c) Use Proposition 5 to estimate the production parameters that are common across locations $\left\{\alpha_{L}^{\rho}, \alpha_{H}^{\rho}, \alpha_{R}^{\rho}\right\}_{\rho \in \varrho_{\omega}, \omega \in \Omega}$ and a new set of the state specific variables, $\left\{\bar{t}_{x}^{d}\right\}$.

(d) Go back to step $1 \mathrm{~b}$ until the $\bar{t}_{x}^{d}$ have converged.

2. Compute $t_{x}^{*}$ for each state. Assumption 4 implies that $\bar{t}_{x}=1+\frac{1}{\zeta_{R}+\tau_{d}}$ and $t_{x}^{*}=\left(\frac{\tau_{d}+\zeta_{R}}{\tau_{d}}\right)^{1 / \zeta_{R}}$. We estimate $\zeta_{R}$ externally, and then use this along with our estimates of $\bar{t}_{x}$ to compute $t_{x}^{*}$.

3. For the counterfactual, we also need values of the industry-level output elasticities of each input for each recipe, $\left\{\alpha_{\hat{\omega}}^{\rho}\right\}$. To do this, we pool data across states to estimate the remaining production function parameters, $\alpha_{\hat{\omega}}$, by using the aggregate expenditures. For example, if the sourcing industry $\hat{\omega}$ is relationship specific, then $\alpha_{\hat{\omega}}^{\rho}$ is equal $\alpha_{R}^{\rho}$ multiplied by the ratio of total expenditure on input $\hat{\omega}$ by those that use recipe $\rho$ to total expenditure on relationship-specific inputs.

4. For each state-recipe, directly measure the share of industry $\omega$ revenue earned by firms that, in equilibrium, use recipe $\rho,\left\{R_{\omega \rho}\right\}$. Similarly, directly measure for each state the share of final demand spent on industry $\omega,\left\{H H_{\omega}\right\}$.

\footnotetext{
${ }^{31}$ This follows from the fact that the Pareto family is closed under the minimum operation.
} 


\section{Calibrate $\eta$ and $\gamma$ externally.}

In implementing this algorithm, we make several auxiliary assumptions that, in principle, could be relaxed. First, we assume that there is no trade across state borders. While it would be fairly straightforward to incorporate interstate trade, we lack the relevant data. ${ }^{32} \mathrm{~A}$ second assumption is that the recipes used by multi-product firms and the distribution of wedges facing them are the same as those of single-product firms. This type of assumption, while strong, is standard in the literature, as we lack the data that indicates which inputs are used in the production of which products. It allows us to estimate wedge distribution parameters and the $\alpha$ 's using single-product plants only, while still being able to make statements about the whole formal manufacturing sector by including multi-product plants when we calculate revenue and expenditure shares $R_{\omega \rho}$ and $H H_{\omega}$. Third, we treat service inputs and energy inputs as primary inputs.

\subsection{Defining recipes}

One of the salient facts of the Indian manufacturing data is that even within narrow industries, plants use vastly different combinations of intermediate inputs to produce the same output. Our model provides a natural way to think of these input-output combinations as different recipes $\rho \in \rho(\omega)$ that could be used to produce the same output $\omega$. In order to estimate the model from the microdata, we need a procedure that classifies each plant-year observation into which recipe the plant is using.

The idea that guides our classification is that, for a given output good, similar input mixes should belong to the same recipe. We describe each plant $j$ 's input mix by the vector of its input expenditure shares, $\left(m_{j \omega}\right)_{\omega \in \Omega}=\left(X_{j \omega} / \sum_{\omega^{\prime}} X_{j \omega^{\prime}}\right)_{\omega \in \Omega}$. Graphically, each vector corresponds to a point in the $|\Omega|$-dimensional hypercube that is lying on the hyperplane where the sum of all coordinates equals to one. Our task is to find plants with similar input mixes, i.e. clouds of points that are close to each other (according to some metric). In statistics, this task is known as cluster analysis, and there is a large number of algorithms that classify clusters based on distance, density, shape, and other criteria. Looking at the input mixes of plants in many different industries (see the examples of bleached cotton cloth and polished diamonds in Figure 1) convinced us that these clusters do exist and have a meaningful economic interpretation.

Our preferred method is due to Ward (1963), and constructs clusters recursively, starting with the partition where every cluster is a singleton. In each step, two clusters are merged to minimize the sum of squared errors:

$$
\min _{\rho_{n} \geq \rho_{n-1}} \sum_{\rho \in \rho_{n}} \sum_{j \in \rho} \sum_{\omega}\left(m_{j \omega}-\bar{m}_{\rho \omega}\right)^{2}
$$

where the $\rho_{n}$ are partitions of $J_{\omega}$, and in each step $\rho_{n}$ runs over all partitions that are coarser than $\rho_{n-1}$. This method constructs a hierarchical set of partitions of $J_{\omega}$ : one for each desired number

\footnotetext{
${ }^{32}$ To this point there is no comprehensive, publicly available data about cross-state trade in goods. The conventional wisdom has been that interstate trade is minimal, although the 2016-17 Economic Survey of India's Ministry of Finance challenges this conventional wisdom.
} 
of clusters.

Table IV Statistics on recipes

\begin{tabular}{lr}
\hline & Count \\
\hline Products (5-digit ASIC) & 4,530 \\
Products with $\geq 3$ plant-years & 3,573 \\
Products with $\geq 5$ plant-years & 3,034 \\
\hline Recipes & 18,838 \\
Recipes with $\geq 3$ plant-years & 10,996 \\
Recipes with $\geq 5$ plant-years & 7,908 \\
Avg. plants per recipe & 11.8 \\
SD plants per recipe & 40.4 \\
\hline "Products" are the 5-digit ASIC codes in our data that \\
appear as output, "Recipes" are the output from our \\
clustering procedure. Plant counts include only single- \\
product plants.
\end{tabular}

Our implementation of the clustering procedure to identify recipes uses not only the five-digit materials shares, but also three-digit shares to allow for the possibility of misclassification of inputs within three-digit baskets. We set the number of potential recipes within each industry $\omega$ to $\left\lceil n \log \left((\# \text { Observations })_{\omega}\right)\right\rceil$, for varying parameters $n$. This allows industries with more plant-year observations to have more recipes. We inspect the cluster hierarchy and choose $n=1.5$, where we find that the resulting recipes correspond well to different modes of organization. ${ }^{33}$ Table IV shows statistics on the number and size of clusters (recipes) that we define.

To give a example of the usefulness of our procedure, Table $\mathrm{V}$ shows the resulting four most important recipes for product 63303 (bleached cotton cloth), which correspond to different ways of producing bleached cotton cloth: either by weaving bleached or dyed cotton yarn (recipes 1 and 2), by weaving and bleaching unbleached cotton yarn (recipe 3), and by bleaching and dyeing greige cloth (recipe 4).

Once we have defined recipes, we assign plants to belong to a recipe with a probability that is proportional to the inverse Euclidean distance to the recipe center:

$$
P(j \in \rho)=\frac{\frac{1}{\sqrt{\sum_{\omega^{\prime}}\left(m_{j \omega^{\prime}}-\bar{m}_{\rho \omega^{\prime}}\right)^{2}}}}{\sum_{\rho^{\prime} \in \rho(\omega)} \frac{1}{\sqrt{\sum_{\omega^{\prime}}\left(m_{j \omega^{\prime}}-\bar{m}_{\rho^{\prime} \omega^{\prime}}\right)^{2}}}}
$$

We use these assigned probabilities as weights in the estimation below.

\subsection{Estimation}

We estimate the $\bar{t}_{x}^{d}, \alpha_{R}^{\rho}, \alpha_{H}^{\rho}$, and $\alpha_{L}^{\rho}$ from the moment conditions in Proposition 5 using our algorithm described above. To identify the level of $\bar{t}_{x}$, we set the smallest $\bar{t}_{x}$ to one, thereby making the assumption that the least distorted state is undistorted. ${ }^{34}$ We also exclude state-recipe

\footnotetext{
${ }^{33}$ In Appendix F.2 we show results for varying degrees of recipe fineness.

${ }^{34}$ We view this as conservative. Given the expenditure shares we see in the data, more severe distortions (smaller $\bar{t}_{x}$ ) would raise the estimated output elasticities of relationship-specific inputs (higher $\alpha_{R}^{\rho}$ ). This would amplify the
} 
Table V Recipe classification: cloth, bleached, cotton (63303)

\begin{tabular}{|c|c|c|c|c|c|c|c|}
\hline Recipe & Description & Value, $\%$ & $N$ & Recipe & Description & Value, \% & $N$ \\
\hline \multirow[t]{4}{*}{ \# 1} & Yarn bleached, cotton & 98 & 50 & $\# 3$ & Yarn unbleached, cotton & $>99$ & 19 \\
\hline & Grey cloth (bleached / unbleached) & 2 & & & Colour, chemicals & $<1$ & \\
\hline & Thread, others, cotton & $<1$ & & & Gen. purpose machinery, n.e.c & $<1$ & \\
\hline & Colour (r.c) special blue & $<1$ & & & Dye, vat & $<1$ & \\
\hline \multirow[t]{10}{*}{$\# 2$} & Yarn dyed, cotton & 41 & 21 & $\# 4$ & Grey cloth & 42 & 16 \\
\hline & Yarn, finished / processed (knitted) & 23 & & & Colour, chemicals & 10 & \\
\hline & Yarn bleached, cotton & 16 & & & Yarn dyed, synthetic & 10 & \\
\hline & Yarn, grey-cotton & 3 & & & Kapas (cotton raw) & 5 & \\
\hline & Chemical \& allied substances, n.e.c & 3 & & & Grey cotton - others & 5 & \\
\hline & Fabrics, cotton & 3 & & & Fabrics, cotton & 4 & \\
\hline & Thread, others, cotton & 2 & & & Cotton raw, ginned \& pressed & 4 & \\
\hline & Colour, chemicals & 2 & & & Colour, ink, n.e.c & 4 & \\
\hline & Dye stuff & 2 & & & Other & 16 & \\
\hline & Other & 5 & & & & & \\
\hline
\end{tabular}

pairs where the average share of relationship-specific inputs in sales exceeds that of homogeneous inputs by a factor of one hundred (and vice versa).

Figure 3 shows the estimated $\bar{t}_{x}^{d}$ and their correlation with the quality of high courts as measured by the average age of pending civil cases. Frictions are large: $\bar{t}_{x}$ exceeds two in the most heavily distorted states. Some of that variation is explained by the quality of courts. In states with slower courts, firms face larger distortions (higher $\bar{t}_{x}$ ) when sourcing relationship-specific intermediate inputs. The solid line is the fit of an OLS regression of $\bar{t}_{x}$ on court quality; the dashed line the fit of an IV regressions where we instrument court quality using the log age of the high court. The estimated IV slope coefficient is similar to the one in the OLS. This relationship between $\bar{t}_{x}$ and the age of pending court cases is closely related to the fact that intermediate input bundles are tilted towards homogeneous inputs in states where enforcement is weak (Fact 2 in Section 2.3). The main difference here (beyond the fact that the $\bar{t}_{x}$ are coming from a nonlinear regression) is that the $\bar{t}_{x}$ are identified from within-recipe variation in the input mix, whereas Fact 2 is about within-product variation.

\subsection{Counterfactual}

To perform a counterfactual where we assess the aggregate impact of a change in the wedge distribution $T$, Proposition 4 tells us that we need to know the change in the moment $t_{x}^{*}$ of the wedge distribution that is relevant for the industry's cost distribution, which depends on the parameter $\zeta_{R}$ and, under our parameterization of the wedge distribution, on its Pareto tail $\tau_{d}$. We also need to know the parameters $\alpha_{\hat{\omega}}^{\rho}$, the within-industry sales shares $R_{\omega \rho}$ of each recipe, the household's expenditure shares $H H_{\omega}$, and the elasticities $\gamma$ and $\eta$.

The parameter $\zeta_{R}$, which allows us to back out $\tau_{d}$ from $\bar{t}_{x}$, also governs the elasticity of substitution across sets of suppliers of the same input. While our data does not indicate the identity responses to changes in enforcement. 
Figure 3 Correlation between $\bar{t}_{x}$ and court quality

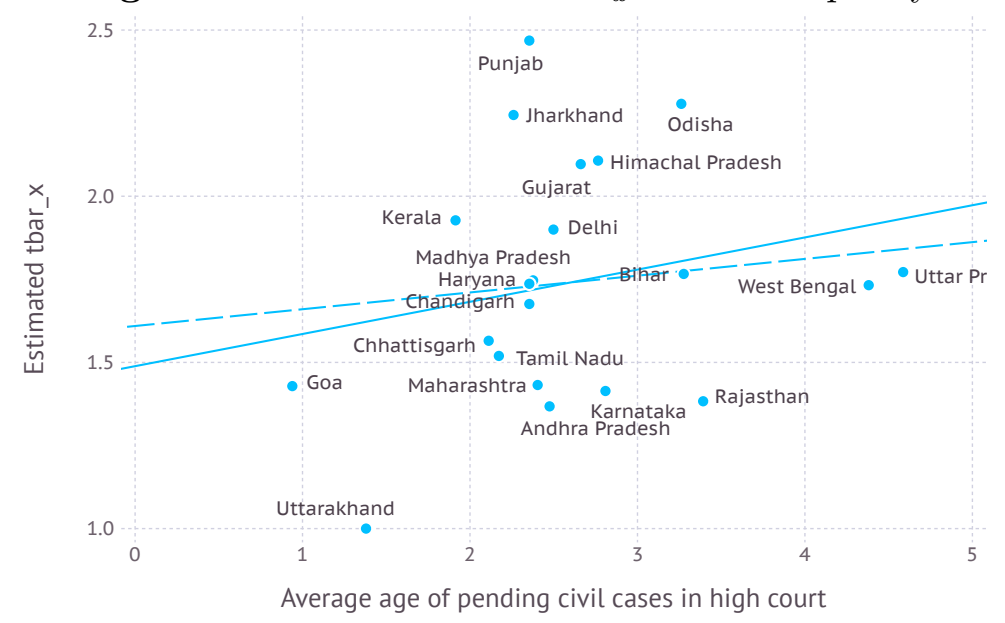

The figure shows the correlation between $\bar{t}_{x}^{d}$ and the average age of pending civil cases in the state's high court. The solid line is the OLS regression line; the dashed line is fit of an IV regression where the age of pending cases is instrumented using the log age of the high court.

of the supplier of an input, it does indicate whether it was purchased from a foreign or domestic supplier. We can thus estimate $\zeta_{R}$ using these two groups for each input-output pair:

$$
\log \left(\frac{X_{\omega \hat{\omega} t}^{D O M}}{X_{\omega \hat{\omega} t}^{I M P}}\right)=\zeta \log \left(1+\iota_{\hat{\omega} t}\right)+\lambda_{t}+\lambda_{\omega \hat{\omega}}+\eta_{\omega \hat{\omega} t}
$$

where $\iota_{\hat{\omega} t}$ is the import tariff on $\hat{\omega}$ at time $t$, and the $\lambda$ 's are fixed effects. Table VI shows the results for this regression. We use the point estimate of 0.218 for $\zeta_{R} \cdot{ }^{35}$

Table VI Estimating $\zeta$

\begin{tabular}{lccc}
\hline & \multicolumn{3}{c}{ Dependent variable: $\log \left(X_{\omega \hat{\omega} t}^{D O M} / X_{i \omega \hat{\omega} t}^{I M P}\right)$} \\
\cline { 2 - 4 } & $(1)$ & $(2)$ & $(3)$ \\
\hline $\log \left(1+\iota_{\hat{\omega} t}\right)$ & 0.617 & 0.218 & $1.209^{*}$ \\
& $(0.44)$ & $(0.77)$ & $(0.52)$ \\
\hline Industry $\times$ Input FE & Yes & Yes & Yes \\
Year FE & Yes & Yes & Yes \\
\hline Level & 5 -digit & 5 -digit & -digit \\
\hline Sample & All inputs & R only & H only \\
\hline$R^{2}$ & 0.601 & 0.580 & 0.623 \\
Observations & 23692 & 12002 & 11690 \\
\hline Robust errors in parentheses, clustered at the state $\times$ industry level. Sample \\
$+p<0.10,{ }^{*} p<0.05,{ }^{* *} p<0.01$ & &
\end{tabular}

Notes: Dependent variable is the log ratio of total expenditure on domestically sourced to total imported intermediate inputs of type $\hat{\omega}$ among producers of $\omega$ at time $t$. We only use census plants (which are surveyed every year) to reduce artificial fluctuations that result from sampling.

\footnotetext{
${ }^{35}$ Choosing a low $\zeta_{R}$ is conservative; see the discussion in 4.4 below. We conduct sensitivity checks in Appendix F.1.
} 
The elasticities $\alpha_{\hat{\omega}}$ can be recovered as the product of the input-type elasticity $\left(\alpha_{R}^{\rho}\right.$ or $\left.\alpha_{H}^{\rho}\right)$ and the average cost share of plants that produce using recipe $\rho$ :

$$
\alpha_{\hat{\omega}}^{\rho}=\alpha_{R}^{\rho} \frac{\bar{m}_{\rho \hat{\omega}}}{\sum_{\omega^{\prime} \in \Omega^{R}} \bar{m}_{\rho \hat{\omega}^{\prime}}} \text { if } \hat{\omega} \text { relationship-specific, } \quad \alpha_{\hat{\omega}}^{\rho}=\alpha_{H}^{\rho} \frac{\bar{m}_{\rho \hat{\omega}}}{\sum_{\omega^{\prime} \in \Omega^{H}} \bar{m}_{\rho \hat{\omega}^{\prime}}} \text { if } \hat{\omega} \text { homogenous. }
$$

We target the demand aggregator's expenditure shares $H H_{\omega}$ and the recipe revenue shares $R_{\omega \rho}$ to represent the aggregate of India's formal manufacturing sector. We calculate $H H_{\omega}$ separately for each state as total sales of $\omega$ minus total intermediate consumption (less imports) of $\omega$ (or zero, if this difference is negative), divided by the sum of this difference over all products. To calculate the recipe revenue shares $R_{\omega \rho}$, we need to assign the revenue of multiproduct plants to a particular recipe. To do this, we choose each multi-product plants' recipe shares to minimize the Euclidean distance of its cost share vector from the weighted average of the recipe centers' cost shares. When calculating $R_{\omega \rho}$, we pool observations across states and years, but weigh each plant-year observation by the inverse of the number of times the plant shows up in the ASI. This weighting allows us to construct parameters that better represent the aggregate of India's formal manufacturing sector. ${ }^{36}$

Finally, we calibrate $\eta=1$ and $\gamma=1$; we show in Appendix F.1 that our counterfactuals are insensitive to these parameters. Inputs which do not show up in our data as outputs (predominantly agricultural and mineral commodities) are assumed to have unchanged productivity distributions.

We then perform a counterfactual where we reduce $\bar{t}_{x}^{d}$ for each state by the amount that is implied by the IV regression in Figure 3, down to a point where the average age of pending cases is one year (which is roughly the level of court quality enjoyed by the best state, Goa). Using our estimate for $\zeta_{R}$, we back out $\tau_{d}$ at the original and counterfactual level, and compute the change

in the welfare-relevant moment $t_{x}^{*}=\left(\frac{\tau_{d}+\zeta_{R}}{\tau_{d}}\right)^{1 / \zeta_{R}}$. We then compute the corresponding change in the household's utility aggregate as given by Proposition 4 .

Figure 4 shows the counterfactual increase in the household's consumption aggregate $U$. The numbers are in the range of zero to ten percent, suggesting that the gains from improving contract enforcement institutions can be large.

\subsection{Direct and Indirect Costs of Distortions}

The model captures the idea that buyer-supplier relationships differ in their susceptibility to imperfect contract enforcement. Some buyer-supplier pairs are able to enforce contracts informally, or transact in a way that avoids holdup problems. To capture this in a parsimonious way, we assume that the buyer draws a distortion for each potential supplier from a distribution that deteriorates when formal enforcement is less reliable.

Our estimation procedure identifies $\bar{t}_{x}$ for each state, which is the (harmonic) average of the realized distortions. This summarizes the direct cost of weak enforcement on users of relationshipspecific inputs. $t_{x}^{*}$ captures the direct and indirect cost of the distortions. We infer the indirect cost by estimating $\zeta_{R}$, which indexes the probability that a firm has a comparable alternative supplier.

\footnotetext{
${ }^{36}$ Recall that in the ASI, large plants are surveyed every year, while smaller plants are surveyed every five years.
} 
Figure 4 Counterfactural increases in aggregate productivity

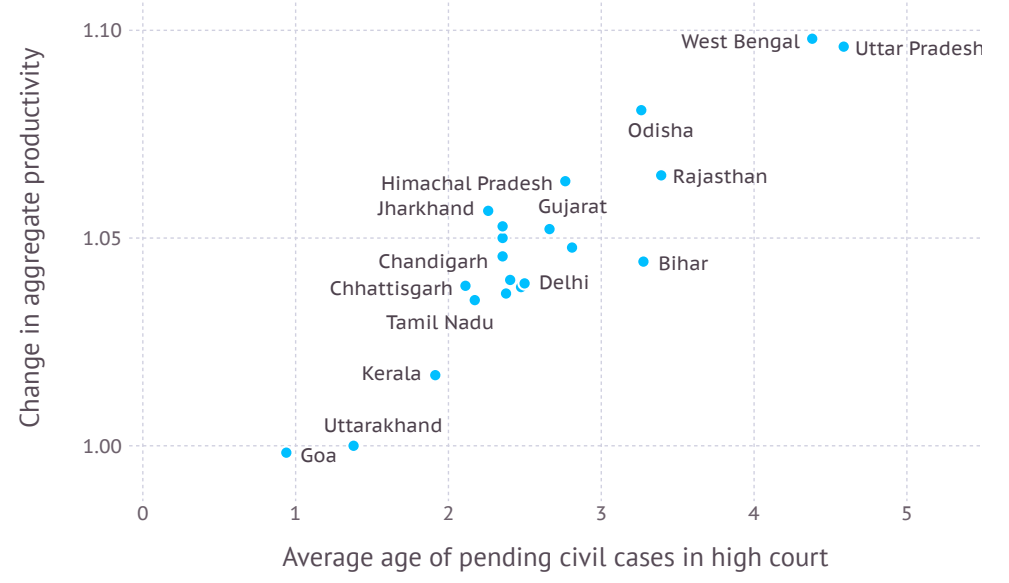

The figure shows the counterfactual increase in $C$ when the wedges on relationship-specific inputs are reduced according to the fraction of $\bar{t}_{x}$ that is explained by court quality in a linear regression.

We can show formally that $\bar{t}_{x} \leq t_{x}^{*}$, which implies that the $\bar{t}_{x}$ is a lower bound for the total impact, and that this lower bound is attained only if the distribution of distortions $T$ is degenerate, i.e., distortion draws are deterministic. In that case, a firm faces the same wedge for all suppliers, and could not avoid a distortion by substituting to an alternative supplier; as a result, there would be no indirect cost. ${ }^{37}$

The respective contributions of the direct and indirect impacts depend on both the value of $\zeta_{R}$ and the levels of the distortion. Given our estimates and the range of $\bar{t}_{x}$ that we observe, the direct impact comprises more than half of the impact of weak enforcement, but the indirect impacts are nontrivial. For the average state, the indirect impact accounts for $\frac{t_{x}^{*}-\bar{t}_{x}}{t_{x}^{*}}=24.8 \%$ of the total impact, and for the most distorted state the indirect impact accounts for about $58 \%$.

\subsection{The Role of Heterogeneity}

An alternative approach that is common in studies that measure misallocation using input-output tables is to posit industry-level Cobb-Douglas production functions and back out distortions from differences across states (or countries) in industry-level cost shares. ${ }^{38}$ In our view, our approach

\footnotetext{
${ }^{37}$ Since $t^{\frac{\zeta}{\zeta+1}}$ is a strictly concave function of $t$, Jensen's Inequality gives $\int_{1}^{\infty} t_{x}^{-(\zeta+1)} d T\left(t_{x}\right) \quad \geq$ $\left\{\int_{1}^{\infty}\left(t_{x}^{-(\zeta+1)}\right)^{\frac{\zeta}{\zeta+1}} d T\left(t_{x}\right)\right\}^{\frac{\zeta+1}{\zeta}} \cdot$ This implies

$$
\frac{1}{\overline{t_{x}}}=\frac{\int_{1}^{\infty} t_{x}^{-(\zeta+1)} d T\left(t_{x}\right)}{\int_{1}^{\infty} t_{x}^{-\zeta} d T\left(t_{x}\right)} \geq \frac{\left\{\int_{1}^{\infty} t_{x}^{-\zeta} d T\left(t_{x}\right)\right\}^{\frac{\zeta+1}{\zeta}}}{\int_{1}^{\infty} t_{x}^{-\zeta} d T\left(t_{x}\right)}=\frac{1}{t_{x}^{*}}
$$
}

with equality only if the distribution of $t_{x}$ is degenerate.

${ }^{38}$ Our model nests such a model as a special case when there is a single recipe per industry and the distribution of wedges $T$ is degenerate so that all suppliers of relationship-specific inputs face the same wedge. 
has several advantages over this alternative.

First, a cursory look at the data indicates that plants are producing using different technologies (i.e., some appear to be more vertically integrated than others). We believe that allowing for several recipes facilitates making apples-to-apples comparisons when measuring the direct impact of distortions. Our identification strategy relies on comparing inputs expenditures among plants that, in equilibrium, use the same recipe. With the industry-level approach, differences in recipe composition across states could lead researchers to infer spurious distortions.

Second, the industry-level approach would miss the indirect impact of the distortions. Given our identification strategy and conditioning on the data, the fact that wedges differ across suppliers implies indirect productivity losses due to plant's switching to alternative suppliers to avoid a distorted input. This raises the implied productivity loss from imperfect enforcement. Our identification strategy consists of measuring $\left\{\bar{t}_{x}\right\}$ and then using these along with our functional form assumptions to compute $t_{x}^{*}$. In the industry-level approach there is typically only a direct impact.

Third, as discussed earlier, there is quite a bit of heterogeneity in cost shares across plants. This leads to the following situation: there are occasionally state-industry pairs that are dominated by a small number of plants, and the aggregate cost shares among these plants happen to deviate quite a bit from the industry average. If we used the industry-level cost shares to back out a wedge for that state-industry, we would conclude that the state-industry is severely distorted. In contrast, our estimating equations treat each individual plant as an observation, and the model has a structural error term for the cost share of each plant which stems from different productivity and cost draws. Thus our approach allows for the possibility that such a state-industry has an extreme cost share because of its draw of a technique; we are not forced to conclude that the distortion for the state-industry is severe.

\subsection{Entry and Exit}

In our benchmark model, we assumed that the number of producers of each product is given exogenously. Of course we would expect that if the formal enforcement improved, profitability would increase more in industries that rely more heavily on relationship-specific inputs. We do, in fact observe that as formal enforcement deteriorates, the number of firms decreases relatively more in the industries that rely more heavily on relationship-specific inputs (see Table XXVI in Appendix E.4). Thus it is likely the quality of enforcement affects firms' entry and exit decisions.

How would our estimates differ if firms could endogenously enter and exit? The answer depends on the specifics of entry and exit and the particular counterfactual. Consider the following two possibilities. First suppose firms were committed to enter, but could choose which industry to enter. Then the additional adjustment after formal enforcement improved would raise aggregate productivity even more than a benchmark model suggests. Second, suppose that firms were committed to producing in a particular industry but choose which state to locate in. Here, if formal enforcement improves in one state, aggregate productivity in that state would rise as firms for other states moved in. However, aggregate productivity in other states would fall as firms moved out. 
This suggests that the response to nation-wide improvement in formal enforcement would differ from the response to a single state improving enforcement. Further, systematic differences across states in how the number of firms responds to cross-sectional difference in legal enforcement may not be informative about the economy's response to a nationwide improvement.

\subsection{Interpretation of our estimates}

Our estimates suggest that improving the quality of high courts to the level enjoyed by the most efficient states would bring about productivity increases of on average five percent. This estimate is likely to be a lower bound for role of courts in enforcing contracts between buyers and suppliers for several reasons. First, even the best Indian courts are probably still worse than good courts in the developed world, in particular along dimensions that are not captured by our court quality measure (such as objectivity and incorruptibility). Second, if contracting frictions are also present for homogeneous intermediate inputs, our estimates of the productivity gains from improving courts are biased downwards. ${ }^{39}$ Third, hold-up problems are particularly severe for services inputs, which account for a substantial fraction of cost in some industries; hence court improvement could lead to substantial additional cost reductions (Boehm, 2016). Formal enforcement is also likely to be important for the smallest firms that may be less able to rely on reputation. Moreover, courts matter for economic outcomes beyond their role in mitigating holdups with suppliers, notably by improving contracting between managers and workers (Besley and Burgess, 2004, and Bloom, Sadun and Reenen, 2012), and improving access to financing (Visaria, 2009).

\section{Conclusion}

This paper studies the organization of production in the Indian manufacturing sector, and how it relates to the quality of formal contract enforcement institutions. We make two main points: one about the within-industry heterogeneity and measurement of the organization of production, and a second one about how institutions shape intermediate input use and aggregate productivity.

First, we show that there is considerable amount of heterogeneity in technology and organization even within narrowly-defined industries. These differences should be reflected in the level of aggregation at which researchers assume a homogeneous shape of the production function. We argue that information on input use can be helpful in understanding differences in organization and technology within industries: a plant that produces cotton cloth from raw cotton is vertically integrated and performs both spinning and weaving, whereas a plant that produces cotton cloth from cotton yarn will only perform the weaving, and might therefore have different factor intensities. We provide a simple and flexible way of defining homogeneous technologies using a statistical clustering algorithm.

\footnotetext{
${ }^{39}$ That said, Johnson, McMillan and Woodruff (2002) bring survey evidence that the role of courts in determining supplier switching is about five times as large for relationship-specific inputs than for standardized inputs, suggesting that most of the productivity gains are correctly accounted for.
} 
Second, we find that the organization of production is shaped by the contracting environment. We find that slow enforcement of contracts impedes the use of relationship-specific materials. As a result, firms tilt their input basket towards the use of more standardized inputs, for which spot markets exist, and for which enforcement by courts in not necessary. We develop a multi-industry general equilibrium model where firms source multiple inputs and choose the organizational form optimally to minimize the cost of production. We estimate the relative distortions associated with the use of relationship-specific inputs from first moments of cost shares, which, compared to the standard approaches of estimating input wedges, is more robust to potentially imprecise measurement of input use. Our results suggest that distortions associated with poor courts are sizable and that improving couurts would increase welfare: reducing the average age of pending cases by a year would, on average, increase a state's aggregate productivity by about three percent. 


\section{References}

Acemoglu, Daron, and Pablo D Azar. 2017. "Endogenous Production Networks." National Bureau of Economic Research.

Acemoglu, Daron, and Simon Johnson. 2005. "Unbundling Institutions." Journal of Political Economy, 113: 5 .

Acemoglu, Daron, Pol Antràs, and Elhanan Helpman. 2007. "Contracts and Technology Adoption." American Economic Review, 97(3): 916-943.

Alfaro, Laura, Pol Antràs, Davin Chor, and Paola Conconi. 2015. "Internalizing Global Value Chains: A Firm-Level Analysis." Working paper, Harvard University.

Amirapu, Amrit. 2017. "Justice Delayed is Growth Denied: The Effect of Slow Courts on Relationship-Specific Industries in India." School of Economics, University of Kent.

Antràs, Pol, and Alonso de Gortari. 2017. "On the Geography of Global Value Chains." National Bureau of Economic Research.

Antràs, Pol, Davin Chor, Thibault Fally, and Russell Hillberry. 2012. "Measuring the upstreamness of production and trade flows." American Economic Review, 102(3): 412-16.

Antras, Pol, Teresa C Fort, and Felix Tintelnot. 2017. "The Margins of Global Sourcing: Theory and Evidence from US Firms." American Economic Review, 107(9): 2514-64.

Atalay, Enghin. 2017. "How important are sectoral shocks?" American Economic Journal: Macroeconomics, 9(4): 254-80.

Baqaee, David Rezza, and Emmanuel Farhi. 2017. "Productivity and Misallocation in General Equilibrium." National Bureau of Economic Research.

Bartelme, Dominick, and Yuriy Gorodnichenko. 2014. "Linkages and Economic Development." Mimeo, UC Berkeley.

Bas, Maria, and Vanessa Strauss-Kahn. 2015. "Input-trade liberalization, export prices and quality upgrading." Journal of International Economics, 95(2): 250-262.

Besley, Timothy, and Robin Burgess. 2004. "Can labor regulation hinder economic performance? Evidence from India." The Quarterly Journal of Economics, 119(1): 91-134.

Bigio, Saki, and Jennifer La'O. 2016. "Financial frictions in production networks." National Bureau of Economic Research.

Bils, Mark, Peter J Klenow, and Cian Ruane. 2017. "Misallocation or Mismeasurement?" Society for Economic Dynamics.

Bloom, Nicholas, Raffaella Sadun, and John Van Reenen. 2012. "The organization of firms across countries." The Quarterly Journal of Economics, 127(4): 1663-1705.

Boehm, Johannes. 2016. "The Impact of Contract Enforcement Costs on Outsourcing and Aggregate Productivity." 
Buera, Francisco J, and Ezra Oberfield. 2016. "The Global Diffusion of Ideas." National Bureau of Economic Research.

Caliendo, Lorenzo, Fernando Parro, and Aleh Tsyvinski. 2017. "Distortions and the Structure of the World Economy." National Bureau of Economic Research.

Caprettini, Bruno, and Antonio Ciccone. 2015. "Turnover Taxes and Productivity: Evidence from a Brazilian Tax Reform."

Chaney, Thomas. 2014. "The network structure of international trade." The American Economic Review, 104(11): 3600-3634.

Chemin, Matthieu. 2012. "Does court speed shape economic activity? Evidence from a court reform in India." Journal of Law, Economics, and Organization, 28(3): 460-485.

Costinot, Arnaud, Jonathan Vogel, and Su Wang. 2012. "Global Supply Chains and Wage Inequality." American Economic Review, 102(3): 396-401.

Djankov, Simeon, Rafael La Porta, Florencio Lopez de Silanes, and Andrei Shleifer. 2003. "Courts." The Quarterly Journal of Economics, 118(2): 453-517.

Eaton, Jonathan, Samuel Kortum, and Francis Kramarz. 2015. "Firm-to-Firm Trade: Imports, Exports, and the Labor Market."

Fadinger, Harald, Christian Ghiglino, and Mariya Teteryatnikova. 2016. "Income differences and input-output structure."

Fally, Thibault, and Russell Hillberry. 2015. "A Coasian Model of International Production Chains." National Bureau of Economic Research.

Goldberg, Pinelopi Koujianou, Amit Kumar Khandelwal, Nina Pavcnik, and Petia Topalova. 2010. "Imported intermediate inputs and domestic product growth: Evidence from India." The Quarterly Journal of Economics, 125(4): 1727-1767.

Grossman, Gene M., and Elhanan Helpman. 2002. "Integration versus Outsourcing in Industry Equilibrium." The Quarterly Journal of Economics, 117(1): 85-120.

Growiec, Jakub. 2013. "A Microfoundation for Normalized CES Production Functions with Factor-Augmenting Technical Change." Journal of Economic Dynamics and Control, 37(11): $2336-2350$.

Hazra, Arnab Kumar, and Bibek Debroy. 2007. Judicial reforms in India: Issues and aspects. Academic Foundation.

Hopenhayn, Hugo A. 2014. "Firms, misallocation, and aggregate productivity: A review." Annu. Rev. Econ., 6(1): 735-770.

Houthakker, Hendrik. 1955. "The Pareto Distribution and the Cobb-Douglas Production Function in Activity Analysis." The Review of Economic Studies, 23(1): pp. 27-31.

Hsieh, Chang-Tai, and Peter J Klenow. 2009. "Misallocation and manufacturing TFP in China and India." The quarterly journal of economics, 124(4): 1403-1448.

Hummels, David. 1999. "Toward a geography of trade costs." Purdue University Working Papers. 
Iyer, Rajkamal, and Antoinette Schoar. 2008. "The Importance of Holdup in Contracting: Evidence from a Field Experiment."

Johnson, Simon, John McMillan, and Christopher Woodruff. 2002. "Courts and relational contracts." Journal of Law, Economics, and organization, 18(1): 221-277.

Jones, Charles I. 2005. "The shape of production functions and the direction of technical change." The Quarterly Journal of Economics, 120(2): 517-549.

Jones, Charles I. 2013. "Misallocation, Economic Growth, and Input-Output Economics." Vol. 2, 419, Cambridge University Press.

Khandelwal, Amit, and Petia Topalova. 2011. "Trade liberalization and firm productivity: The case of india." Review of Economics and Statistics, 93(3): 995-1009.

Kortum, Samuel S. 1997. "Research, Patenting, and Technological Change." Econometrica, 65(6): 1389-1420.

Laeven, Luc, and Christopher Woodruff. 2007. "The quality of the legal system, firm ownership, and firm size." The Review of Economics and Statistics, 89(4): 601-614.

Lagos, Ricardo. 2006. "A Model of TFP." The Review of Economic Studies, 73(4): 983-1007.

La Porta, Rafael, Florencio Lopez de Silanes, Andrei Shleifer, and Robert W. Vishny. 1997. "Legal Determinants of External Finance." The Journal of Finance, 52(3): 1131-50.

Law Commission of India. 2014. "Report No. 245. Arrears and Backlog: Creating Additional Judicial (wo)manpower."

Levchenko, Andrei A. 2007. "Institutional quality and international trade." The Review of Economic Studies, 74(3): 791-819.

Lim, Kevin. 2017. "Firm-to-firm Trade in Sticky Production Networks."

Liu, Ernest. 2017. "Industrial policies and economic development."

Lu, Dan, Asier Mariscal, and Luis Fernando Mejia. 2013. "Imports Switching and the Impact of Large Devaluation."

Mangin, Sephorah. 2017. "A Theory of Production, Matching, and Distribution." Journal of Economic Theory, 172: 376-409.

Narasappa, Harish, and Shruti Vidyasagar. 2016. State of the Indian Judiciary: A Report by Daksh. Eastern Book Company.

Nunn, Nathan. 2007. "Relationship-specificity, incomplete contracts, and the pattern of trade." The Quarterly Journal of Economics, 122(2): 569-600.

Oberfield, Ezra. 2018. "A Theory of Input-Output Architecture.” Econometrica, 86(2): 559-589.

Oberfield, Ezra, and Devesh Raval. 2014. "Micro data and macro technology." National Bureau of Economic Research.

Osotimehin, Sophie, and Latchezar Popov. 2017. "Misallocation and Intersectoral Linkages." Mimeo. 
Pavcnik, Nina. 2002. "Trade liberalization, exit, and productivity improvements: Evidence from Chilean plants." The Review of Economic Studies, 69(1): 245-276.

Ponticelli, Jacopo, and Leonardo S. Alencar. 2016. "Court Enforcement, Bank Loans, and Firm Investment: Evidence from a Bankruptcy Reform in Brazil." The Quarterly Journal of Economics, 131(3): 1365-1413.

Rauch, James E. 1999. "Networks versus markets in international trade." Journal of International Economics, 48(1): 7-35.

Robinson, Nick. 2016. "Judicial Architecture and Capacity." In The Oxford Handbook of the Indian Constitution. , ed. Sujit Choudhry, Madhav Khosla and Pratap Bhanu Mehta. Oxford:Oxford University Press.

Rotemberg, Martin, and T Kirk White. 2017. "Measuring Cross-Country Differences in Misallocation."

Taschereau-Dumouchel, Mathieu. 2017. "Cascades and fluctuations in an economy with an endogenous production network."

Tintelnot, Felix, Ken Kikkawa, Magne Mogstad, and Emmanuel Dhyne. 2017. "Trade and Domestic Production Networks." Unpublished Manuscript, University of Chicago.

Visaria, Sujata. 2009. "Legal Reform and Loan Repayment: The Microeconomic Impact of Debt Recovery Tribunals in India." American Economic Journal: Applied Economics, 1(3): 59-81. 


\section{Appendix}

\section{A Data Appendix}

\section{A.1 Data Sources and Variable Definitions}

- Plant-level data: Our plant data is India's Annual Survey of Industries (ASI), published by the Central Statistics Office, Ministry of Statistics and Program Implementation. The data is at annual frequency, each reporting year starts on April 1st and ends on March 31st. Our data covers the years 2000/01 to $2012 / 13$. The input and output product codes for 2008/09 and 2009/10 are different to the ones from earlier years; we created a concordance using the product names (which often match perfectly), and concord the few remaining ones by hand. The years 2010/11 to 2012/13 use the NPCMS product classification, which we convert to ASIC 2007/08 product codes using the concordance published by the Ministry.

- Total cost: Sum of the user cost of capital, the total wage bill, energy, services, and materials inputs. Total cost is set to be missing if and only if the user cost of capital, the wage bill, or total materials are missing. The user cost of capital is constructed using the perpetual inventory method as in the Appendix of Greenstreet (2007), using depreciation rates of $0 \%, 5 \%, 10 \%, 20 \%$, and $40 \%$ for land, buildings, machinery, transportation equipment, and computers \& software, respectively. Capital deflators are from the Ministry's wholesale price index, and the nominal interest rate is the India Bank Lending Rate, from the IMF's International Financial Statistics (on average about 11\%).

- Materials expenditure in total cost: (as used in Table I and subsequent tables) Total expenditure on intermediate inputs which are associated with a product code (that excludes services and most energy inputs) divided by total cost (see above).

- Pending High Court cases: From Daksh India (www.dakshindia.org). Daksh collects and updates pending cases by scraping High Court websites. Cases were retrieved on 11 June 2017. To eliminate biases resulting from possible delays in the digitisation, we exclude all cases that were filed after $1 / 1 / 2017$. We divide cases into civil and criminal based on state-specific case type codes (which are part of the case identifiers), and a correspondence between case types and whether they are civil or criminal cases (from High Courts, where available).

- Rauch classification of goods: From James Rauch's website, for 5-digit SITC codes. Concorded from SITC codes to ASIC via the SITC-CPC concordance from UNSTATS, and the NPCMS-ASIC concordance from the Indian Ministry of Statistics (NPCMS is based on CPC codes).

- Dependence on relationship-specific inputs, by industry: (as used in Table I) Total expenditure of single-product plants in an industry on relationship-specific inputs (according to the concorded Rauch classification), by 3-digit industry, divided by total expenditures on intermediate inputs that are associated with a 5-digit product code (which excludes services and most energy intermediate inputs).

- Gross domestic product per capita, by district: District domestic product was assembled from various state government reports, for the year 2005 (to maximize coverage). Missing for Goa and Gujarat and some union territories, and for some individual districts in the other states. Population data from the 2001 and 2011 Census of India, interpolated to 2005 assuming a constant population growth rate in each district. Whenever district domestic product per capita was unavailable, we used gross state domestic product per capita, as reported by the Ministry of Statistics and Program Implementation.

- Vertical Integration: See Appendix B. Due to the change in product classification from ASIC to NPCMS after 2010, we construct vertical distance only for the pre-2011 years.

- Trust: Fraction of respondents that answer "Most people can be trusted" in the World Value Survey's trust question: "Generally speaking, would you say that most people can be trusted or that you need to be very careful in dealing with people?" Data from waves 4, 5, and 6 of the World Values Survey, except for Himachal Pradesh, Puducherry, and Uttarakhand, which are only available in wave 6. Data is missing for Goa and the UT's, except for Delhi and Puducherry. 
- Language: Data on population by mother tongue in each state, from the 2001 Census of India, as published by the Office of the Registrar General and Census Commissioner.

- Caste: Data on caste from the 2014 round of CMIE's Consumer Pyramids Survey (as made available by ICPSR), covering all states of India except the northeastern states and the UT's of Andaman and Nicobar, Lakshadweep, Dadra and Nagar Haveli and Daman and Diu. Observations have been weighted to be representative at the level of a "homogeneous region", which is "a set of neighbouring districts that have similar agro-climatic conditions, urbanisation levels and female literacy" (CPS 2014 User guide). Data covers 364 castes and caste categories. Herfindahls are constructed at the level of a homogeneous region, and mapped to districts. ${ }^{40}$

- Corruption: Number of self-reported bribes per 1,000 inhabitants. Data on bribes is the full history of 35,391 self-reported bribes paid from IPaidABribe.com (as of 03/28/2018), which we aggregate at the state level. Population by state is from the 2011 Census of India.

- Capital Intensity: Average plant-level cost share of capital inputs (user cost of capital, see above), by 5 -digit industry.

- Wage Premium: Average plant-level wage bill divided by the total number of man-days worked, by 5 -digit industry.

- Contract Labor Share: Average plant-level cost share of contract (non-permanent) workers in the total wage bill, by 5 -digit industry.

- Upstreamness: Upstreamness as defined by Antràs et al. (2012) of 3-digit industries, calculated by year and averaged across years. Some goods show up mostly as inputs and not as outputs because as outputs they fall outside of the scope of the ASI (chiefly agricultural and mining goods); for these inputs total observed intermediate consumption exceeds total observed production by plants in our sample. We set total production of these goods equal to total intermediate consumption (hence assuming zero sales to final goods consumers). ${ }^{41}$ The resulting variable looks very similar to those constructed by Antràs et al. (2012) for industrialized countries.

- Tradability: Weighted average freight rates of industry's inputs, by 5-digit industry (using only singleproduct plants). Freight rates are the "average trade-weighted freight rates" by 2-digit SITC codes, from Hummels (1999), concorded to ASIC codes using the SITC-ASIC concordance that we used for the Rauch classification as well.

- Household consumption shares $H H_{\omega}$ : Define total net production as the total production of $\omega$ (from the ASI, pooled across all years within each state, with each plant-year observation weighted by the inverse of the number of times the plant shows up in the ASI), minus the total consumption of $\omega$ as intermediate inputs by ASI firms (constructed and weighted analogously). If total net production of a good is negative, we set it equal to zero. The value of $H H_{\omega}$ is then the fraction of total net production of $\omega$ is the sum of total net production of all goods $\omega^{\prime} \in \Omega$.

- Recipe revenue shares $R_{\omega \rho}$ : Share of sales of $\omega$ using recipe $\rho$ in total sales of $\omega$. The sales of $\omega$ using $\rho$ of a single-product plant $j$ are the sales of $\omega$ by $j$ multiplied by the probability that $j$ produces using $\rho$ (equation (3)). To construct the sales of $\omega$ using $\rho$ of a multi-product plant $j$, we choose plant-specific recipe shares to minimize the Euclidean distance of the plant's vector of observed cost shares from the weighted average of the recipes' mean cost shares $\bar{m}_{\rho \omega}$, where the weights are the plant-specific recipe shares (subject to the constraint that weights have to sum up to one for each product $\omega$ ). To construct $R_{\omega \rho}$, we weigh all plant-year observations by the inverse of the number of times the plant shows up in the ASI, pooling across all states and years.

\footnotetext{
${ }^{40}$ We are grateful to Renuka Sané and CMIE for helping us get a description of the homogeneous regions.

${ }^{41}$ While this may make these goods look more upstream than they actually are, the biases incurred are likely to be small: minerals are usually not directly sold to households; agricultural goods are either very upstream in the value chain of processed foods, or directly sold to households, but do not appear "in the middle" of the value chain.
} 


\section{A.2 Sample}

For the linear regressions in Section 2, the sample consists of all plants are reported as operating, produce a single 5-digit product, and have materials shares in output strictly between zero and two. We also drop the few observations from Sikkim and the Seven Sister States in North East India (Assam, Meghalaya, Manipur, Mizoram, Nagaland, and Tripura; Arunachal Pradesh is not covered by the ASI) because they have a different sampling methodology in the ASI, and Jammu and Kashmir, because coverage of its court cases is inadequate, and because many federal laws do not apply to it due to its special status within the union.

For the structural estimation, we also remove observations where the shares of relationship-specific materials, homogeneous materials, or labor in sales exceed two, and observations where sales or non-materials expenditures are non-positive. To construct the households consumption shares $H H_{\omega}$ and the recipe sales shares $R_{\omega \rho}$ in the counterfactual, we weigh each plant-year observation by the inverse of the number of times the plant shows up in our sample.

The regression to estimate $\zeta$ (Table VI) is the only one where we identify parameters from time variation. Our sample to construct the expenditure aggregates consists of all census plants (which are surveyed every

year). We restrict the sample in this way to eliminate fluctuations in the expenditure ratios that arise artificially from changes in the sample.

\section{A.3 Details on High Court and State creation}




\begin{tabular}{|c|c|c|c|c|c|}
\hline Name & $\begin{array}{ll}\text { Jurisdiction } & \text { over } \\
\text { States/UT's } & \end{array}$ & $\begin{array}{l}\text { Year } \\
\text { founded }\end{array}$ & $\begin{array}{l}\text { Created with } \\
\text { State }\end{array}$ & Notes on High Court creation & Reasons for State creation \\
\hline Allahabad High Court & Uttar Pradesh & 1866 & no & $\begin{array}{l}\text { Created as HC of Judicature of the } \\
\text { Northwestern Provinces by the Indian } \\
\text { High Courts Act } 1861 \text {. }\end{array}$ & \\
\hline High Court of Judicature at Hyderabad & $\begin{array}{l}\text { Andhra Pradesh, Telan- } \\
\text { gana }\end{array}$ & 1956 & yes & $\begin{array}{l}\text { Created when Andhra Pradesh was cre- } \\
\text { ated as part of the State Reorganization } \\
\text { Act } 1956\end{array}$ & $\begin{array}{l}\text { Creation of Andhra Pradesh was trig- } \\
\text { gered by the independence movement } \\
\text { of the Telugu-speaking population of } \\
\text { Madras Presidency. }\end{array}$ \\
\hline Mumbai High Court & $\begin{array}{l}\text { Goa, Dadra and Nagar } \\
\text { Haveli,Daman and Diu, } \\
\text { Maharashtra }\end{array}$ & 1862 & no & $\begin{array}{l}\text { Created by the Indian High Courts Act } \\
1861 .\end{array}$ & \\
\hline Kolkata High Court & $\begin{array}{l}\text { Andaman and Nicobar Is- } \\
\text { lands, West Bengal }\end{array}$ & 1862 & no & $\begin{array}{l}\text { Created by the Indian High Courts Act } \\
1861 .\end{array}$ & \\
\hline Chhattisgarh High Court & Chhattisgarh & 2000 & yes & $\begin{array}{l}\text { Created when Chhattisgarh state was } \\
\text { carved out of Mandhya Pradesh in } 2000 \\
\text { (Madhya Pradesh Reorganisation Act) }\end{array}$ & $\begin{array}{l}\text { Chhattisgarh was a separate division } \\
\text { in the Central Provinces under British } \\
\text { rule. Demand for a separate state goes } \\
\text { back to } 1920 \text {. }\end{array}$ \\
\hline Delhi High Court & Delhi & 1966 & no & $\begin{array}{l}\text { At the time of independence, Punjab } \\
\text { HC had jurisdiction for Delhi. With the } \\
\text { State Reorganisation Act 1956, Punjab } \\
\text { merged with Pepsu. Given Delhi's im- } \\
\text { portance as capital, it was decided that } \\
\text { they should have their own HC. }\end{array}$ & \\
\hline Gauhati High Court & $\begin{array}{l}\text { Arunachal Pradesh, As- } \\
\text { sam,Mizoram, Nagaland * }\end{array}$ & 1948 & yes & $\begin{array}{l}\text { Created as HC of Assam in 1948, } \\
\text { with the Indian constitution; renamed } \\
\text { Gauhati HC in } 1971 \text { with the North } \\
\text { East Areas Reorganization Act. Lost } \\
\text { jurisdiction over Meghalaya, Manipur, } \\
\text { and Tripura in } 2013\end{array}$ & \\
\hline Gujarat High Court & Gujarat & 1960 & yes & $\begin{array}{l}\text { Created when Gujarat split from Bom- } \\
\text { bay State with the Bombay Reorgani- } \\
\text { sation Act } 1960 .\end{array}$ & $\begin{array}{l}\text { Gujarat was created following the de- } \\
\text { mand of Gujarati-speaking people for } \\
\text { their own state (Mahagujarat move- } \\
\text { ment). }\end{array}$ \\
\hline Himachal Pradesh High Court & Himachal Pradesh & 1971 & yes & $\begin{array}{l}\text { Created with Himachal Pradesh becom- } \\
\text { ing a state (and therefore should have } \\
\text { a separate HC under the Indian consti- } \\
\text { tution) }\end{array}$ & \\
\hline Jammu and Kashmir High Court & Jammu and Kashmir & 1928 & no & $\begin{array}{l}\text { Created by the Maharaja in } 1928 \text {. Spe- } \\
\text { cial status: Laws passed by the Indian } \\
\text { parliament generally do not apply to } \\
\text { J\&K (except foreign policy, communi- } \\
\text { cation, defense). }\end{array}$ & \\
\hline Jharkhand High Court & Jharkhand & 2000 & yes & $\begin{array}{l}\text { Created when Jharkhand state was } \\
\text { carved out of Bihar in } 2000 \text { (Bihar Re- } \\
\text { organisation Act) }\end{array}$ & $\begin{array}{l}\text { Jharkhand was richer in natural re- } \\
\text { sources than the rest of Bihar; Jhark- } \\
\text { hand Mukti Morcha independence } \\
\text { movement, and political considerations } \\
\text { by ruling parties. }\end{array}$ \\
\hline
\end{tabular}




\begin{tabular}{|c|c|c|c|c|c|}
\hline Karnataka High Court & Karnataka & 1884 & no & $\begin{array}{l}\text { Founded by the British as the Chief } \\
\text { Court of Mysore in } 1884 \text {. }\end{array}$ & \\
\hline Kerala High Court & Kerala, Lakshadweep & 1956 & yes & $\begin{array}{l}\text { Created when Kerala was created as } \\
\text { part of the State Reorganization Act } \\
1956\end{array}$ & $\begin{array}{l}\text { Idea of Kerala was to combine } \\
\text { Malayalam-speaking regions. }\end{array}$ \\
\hline Madhya Pradesh High Court & Madhya Pradesh & 1936 & no & $\begin{array}{l}\text { Established as Nagpur High Court } \\
\text { by King George V through a Letters } \\
\text { Patent on } 2 \text { Jan } 1936 \text {. Moved to its } \\
\text { present location at Jabalpur with the } \\
\text { State Reorganization Act } 1956 \text {. }\end{array}$ & \\
\hline Chennai High Court & Puducherry, Tamil Nadu & 1862 & no & $\begin{array}{l}\text { Created by the Indian High Courts Act } \\
1861 .\end{array}$ & \\
\hline Odisha High Court & Odisha/Orissa & 1948 & no & $\begin{array}{l}\text { Orissa was split off from Bihar in } 1936 \text {, } \\
\text { but did not get its own high court until } \\
\text { the drafting of the Indian constitution } \\
\text { (1948). }\end{array}$ & \\
\hline Patna High Court & Bihar & 1916 & yes & $\begin{array}{l}\text { Created when Bihar and Orissa were } \\
\text { split off from Bengal Presidency. }\end{array}$ & $\begin{array}{l}\text { Bengal nationalism and the undoing of } \\
\text { the } 1905 \text { Partition of Bengal. }\end{array}$ \\
\hline Punjab and Haryana High Court & $\begin{array}{l}\text { Chandigarh, Haryana, } \\
\text { Punjab }\end{array}$ & 1947 & yes & $\begin{array}{l}\text { Created with the independence of In- } \\
\text { dia in } 1947 \text { (former HC of Punjab in } \\
\text { Lahore was mostly relevant for modern- } \\
\text { day Pakistan) }\end{array}$ & \\
\hline Rajasthan High Court & Rajasthan & 1949 & yes & $\begin{array}{l}\text { Created with the foundation of Ra- } \\
\text { jasthan (1948-1950) }\end{array}$ & \\
\hline Sikkim High Court & Sikkim & 1955 & no & $\begin{array}{l}\text { Established by the Maharaja of Sikkim } \\
\text { in } 1955 \text {, became an Indian High Court } \\
\text { in } 1975 \text { when Sikkim joined India and } \\
\text { the monarchy was abolished }\end{array}$ & \\
\hline Uttarakhand High Court & Uttarakhand & 2000 & yes & $\begin{array}{l}\text { Created when Uttaranchal was carved } \\
\text { out of Uttar Pradesh }\end{array}$ & $\begin{array}{l}\text { Uttarakhand Kranti Dal independence } \\
\text { movement. }\end{array}$ \\
\hline High Court of Mumbai, Goa Bench & $\begin{array}{l}\text { Goa, Daman and Diu, } \\
\text { Dadra and Nagar Haveli }\end{array}$ & 1982 & no & $\begin{array}{l}\text { Prior to the HC, a Judicial Commis- } \\
\text { sioner's court existed in Goa. HC was } \\
\text { established to safeguard the judge's in- } \\
\text { dependence (see Bombay HC at Goa } \\
\text { website). }\end{array}$ & \\
\hline Manipur High Court & Manipur & 2013 & no & $\begin{array}{l}\text { Parties in Manipur demanded their own } \\
\text { high court }\end{array}$ & \\
\hline Meghalaya High Court & Meghalaya & 2013 & no & $\begin{array}{l}\text { Parties in Meghalaya demanded their } \\
\text { own high court }\end{array}$ & \\
\hline High Court Of Tripura & Tripura & 2013 & no & $\begin{array}{l}\text { Parties in Tripura demanded their own } \\
\text { high court }\end{array}$ & \\
\hline
\end{tabular}

High Court of Mumbai, Goa Bench

Goa, Daman and Diu Dadra and Nagar Haveli

\section{Court of Mysore in 1884.}

Created when Kerala was created as part of the State Reorganization Act Established as Nagpur High Court by King George V through a Letters King George $V$ through a Letters Created by the Indian High Courts Act but did not get its own high court until the drafting of the Indian constitution

split off from Bengal Presidency.

Created with the independence of InCreated with the foundation of RaPrior to the HC, a Judicial Commissioner's court existed in Goa. HC was

high court

own high court

high court 


\section{B Vertical Integration Measure}

\section{B.1 Definition}

Let $x_{j \omega^{\prime}}$ be the expenditure of plant $j$ on $\omega^{\prime} \in \Omega$, then define for products $\omega, \omega^{\prime} \in \Omega$, and a set $B \subset \Omega$

$$
\beta_{\omega \omega^{\prime}}^{B}=\frac{\sum_{j \in J_{\omega}} x_{j \omega^{\prime}}}{\sum_{j \in J_{\omega}} \sum_{\omega^{\prime \prime} \in \Omega \backslash B} x_{j \omega^{\prime \prime}}}
$$

if $\omega^{\prime} \notin B$, and $\beta_{\omega \omega^{\prime}}^{B}=0$ otherwise. $\beta_{\omega \omega^{\prime}}^{B}$ is the share of $\omega^{\prime}$ in industry $\omega^{\prime}$ 's materials basket that excludes inputs from $B$.

Denote by $A_{\omega \omega^{\prime}}^{n}$ the set of $(n+1)$-tuples $\left(\omega^{(0)}, \omega^{(1)}, \ldots, \omega^{(n)}\right) \in \Omega^{n+1}$ such that

$$
\begin{aligned}
& \omega^{(0)}=\omega, \quad \omega^{(n)}=\omega^{\prime}, \\
& \omega^{(i)} \neq \omega^{(j)} \quad \forall(i, j) \in\{0, \ldots, n\}^{2}, i \neq j .
\end{aligned}
$$

Intuitively, $A_{\omega \omega^{\prime}}^{n}$ is the set of all possible non-circular product chains of length $n$ between $\omega$ and $\omega^{\prime}$. Then let

$$
\delta_{\omega \omega^{\prime}}=\sum_{n=1}^{\infty} \sum_{a \in A_{\omega \omega^{\prime}}^{n}} \frac{\lambda(a)}{\sum_{n^{\prime}=1}^{\infty} \sum_{a^{\prime} \in A_{\omega \omega^{\prime}}^{n^{\prime}}} \lambda\left(a^{\prime}\right)} \cdot n
$$

where

$$
\lambda: A_{\omega \omega^{\prime}}^{n} \rightarrow \mathbb{R}, \lambda\left(\omega^{(0)}, \omega^{(1)}, \ldots, \omega^{(n)}\right)=\prod_{i=1}^{n} \beta_{\omega^{(i-1)} \omega^{(i)}}^{\left\{\left(\omega^{(0)}, \omega^{(1)}, \ldots, \omega^{(i-1)}\right)\right\}}
$$

is the share of $\omega^{\prime}$ in $\omega^{\prime}$ s input mix through a given product chain. Hence, $\delta_{\omega \omega^{\prime}}$ is the average number of production steps between an output $\omega$ and an input $\omega^{\prime}$, weighted by the overall expenditure of each product chain in industry $\omega$ 's mix of materials, and excluding any circular product chains.

The plant-level measure of vertical integration, and the left-hand side of Table III, is then the average distance of its inputs from the output, weighted by each inputs' share in the plants materials expenditure: let $j \in J_{\omega}$, then

$$
V I_{j}=\sum_{\omega^{\prime} \in \Omega} \frac{x_{j \omega^{\prime}}}{\sum_{\omega^{\prime \prime} \in \Omega} x_{j \omega^{\prime \prime}}} \delta_{\omega \omega^{\prime}}
$$

To understand why we exclude circular product chains, consider the following example: Some plants sell aluminum and use aluminum scrap as an input, whereas some other plants use aluminum as an input and sell aluminum scrap. Thus in the production of aluminum scrap, aluminum would show up as an input one stage away, three stages away, five stages away, etc.

When we see a plant selling aluminum scrap and using aluminum as an input, we believe that it is the distance of one that is relevant, not the distances of three, five, etc. In other words, we believe the plant is turning the aluminum into scrap, but not turning the aluminum into scrap then back to aluminum and then back to scrap. Therefore we believe the circular part of the production chain is not relevant for constructing a plant's distance to its inputs.

\section{B.2 Examples}

Table VIII shows the average vertical distance of several input groups (defined as all inputs that contain the strings "fabric" / "cloth", "yarn", or "cotton, raw" in their description") from the output "cotton shirts". Fabrics and cloths are closest to the final output; yarns, which are used in the production of cloths and fabrics, are further upstream, and raw cotton inputs are even further upstream.

Table IX shows vertical distances between aluminium ingots as an output, and several intermediate inputs. Aluminium ingots can be made both by recycling castings and alloys, but also by casting molten aluminium. The latter also serves as an intermediate input in the production of castings and alloys, and is hence vertically more distant than the inputs which undergo recycling. Aluminium itself is produced from aluminium oxide using electrolytic reduction (Hall-Heroult process). In turn, aluminium oxide is produced by dissolving bauxite in caustic soda at high temperatures (hence the coal inputs). 
Table VIII Vertical distance examples for 63428: Cotton Shirts

\begin{tabular}{ll}
\hline Input group & Average vertical distance \\
\hline Fabrics Or Cloths & 1.67 \\
Yarns & 2.78 \\
Raw Cotton & 3.55 \\
\hline
\end{tabular}

Table IX Vertical distance examples for 73107: Aluminium Ingots

\begin{tabular}{lll}
\hline ASIC code & Input description & Vertical distance \\
\hline 73105 & Aluminium Casting & 1.23 \\
73104 & Aluminium Alloys & 1.46 \\
73103 & Aluminium & 1.92 \\
22301 & Alumina (Aluminium Oxide) & 2.92 \\
31301 & Caustic Soda (Sodium Hydroxide) & 3.81 \\
23107 & Coal & 3.85 \\
22304 & Bauxite, raw & 3.93 \\
\hline
\end{tabular}

\section{Additional Reduced Form Results}

\section{C.1 Controlling for Interactions with State and Industry Characteristics}

Tables X, XI, and XII show the main regressions of materials cost shares, input mixes, and vertical integration with a full set of controls. See Appendix A for definitions of the variables.

Tables XIII and XV also include interactions of industry characteristics with court quality. Tables XIV and XVI show IV regressions where the court quality $\times$ industry characteristic interactions are instrumented by the interaction of log court age and the corresponding industry characteristic. 
Table X Additional Controls - Materials Cost Share

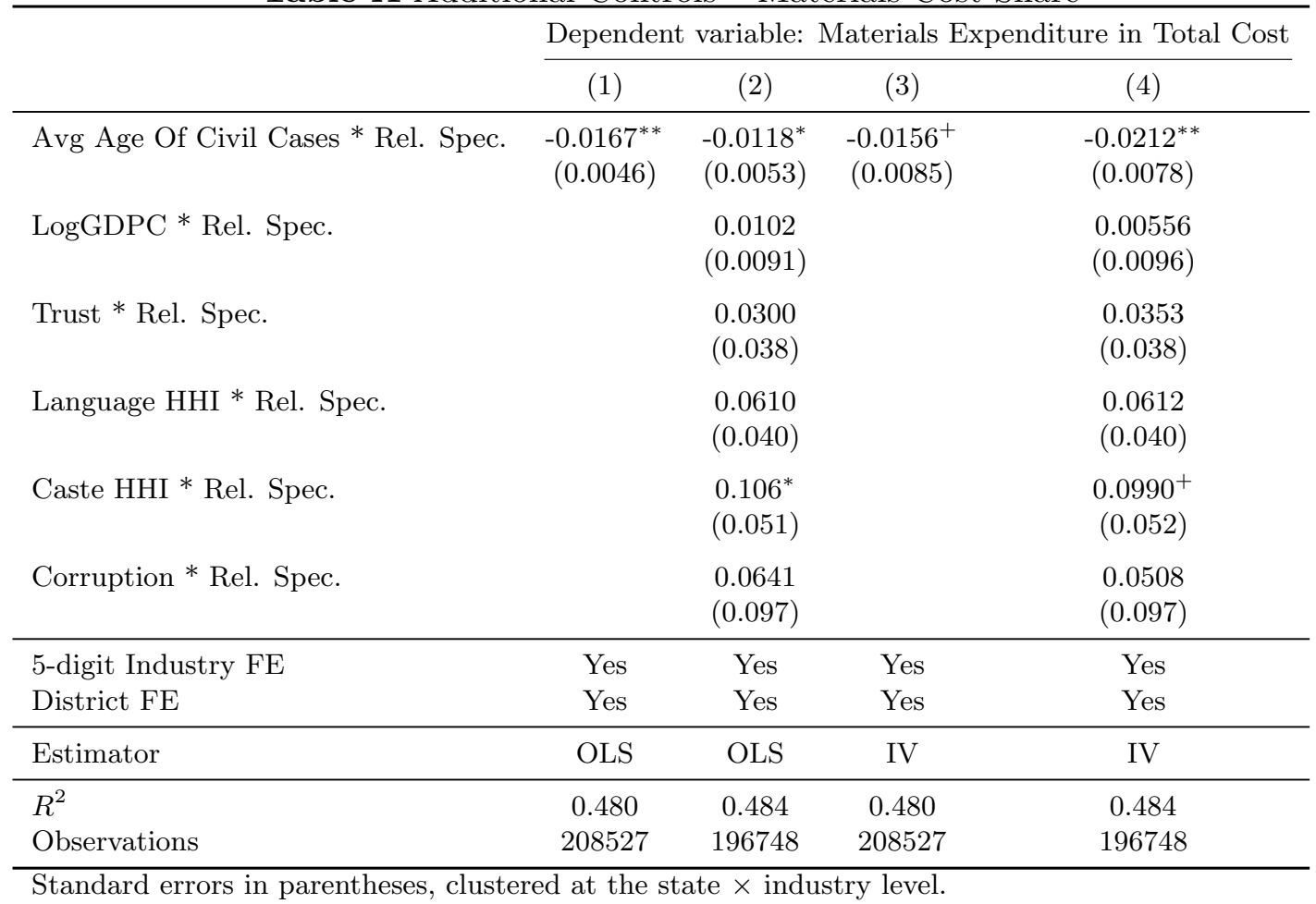

$+p<0.10,{ }^{*} p<0.05,{ }^{* *} p<0.01$

Table XI Additional Controls - Vertical Integration

\begin{tabular}{lcccc}
\hline & \multicolumn{3}{c}{ Dependent variable: Vertical Integration } \\
\cline { 2 - 5 } & $(1)$ & $(2)$ & $(3)$ & $(4)$ \\
\hline Avg Age Of Civil Cases * Rel. Spec. & $0.0195^{+}$ & $0.0280^{*}$ & 0.0292 & $0.0368^{*}$ \\
LogGDPC * Rel. Spec. & $(0.011)$ & $(0.012)$ & $(0.019)$ & $(0.018)$ \\
& & 0.0288 & & 0.0330 \\
Trust * Rel. Spec. & $(0.024)$ & & $(0.024)$ \\
& & -0.0939 & & -0.0984 \\
Language HHI * Rel. Spec. & & $(0.090)$ & & $(0.091)$ \\
& & -0.0742 & & -0.0743 \\
Caste HHI * Rel. Spec. & & $-0.092)$ & & $(0.092)$ \\
Corruption * Rel. Spec. & & $(0.12)$ & & -0.176 \\
& & $0.481^{*}$ & & $0.12)$ \\
\hline 5-digit Industry FE & & $(0.24)$ & & $(0.24)$ \\
\hline District FE & Yes & Yes & Yes & Yes \\
\hline Estimator & Yes & Yes & Yes & Yes \\
\hline$R^{2}$ & OLS & OLS & IV & IV \\
\hline Observations & 0.443 & 0.453 & 0.443 & 0.453 \\
\hline Standard & 163334 & 154021 & 163334 & 154021 \\
\hline
\end{tabular}

Standard errors in parentheses, clustered at the state $\times$ industry level.

$+p<0.10,{ }^{*} p<0.05,{ }^{* *} p<0.01$ 
Table XII Additional Controls - Input Mix

\begin{tabular}{|c|c|c|c|c|}
\hline & \multicolumn{4}{|c|}{ Dependent variable: $X_{j}^{R} /\left(X_{j}^{R}+X_{j}^{H}\right)$} \\
\hline & (1) & $(2)$ & $(3)$ & $(4)$ \\
\hline Avg age of Civil HC cases & $\begin{array}{c}-0.00547^{*} \\
(0.0022)\end{array}$ & $\begin{array}{c}-0.00530^{*} \\
(0.0024)\end{array}$ & $\begin{array}{c}-0.0144^{* *} \\
(0.0044)\end{array}$ & $\begin{array}{c}-0.0167^{* *} \\
(0.0045)\end{array}$ \\
\hline Log district GDP/capita & & $\begin{array}{c}-0.00384 \\
(0.0046)\end{array}$ & & $\begin{array}{r}-0.00980^{+} \\
(0.0051)\end{array}$ \\
\hline Trust & & $\begin{array}{c}-0.00740 \\
(0.018)\end{array}$ & & $\begin{array}{c}-0.00160 \\
(0.019)\end{array}$ \\
\hline Language HHI & & $\begin{array}{c}-0.0553^{* *} \\
(0.021)\end{array}$ & & $\begin{array}{c}-0.0567^{* *} \\
(0.022)\end{array}$ \\
\hline Caste HHI & & $\begin{array}{c}-0.0428 \\
(0.028)\end{array}$ & & $\begin{array}{r}-0.0525^{+} \\
(0.029)\end{array}$ \\
\hline Corruption & & $\begin{array}{r}-0.0676 \\
(0.044)\end{array}$ & & $\begin{array}{r}-0.0844^{+} \\
(0.045)\end{array}$ \\
\hline 5-digit Industry FE & Yes & Yes & Yes & Yes \\
\hline Estimator & OLS & OLS & IV & IV \\
\hline$R^{2}$ & 0.441 & 0.449 & 0.441 & 0.449 \\
\hline Observations & 225590 & 199339 & 225590 & 199339 \\
\hline
\end{tabular}

Table XIII Materials Cost Share: Industry Characteristic Interactions

\begin{tabular}{|c|c|c|c|c|c|c|}
\hline & \multicolumn{6}{|c|}{ Dependent variable: Materials Expenditure in Total Cost } \\
\hline & $(1)$ & $(2)$ & $(3)$ & $(4)$ & $(5)$ & $(6)$ \\
\hline Avg Age Of Civil Cases * Rel. Spec. & $\begin{array}{c}-0.0117^{*} \\
(0.0052)\end{array}$ & $\begin{array}{c}-0.00987^{*} \\
(0.0049)\end{array}$ & $\begin{array}{c}-0.0118^{*} \\
(0.0053)\end{array}$ & $\begin{array}{c}-0.0112^{*} \\
(0.0053)\end{array}$ & $\begin{array}{c}-0.0105^{+} \\
(0.0054)\end{array}$ & $\begin{array}{c}-0.00675 \\
(0.0049)\end{array}$ \\
\hline Capital Intensity $*$ Avg. age of cases & $\begin{array}{c}-0.110^{* *} \\
(0.038)\end{array}$ & & & & & $\begin{array}{c}-0.0624^{+} \\
(0.033)\end{array}$ \\
\hline Ind. Wage Premium * Avg. age of cases & & $\begin{array}{c}-0.00146 \\
(0.0011)\end{array}$ & & & & $\begin{array}{c}-0.00180^{*} \\
(0.00088)\end{array}$ \\
\hline Ind. Contract Worker Share ${ }^{*}$ Avg. age of cases & & & $\begin{array}{c}-0.00116 \\
(0.030)\end{array}$ & & & $\begin{array}{c}0.0207 \\
(0.027)\end{array}$ \\
\hline Upstreamness $*$ Avg. age of cases & & & & $\begin{array}{c}0.00289^{+} \\
(0.0015)\end{array}$ & & $\begin{array}{c}0.00363^{*} \\
(0.0015)\end{array}$ \\
\hline Tradability $*$ Avg. age of cases & & & & & $\begin{array}{c}-0.00104^{+} \\
(0.00058)\end{array}$ & $\begin{array}{c}-0.00150^{* *} \\
(0.00051)\end{array}$ \\
\hline State $\times$ Rel. Spec. Controls & Yes & Yes & Yes & Yes & Yes & Yes \\
\hline 5-digit Industry FE & Yes & Yes & Yes & Yes & Yes & Yes \\
\hline District FE & Yes & Yes & Yes & Yes & Yes & Yes \\
\hline$R^{2}$ & 0.484 & 0.484 & 0.484 & 0.484 & 0.484 & 0.484 \\
\hline Observations & 196748 & 196748 & 196748 & 196748 & 196735 & 196735 \\
\hline
\end{tabular}


Table XIV Materials Cost Share: Industry Characteristic Interactions (IV)

\begin{tabular}{|c|c|c|c|c|c|c|}
\hline & \multicolumn{6}{|c|}{ Dependent variable: Materials Expenditure in Total Cost } \\
\hline & (1) & $(2)$ & $(3)$ & $(4)$ & $(5)$ & $(6)$ \\
\hline Avg Age Of Civil Cases * Rel. Spec. & $\begin{array}{c}-0.0211^{* *} \\
(0.0078)\end{array}$ & $\begin{array}{c}-0.0155^{*} \\
(0.0074)\end{array}$ & $\begin{array}{c}-0.0211^{* *} \\
(0.0077)\end{array}$ & $\begin{array}{c}-0.0194^{*} \\
(0.0080)\end{array}$ & $\begin{array}{c}-0.0217^{* *} \\
(0.0078)\end{array}$ & $\begin{array}{c}-0.0149^{*} \\
(0.0075)\end{array}$ \\
\hline Capital Intensity ${ }^{*}$ Avg. age of cases & $\begin{array}{r}-0.0262 \\
(0.065)\end{array}$ & & & & & $\begin{array}{c}-0.00252 \\
(0.062)\end{array}$ \\
\hline Ind. Wage Premium * Avg. age of cases & & $\begin{array}{r}-0.00406^{*} \\
(0.0018)\end{array}$ & & & & $\begin{array}{r}-0.00343^{*} \\
(0.0016)\end{array}$ \\
\hline Ind. Contract Worker Share ${ }^{*}$ Avg. age of cases & & & $\begin{array}{l}0.0311 \\
(0.040)\end{array}$ & & & $\begin{array}{c}0.00893 \\
(0.041)\end{array}$ \\
\hline Upstreamness * Avg. age of cases & & & & $\begin{array}{c}0.00641^{*} \\
(0.0032)\end{array}$ & & $\begin{array}{c}0.00593^{+} \\
(0.0031)\end{array}$ \\
\hline Tradability $*$ Avg. age of cases & & & & & $\begin{array}{c}0.00108 \\
(0.00100)\end{array}$ & $\begin{array}{c}0.000551 \\
(0.0010)\end{array}$ \\
\hline State $\times$ Rel. Spec. Controls & Yes & Yes & Yes & Yes & Yes & Yes \\
\hline 5-digit Industry FE & Yes & Yes & Yes & Yes & Yes & Yes \\
\hline District FE & Yes & Yes & Yes & Yes & Yes & Yes \\
\hline$R^{2}$ & 0.484 & 0.484 & 0.484 & 0.484 & 0.483 & 0.483 \\
\hline Observations & 196748 & 196748 & 196748 & 196748 & 196735 & 196735 \\
\hline
\end{tabular}

Standard errors in parentheses, clustered at the state $\times$ industry level.

${ }^{+} p<0.10,{ }^{*} p<0.05,{ }^{* *} p<0.01$

"State $\times$ Rel. Spec. controls" are interactions of GDP/capita, trust, language herfindahl, caste herfindahl, and corruption with relationship-specificity. 
Table XV Vertical Integration: Industry Characteristic Interactions

\begin{tabular}{|c|c|c|c|c|c|c|}
\hline & \multicolumn{6}{|c|}{ Dependent variable: Vertical Integration } \\
\hline & (1) & $(2)$ & $(3)$ & $(4)$ & $(5)$ & $(6)$ \\
\hline Avg Age Of Civil Cases * Rel. Spec. & $\begin{array}{c}0.0279^{*} \\
(0.012)\end{array}$ & $\begin{array}{c}0.0232^{+} \\
(0.012)\end{array}$ & $\begin{array}{c}0.0278^{*} \\
(0.012)\end{array}$ & $\begin{array}{c}0.0275^{*} \\
(0.012)\end{array}$ & $\begin{array}{c}0.0295^{*} \\
(0.012)\end{array}$ & $\begin{array}{c}0.0247^{*} \\
(0.012)\end{array}$ \\
\hline Capital Intensity ${ }^{*}$ Avg. age of cases & $\begin{array}{c}0.0279 \\
(0.073)\end{array}$ & & & & & $\begin{array}{l}0.0255 \\
(0.074)\end{array}$ \\
\hline Ind. Wage Premium * Avg. age of cases & & $\begin{array}{r}0.00357^{+} \\
(0.0021)\end{array}$ & & & & $\begin{array}{c}0.00299 \\
(0.0021)\end{array}$ \\
\hline Ind. Contract Worker Share ${ }^{*}$ Avg. age of cases & & & $\begin{array}{c}-0.0263 \\
(0.026)\end{array}$ & & & $\begin{array}{c}0.00432 \\
(0.033)\end{array}$ \\
\hline Upstreamness * Avg. age of cases & & & & $\begin{array}{r}-0.00447 \\
(0.0036)\end{array}$ & & $\begin{array}{c}-0.00363 \\
(0.0036)\end{array}$ \\
\hline Tradability $*$ Avg. age of cases & & & & & $\begin{array}{c}-0.00118^{*} \\
(0.00059)\end{array}$ & $\begin{array}{r}-0.000961 \\
(0.00079)\end{array}$ \\
\hline State $\times$ Rel. Spec. Controls & Yes & Yes & Yes & Yes & Yes & Yes \\
\hline 5-digit Industry FE & Yes & Yes & Yes & Yes & Yes & Yes \\
\hline District FE & Yes & Yes & Yes & Yes & Yes & Yes \\
\hline$R^{2}$ & 0.453 & 0.453 & 0.453 & 0.453 & 0.453 & 0.453 \\
\hline Observations & 154021 & 154021 & 154021 & 154021 & 154011 & 154011 \\
\hline
\end{tabular}

Standard errors in parentheses, clustered at the state $\times$ industry level.

${ }^{+} p<0.10,{ }^{*} p<0.05,{ }^{* *} p<0.01$

"State $\times$ Rel. Spec. controls" are interactions of GDP/capita, trust, language herfindahl, caste herfindahl, and corruption with relationship-specificity. 
Table XVI Vertical Integration: Industry Characteristic Interactions (IV)

\begin{tabular}{|c|c|c|c|c|c|c|}
\hline & \multicolumn{6}{|c|}{ Dependent variable: Vertical Integration } \\
\hline & $(1)$ & $(2)$ & $(3)$ & $(4)$ & $(5)$ & $(6)$ \\
\hline Avg Age Of Civil Cases * Rel. Spec. & $\begin{array}{c}0.0351^{*} \\
(0.018)\end{array}$ & $\begin{array}{c}0.0211 \\
(0.019)\end{array}$ & $\begin{array}{c}0.0362^{*} \\
(0.018)\end{array}$ & $\begin{array}{c}0.0360^{*} \\
(0.018)\end{array}$ & $\begin{array}{c}0.0388^{*} \\
(0.018)\end{array}$ & $\begin{array}{l}0.0257 \\
(0.019)\end{array}$ \\
\hline Capital Intensity $*$ Avg. age of cases & $\begin{array}{c}0.259^{+} \\
(0.15)\end{array}$ & & & & & $\begin{array}{l}0.370^{*} \\
(0.17)\end{array}$ \\
\hline Ind. Wage Premium * Avg. age of cases & & $\begin{array}{c}0.0110^{* *} \\
(0.0042)\end{array}$ & & & & $\begin{array}{c}0.00927^{*} \\
(0.0043)\end{array}$ \\
\hline Ind. Contract Worker Share * Avg. age of cases & & & $\begin{array}{c}-0.0483 \\
(0.047)\end{array}$ & & & $\begin{array}{l}0.110^{+} \\
(0.060)\end{array}$ \\
\hline Upstreamness * Avg. age of cases & & & & $\begin{array}{r}-0.00405 \\
(0.0070)\end{array}$ & & $\begin{array}{l}0.00258 \\
(0.0070)\end{array}$ \\
\hline Tradability $*$ Avg. age of cases & & & & & $\begin{array}{c}-0.00397^{* *} \\
(0.0013)\end{array}$ & $\begin{array}{c}-0.00544^{* *} \\
(0.0018)\end{array}$ \\
\hline State $\times$ Rel. Spec. Controls & Yes & Yes & Yes & Yes & Yes & Yes \\
\hline 5-digit Industry FE & Yes & Yes & Yes & Yes & Yes & Yes \\
\hline District FE & Yes & Yes & Yes & Yes & Yes & Yes \\
\hline$R^{2}$ & 0.453 & 0.453 & 0.453 & 0.453 & 0.453 & 0.453 \\
\hline Observations & 154021 & 154021 & 154021 & 154021 & 154011 & 154011 \\
\hline
\end{tabular}

Standard errors in parentheses, clustered at the state $\times$ industry level.

$+p<0.10,{ }^{*} p<0.05,{ }^{* *} p<0.01$

"State $\times$ Rel. Spec. controls" are interactions of GDP/capita, trust, language herfindahl, caste herfindahl, and corruption with relationship-specificity. 


\section{C.2 Time variation: creation of new High Court benches}

\section{C.2.1 Background}

Two new benches of the Karnataka High Court were set up Dharwad and Gulbarga in July 2008. They have jurisdiction over Belgaum, Balgakot, Koppal, Gadag, Dharwad, Uttara Kannada, Haveri, and Bellary (Dharwad bench), and Bijapur, Gulbarga, Bidar, and Raichur (Gulbarga bench). The purpose was explicitly to improve access to justice in remote areas.

In July 2004, the Chennai High Court set up a bench in Madurai, which has jurisdiction over Kanniyakumari, Tirunelveli, Tuticorin, Madurai, Dindigul, Ramanathapuram, Virudhunagar, Sivaganga, Pudukkottai, Thanjavur, Tiruchirappalli and Karur districts.

\section{C.2.2 Results}

The regressions in Table XVII look at whether wedges on relationship-specific inputs have decreased differentially in districts that are under the jurisdiction of the new benches. The coefficients are not very precisely estimated, since the districts with new benches account on average only for about $6 \%$ of the plants in the respective states.

Table XVII Identification from Time Variation: Diff-in-Diff

\begin{tabular}{|c|c|c|c|c|}
\hline & $X^{R} /$ Sales & $\underline{s_{R}-s_{H}}$ & Materials/TotalCost & Vert. Distance \\
\hline & (1) & $(2)$ & (3) & (4) \\
\hline$(\text { New Bench in District })_{d} \times(\text { Post })_{t}$ & $\begin{array}{l}0.0126^{* *} \\
(0.0043)\end{array}$ & $\begin{array}{c}0.00960 \\
(0.0076)\end{array}$ & $\begin{array}{r}-0.00305 \\
(0.0033)\end{array}$ & $\begin{array}{c}0.00678 \\
(0.010)\end{array}$ \\
\hline$(\text { New Bench in District })_{d} \times(\text { Post })_{t} \times(\text { Rel.Spec })_{\omega}$ & & & $\begin{array}{l}0.0142 \\
(0.010)\end{array}$ & $\begin{array}{c}-0.0764^{*} \\
(0.031)\end{array}$ \\
\hline Plant $\times$ Product FE & Yes & Yes & Yes & Yes \\
\hline Year FE & Yes & Yes & Yes & Yes \\
\hline$R^{2}$ & 0.832 & 0.824 & 0.906 & 0.813 \\
\hline Observations & 80427 & 74696 & 78462 & 77995 \\
\hline
\end{tabular}

\section{C.2.3 Figures}

Figures 5 and 6 show the relative changes in the input mix in treated vs. untreated districts before and after the new high court benches were installed. 
Figure 5 Relative change in $X^{R} /$ Sales after new court bench is set up

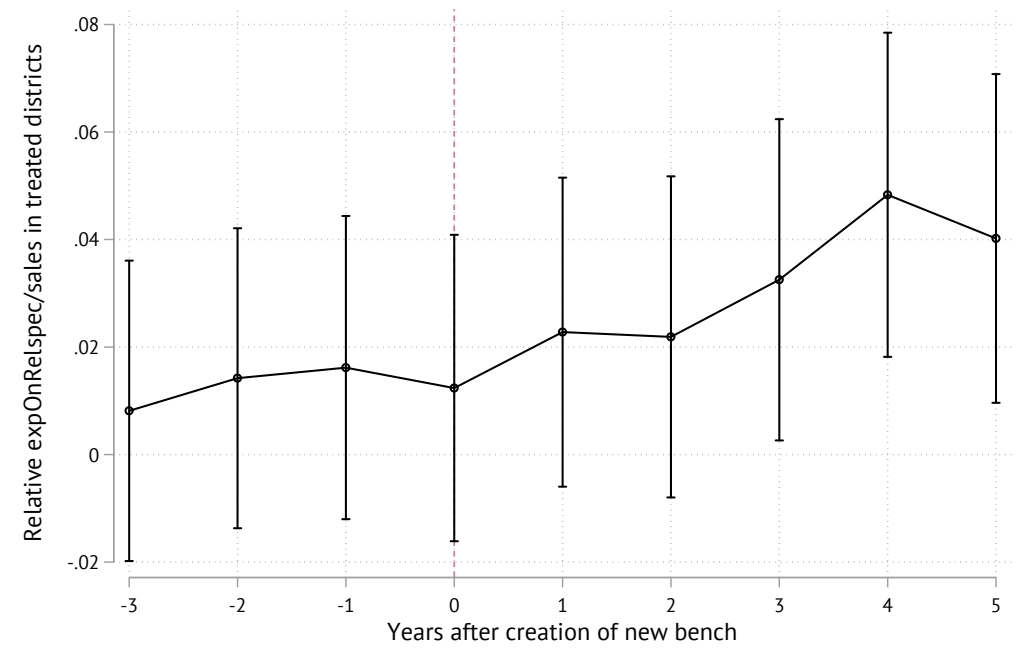

The figure shows the evolution of the share of expenditure on relationship-specific inputs in sales, in treated districts relative to non-treated districts. Treatment happens at the start of period 0 . Regression includes firm $\times$ product fixed effects and year dummies.

Figure 6 Relative change in composition of input mix after new court bench is set up

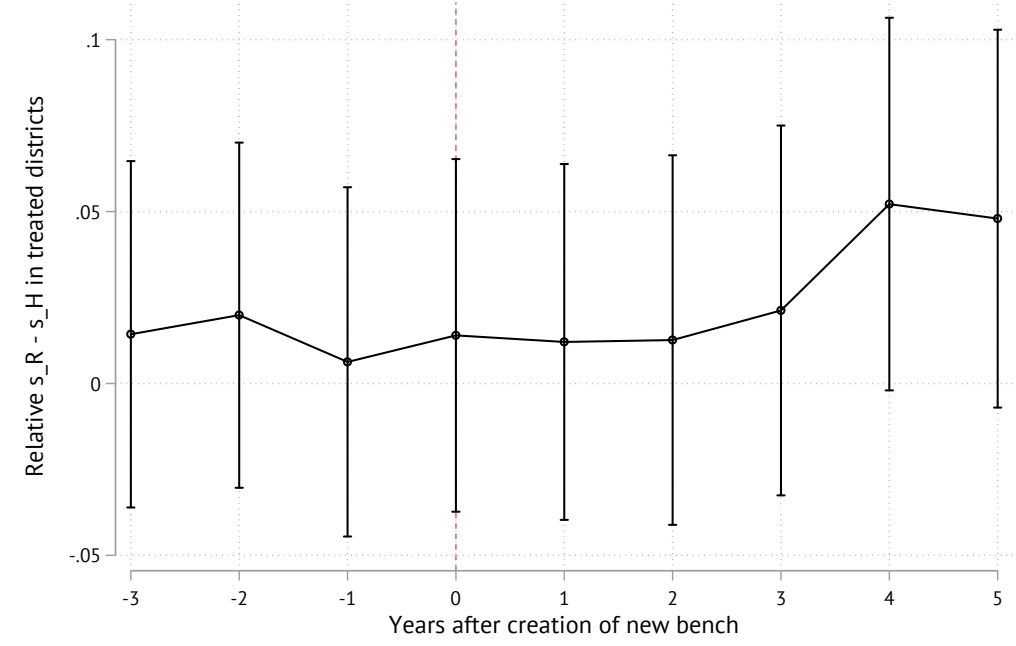

The figure shows the evolution of $s^{R}-s^{H}$, in treated districts relative to non-treated districts. Treatment happens at the start of period 0 . Regression includes firm $\times$ product fixed effects and year dummies. 


\section{C.3 Distortions and International Sourcing}

This section presents three tables describing how plants' usage of domestically- and foreign-sourced inputs varies with distortions. The fourth row of Table XVIII shows that, relative to those in industries that tend to use standardized inputs, the expenditure shares on domestic inputs of plants in industries that use relationship-specific inputs declines as courts get more congested. The second row of Table XVIII shows that this estimated relationship is stronger when we use our instrumental variables strategy with court age as an instrument for congestion.

Table XVIII Domestic Materials Shares and Court Quality (Fact 3)

\begin{tabular}{|c|c|c|c|c|}
\hline & \multicolumn{4}{|c|}{ Dependent variable: Dom. Mat. Exp. in Total Cost } \\
\hline & $(1)$ & $(2)$ & $(3)$ & $(4)$ \\
\hline Avg Age Of Civil Cases * Rel. Spec. & $\begin{array}{r}-0.0110^{+} \\
(0.0057)\end{array}$ & $\begin{array}{c}-0.0127^{*} \\
(0.0063)\end{array}$ & $\begin{array}{c}-0.0349^{* *} \\
(0.0097)\end{array}$ & $\begin{array}{c}-0.0279^{* *} \\
(0.0085)\end{array}$ \\
\hline LogGDPC * Rel. Spec. & & $\begin{array}{c}-0.0124 \\
(0.0098)\end{array}$ & & $\begin{array}{c}-0.0200^{+} \\
(0.010)\end{array}$ \\
\hline Trust $*$ Rel. Spec. & & $\begin{array}{c}-0.0415 \\
(0.043)\end{array}$ & & $\begin{array}{r}-0.0331 \\
(0.043)\end{array}$ \\
\hline Language HHI * Rel. Spec. & & $\begin{array}{c}0.00109 \\
(0.056)\end{array}$ & & $\begin{array}{c}0.00139 \\
(0.056)\end{array}$ \\
\hline Caste HHI * Rel. Spec. & & $\begin{array}{c}0.0466 \\
(0.074)\end{array}$ & & $\begin{array}{l}0.0355 \\
(0.075)\end{array}$ \\
\hline Corruption * Rel. Spec. & & $\begin{array}{c}0.0654 \\
(0.12)\end{array}$ & & $\begin{array}{c}0.0439 \\
(0.12)\end{array}$ \\
\hline 5-digit Industry FE & Yes & Yes & Yes & Yes \\
\hline District FE & Yes & Yes & Yes & Yes \\
\hline Estimator & OLS & OLS & IV & IV \\
\hline$R^{2}$ & 0.432 & 0.439 & 0.431 & 0.439 \\
\hline Observations & 208527 & 196748 & 208527 & 196748 \\
\hline
\end{tabular}

Standard errors in parentheses, clustered at the state $\times$ industry level.

${ }^{+} p<0.10,{ }^{*} p<0.05,{ }^{* *} p<0.01$

Table XIX shows the same regressions but with the cost share of imported intermediates. Here, the OLS and IV specifications point to opposite results, and further investigation is required. The OLS specifications indicate that among those that rely more on more relationship-specific inputs, more congestion leads to lower shares of imported inputs relative to those that rely on standardized inputs. The IV specification indicates that more congestion leads to relatively higher imported input shares in those that rely on relationship-specific inputs, indicating that firms respond to distortions by substituting from domestic to foreign suppliers.

Table XX shows the results on the share of imports in the basket of relationship-specific (first three columns) and homogenous (last three columns) inputs. More congestion leads to a higher share of imports in both baskets, but the substitution is stronger in the basket of relationship-specific goods. 
Table XIX Import Shares and Court Quality, OLS + IV

\begin{tabular}{|c|c|c|c|c|c|}
\hline & \multicolumn{5}{|c|}{ Dependent variable: Imported Materials Expenditure in Total Cost } \\
\hline & $(1)$ & $(2)$ & $(3)$ & $(4)$ & $(5)$ \\
\hline Avg age of Civil HC cases & $\begin{array}{l}-0.00105 \\
(0.0017)\end{array}$ & & $\begin{array}{c}0.000444 \\
(0.0032)\end{array}$ & & \\
\hline Avg Age Of Civil Cases * Rel. Spec. & $\begin{array}{r}-0.00848^{+} \\
(0.0045)\end{array}$ & $\begin{array}{c}0.000870 \\
(0.0040)\end{array}$ & $\begin{array}{c}0.0222^{* *} \\
(0.0068)\end{array}$ & $\begin{array}{l}0.0193^{* *} \\
(0.0062)\end{array}$ & $\begin{array}{l}0.00666 \\
(0.0042)\end{array}$ \\
\hline LogGDPC * Rel. Spec. & & $\begin{array}{l}0.0227^{* *} \\
(0.0054)\end{array}$ & & & $\begin{array}{l}0.0255^{* *} \\
(0.0057)\end{array}$ \\
\hline Trust * Rel. Spec. & & $\begin{array}{c}0.0716^{* *} \\
(0.026)\end{array}$ & & & $\begin{array}{c}0.0683^{* *} \\
(0.026)\end{array}$ \\
\hline Language HHI * Rel. Spec. & & $\begin{array}{l}0.0599 \\
(0.041)\end{array}$ & & & $\begin{array}{l}0.0598 \\
(0.041)\end{array}$ \\
\hline Caste HHI * Rel. Spec. & & $\begin{array}{l}0.0593 \\
(0.051)\end{array}$ & & & $\begin{array}{l}0.0635 \\
(0.052)\end{array}$ \\
\hline Corruption * Rel. Spec. & & $\begin{array}{c}-0.00127 \\
(0.073)\end{array}$ & & & $\begin{array}{c}0.00691 \\
(0.074)\end{array}$ \\
\hline 5-digit Industry FE & Yes & Yes & Yes & Yes & Yes \\
\hline District FE & & Yes & & Yes & Yes \\
\hline Estimator & OLS & OLS & IV & IV & IV \\
\hline$R^{2}$ & 0.276 & 0.342 & 0.265 & 0.329 & 0.342 \\
\hline Observations & 223674 & 196748 & 223674 & 208527 & 196748 \\
\hline
\end{tabular}

Standard errors in parentheses, clustered at the state $\times$ industry level.

${ }^{+} p<0.10,{ }^{*} p<0.05,{ }^{* *} p<0.01$ 
Table XX Substitution into Importing

\begin{tabular}{|c|c|c|c|c|}
\hline & \multicolumn{2}{|c|}{ R-Imports in Total $\mathrm{R}$} & \multicolumn{2}{|c|}{ H-Imports in Total H } \\
\hline & (1) & $(2)$ & $(3)$ & $(4)$ \\
\hline Avg age of Civil HC cases & $\begin{array}{c}0.0193^{* *} \\
(0.0023)\end{array}$ & $\begin{array}{c}0.00925^{* *} \\
(0.0018)\end{array}$ & $\begin{array}{c}0.0112^{* *} \\
(0.0016)\end{array}$ & $\begin{array}{c}0.00440^{* *} \\
(0.0013)\end{array}$ \\
\hline Log district GDP/capita & & $\begin{array}{c}0.0224^{* *} \\
(0.0027)\end{array}$ & & $\begin{array}{c}0.0180^{* *} \\
(0.0019)\end{array}$ \\
\hline Trust in other people (WVS) & & $\begin{array}{l}0.110^{* *} \\
(0.012)\end{array}$ & & $\begin{array}{c}0.0564^{* *} \\
(0.011)\end{array}$ \\
\hline Language Herfindahl & & $\begin{array}{l}0.0162 \\
(0.019)\end{array}$ & & $\begin{array}{c}-0.0292^{* *} \\
(0.0093)\end{array}$ \\
\hline Caste Herfindahl & & $\begin{array}{c}0.0584^{*} \\
(0.028)\end{array}$ & & $\begin{array}{c}0.0171 \\
(0.013)\end{array}$ \\
\hline Corruption & & $\begin{array}{l}0.0315 \\
(0.028)\end{array}$ & & $\begin{array}{c}-0.0912^{* *} \\
(0.022)\end{array}$ \\
\hline 5-digit Industry FE & Yes & Yes & Yes & Yes \\
\hline Estimator & IV & IV & IV & IV \\
\hline$R^{2}$ & 0.227 & 0.251 & 0.180 & 0.197 \\
\hline Observations & 168120 & 148165 & 168953 & 149623 \\
\hline
\end{tabular}

Standard errors in parentheses, clustered at the state $\times$ industry level.

Dependent variable in columns (1) and (2) (resp. (3) and (4)) is the share of relationshipspecific (homogeneous) imports in total relationship-specific (homogeneous) materials.

${ }^{+} p<0.10,{ }^{*} p<0.05,{ }^{* *} p<0.01$ 


\section{C.4 Materials Shares with Size and Age}

Table XXI shows that materials cost shares do not correlate much with size and age of the plant. Table XXII shows correlations of input wedges with various plant-level characteristics.

Table XXI Plant Age and Size

\begin{tabular}{lccc}
\hline & \multicolumn{2}{c}{ Dependent variable: Mat. Exp in Total Cost } \\
\cline { 2 - 4 } & $(1)$ & $(2)$ & $(3)$ \\
\hline Plant Age & $\begin{array}{c}-0.000695^{* *} \\
(0.000065)\end{array}$ & & $-0.000679^{* *}$ \\
& & $-0.00257^{* *}$ & $-0.00176^{*}$ \\
Log Employment & & $(0.00086)$ & $(0.00083)$ \\
\hline 5-digit Industry FE & Yes & Yes & Yes \\
District FE & Yes & Yes & Yes \\
\hline Estimator & & & \\
\hline$R^{2}$ & 0.481 & 0.481 & 0.482 \\
Observations & 205109 & 208179 & 204767 \\
\hline $\begin{array}{l}\text { Standard errors in parentheses } \\
+\end{array}<0.10,{ }^{*} p<0.05,{ }^{* *} p<0.01$ & & \\
\hline
\end{tabular}

Table XXII Wedges and Plant Characteristics

\begin{tabular}{|c|c|c|c|c|}
\hline & Age & Size & Multiproduct & \# Products \\
\hline & (1) & $(2)$ & $(3)$ & (4) \\
\hline Avg Age Of Civil Cases * Rel. Spec. & $\begin{array}{c}0.620^{+} \\
(0.32)\end{array}$ & $\begin{array}{c}-0.0253 \\
(0.040)\end{array}$ & $\begin{array}{l}-0.0121 \\
(0.0076)\end{array}$ & $\begin{array}{c}-0.0580 \\
(0.037)\end{array}$ \\
\hline 5-digit Industry FE & Yes & Yes & Yes & Yes \\
\hline District FE & Yes & Yes & Yes & Yes \\
\hline$R^{2}$ & 0.214 & 0.339 & 0.301 & 0.295 \\
\hline Observations & 353392 & 359820 & 360316 & 360316 \\
\hline
\end{tabular}

Note: Sample includes multiproduct plants. Industry dummies refer to the 5-digit industry with the plants' highest production value.

\section{Proofs}

\section{D.1 Proof of Proposition 1}

Let $F_{\omega}(c)$ be the fraction of firms in industry $\omega$ with cost weakly less than $c$ (when the wage is normalized to unity). Similarly, let $F_{\omega \rho}(c)$ be the fraction of firms in $\omega$ that have a technique of recipe $\rho$ that delivers unit cost weakly less than $c$. These satisfy $1-F_{\omega}(c)=\prod_{\rho \in \varrho(\omega)}\left[1-F_{\omega \rho}(c)\right]$.

It will also be convenient to define, for recipe $\rho$ that uses inputs $\hat{\Omega}^{\rho}=\left(\hat{\omega}_{1}, \ldots, \hat{\omega}_{n}\right)$, the functions $\mathcal{B}_{\omega \rho}(b)$ where $b=\left(b_{l}, b_{1}, \ldots, b_{n}\right)$ and $\mathcal{V}_{\omega \rho}(v)$ where $v=\left(v_{l}, v_{1}, \ldots, v_{n}\right)$. These functions are defined by $\mathcal{B}_{\omega \rho}(b) \equiv B_{\omega \rho} b_{l}^{-\beta_{l}^{\rho}} \prod_{k} b_{k}^{-\beta_{\omega_{k}}^{\rho}}$ so that $\mathcal{B}_{\omega \rho}(d b)=B_{\omega \rho} \beta_{l}^{\rho} b_{l}^{-\beta_{l}^{\rho}-1} d b_{l} \beta_{\hat{\omega}_{1}}^{\rho} b_{1}^{-\beta_{\omega_{1}}^{\rho}-1} d b_{1} \ldots \beta_{\hat{\omega}_{n}}^{\rho} b_{n}^{-\beta_{\omega_{n}}^{\rho}-1} d b_{n}$. Similarly, let $\mathcal{V}_{\omega \rho}(v) \equiv v_{l}^{\beta_{l}^{\rho}} \prod_{k} v_{k}^{\beta_{\omega_{k}}^{\rho}}$ so that $\mathcal{V}_{\omega \rho}(d v)=\beta_{l}^{\rho} v_{l}^{\beta_{l}^{\rho}-1} d v_{l} \beta_{\hat{\omega}_{1}}^{\rho} v_{1}^{\beta_{\omega_{1}}^{\rho}-1} d v_{1} \ldots \beta_{\hat{\omega}_{n}}^{\rho} v_{n}^{\beta_{\omega_{n}}^{\rho}-1} d v_{n}$.

Lemma 1 Under Assumption 2, for a firm of type $\omega$,

$$
\operatorname{Pr}\left(\lambda_{\hat{\omega}}(\phi)>\lambda \mid b_{\hat{\omega}}(\phi)\right)=e^{-\left(\lambda b_{\hat{\omega}}(\phi) / \Lambda_{\omega}\right)^{\zeta}}
$$


where

$$
\Lambda_{\omega \hat{\omega}}= \begin{cases}t_{x}^{*}\left[\int_{0}^{\infty} c^{-\zeta_{R}} d F_{\hat{\omega}}(c)\right]^{-1 / \zeta_{R}}, & \hat{\omega} \in \Omega_{R}^{\rho} \\ {\left[\int_{0}^{\infty} c^{-\zeta_{H}} d F_{\hat{\omega}}(q)\right]^{-1 / \zeta_{H}},} & \hat{\omega} \in \Omega_{H}^{\rho}\end{cases}
$$

and

$$
t_{x}^{*} \equiv\left(\int_{1}^{\infty} t_{x}^{-\zeta_{R}} d T\left(t_{x}\right)\right)^{-1 / \zeta_{R}}
$$

Proof. Consider first a relationship-specific input $\hat{\omega} \in \hat{\Omega}_{R}^{\rho}$. Consider a technique with a common component of input augmenting productivity $b_{\hat{\omega}}(\phi)$. The number of suppliers with match-specific component of inputaugmenting productivity greater than $z$ is Poisson with mean $z^{-\zeta_{R}}$. For a potential supplier with $z$ and input wedge $t_{x}$, the probability that the supplier's cost is low enough so that the supplier delivers an effective cost weakly less than $\lambda$ is $\operatorname{Pr}\left(\frac{p_{s} t_{x}}{b_{\hat{\omega}}(\phi) z} \leq \lambda\right)=\operatorname{Pr}\left(p_{s} \leq \lambda b_{\hat{\omega}}(\phi) z / t_{x}\right)=F_{\hat{\omega}}\left(\lambda z b_{\hat{\omega}}(\phi) / t_{x}\right)$, where $F_{\hat{\omega}}(c)$ is the fraction of firms in $\hat{\omega}$ with unit cost (and hence price) weakly less than $c$. Integrating over realizations of $z$ and $t_{x}$, we have that the number of potential suppliers that deliver effective cost weakly less than $\lambda$ follows a Poisson distribution with mean

$$
\int_{0}^{\infty} \int_{1}^{\infty} F_{\hat{\omega}}\left(\lambda z b_{\hat{\omega}}(\phi) / t_{x}\right) d T\left(t_{x}\right) \zeta_{R} z^{-\zeta_{R}-1} d z
$$

Using the change of variables $v=\lambda z b_{\hat{\omega}}(\phi) / t_{x}$ and the definition of $\Lambda_{\omega \hat{\omega}}$, this is

$$
\left[\lambda b_{\hat{\omega}}(\phi)\right]^{\zeta_{R}} \int_{0}^{\infty} \int_{1}^{\infty} F_{\hat{\omega}}(v) t_{x}^{-\zeta_{R}} d T\left(t_{x}\right) \zeta_{R} v^{-\zeta_{R}-1} d v=\left[\lambda b_{\hat{\omega}}(\phi) / \Lambda_{\omega \hat{\omega}}\right]^{\zeta_{R}}
$$

The probability that no such suppliers arrive is then simply

$$
\operatorname{Pr}\left(\lambda_{\hat{\omega}}(\phi)>\lambda \mid b_{\hat{\omega}}(\phi)\right)=e^{-\left(\lambda b_{\hat{\omega}}(\phi) / \Lambda_{\omega} \hat{\omega}\right)^{\gamma}}
$$

The logic for homogeneous inputs is the same.

Lemma 2 Under Assumption 1,

$$
\int_{0}^{\infty} \cdots \int_{0}^{\infty} 1\left\{\mathcal{C}_{\omega \rho}\left(v_{l}, v_{1}, \ldots, v_{n}\right) \leq 1\right\} \mathcal{V}_{\omega \rho}(d v)<\infty
$$

Proof. Assumption 1 implies that for each $k \in\{l, 1, \ldots, n\}$ there is a $\bar{v}_{k}$ such that $\mathcal{C}_{\omega \rho}\left(0, \ldots, 0, \bar{v}_{k}, 0, \ldots, 0\right)=1$. In other words, $\bar{v}_{k}$ is defined so that if the effective cost of the $k$ th input were equal to $\bar{v}_{k}$ and the cost of all other inputs were equal to zero then the firm's cost would be 1. Thus if the firm's cost of the $k$ th input were higher than $\bar{v}_{k}$, the firm's cost must be greater than 1 . We therefore have

$$
\begin{aligned}
\int_{0}^{\infty} \ldots \int_{0}^{\infty} 1\left\{\mathcal{C}_{\omega \rho}\left(v_{l}, v_{1}, \ldots, v_{n}\right) \leq 1\right\} \mathcal{V}_{\omega \rho}(d v) & =\int_{0}^{\bar{v}_{l}} \int_{0}^{\bar{v}_{1}} \ldots \int_{0}^{\bar{v}_{n}} 1\left\{\mathcal{C}_{\omega \rho}\left(v_{l}, v_{1}, \ldots, v_{n}\right) \leq 1\right\} \mathcal{V}_{\omega \rho}(d v) \\
& \leq \int_{0}^{\bar{v}_{l}} \int_{0}^{\bar{v}_{1}} \ldots \int_{0}^{\bar{v}_{n}} \mathcal{V}_{\omega \rho}(d v) \\
& =\mathcal{V}_{\omega \rho}(\bar{v}) \\
& <\infty
\end{aligned}
$$

where $\bar{v}=\left\{\bar{v}_{l}, \bar{v}_{1}, \ldots, \bar{v}_{n}\right\}$.

Proposition 6 Under Assumptions 1 and 2, the fraction of firms with cost greater than c among those in industry $\omega$ is

$$
e^{-\left(c / C_{\omega}\right)^{\gamma}}
$$


where

$$
\begin{aligned}
C_{\omega} & =\left\{\sum_{\rho \in \varrho(\omega)} \kappa_{\omega \rho} B_{\omega \rho}\left(\left(t_{x}^{*}\right)^{\alpha_{R}^{\rho}\left(t_{l}\right)^{\alpha_{L}^{\rho}}} \prod_{\hat{\omega} \in \hat{\Omega}^{\rho}} C_{\hat{\omega}}^{\alpha_{\hat{\omega}}^{\rho}}\right)^{-\gamma}\right\}^{-\frac{1}{\gamma}} \\
t_{x}^{*} & =\left(\int_{1}^{\infty} t_{x}^{-\zeta^{R}} d T\left(t_{x}\right)\right)^{-1 / \zeta_{R}} \\
\kappa_{\omega \rho} & =\int_{0}^{\infty} \ldots \int_{0}^{\infty} 1\left\{\mathcal{C}_{\omega \rho}\left(v_{l}, v_{1}, \ldots, v_{n}\right) \leq 1\right\} \mathcal{V}_{\omega \rho}(v) \prod_{\hat{\omega} \in \hat{\Omega}^{\rho}} \Gamma\left(1-\frac{\beta_{\hat{\omega}}^{\rho}}{\zeta_{\hat{\omega}}}\right) \Gamma\left(1-\frac{\zeta_{\hat{\omega}}}{\gamma}\right)^{\beta_{\hat{\omega}}^{\rho} / \zeta_{\hat{\omega}}}
\end{aligned}
$$

Proof. Consider recipe $\rho$ that uses labor and intermediate inputs $\hat{\Omega}^{\rho}=\left\{\hat{\omega}_{1}, \ldots, \hat{\omega}_{n}\right\}$. Let $H_{\omega \rho}(c)$ be the arrival rate of a technique that delivers cost weakly less than $c$. Then $1-F_{\omega \rho}(c)$ is the probability that no such techniques arrive, or $e^{-H_{\omega \rho}(c)}$. To find $H_{\omega \rho}(c)$, we consider first a technique of recipe $\rho$ for which the common components of input-augmenting productivities are $b_{l}, b_{1}, \ldots, b_{n}$. To find the probability that the technique delivers unit cost weakly less than $c$ we integrate over the effective cost of all inputs:

$$
\int_{0}^{\infty} \ldots \int_{0}^{\infty} 1\left\{\mathcal{C}_{\omega \rho}\left(\lambda_{l}, \lambda_{\hat{\omega}_{1}}, \ldots, \lambda_{\hat{\omega}_{n}}\right) \leq c\right\} \prod_{k=1}^{n} e^{-\left(\lambda_{k} b_{k} / \Lambda_{\omega \hat{\omega}_{k}}\right)^{\zeta \hat{\omega}_{k}}} \frac{b_{k}^{\zeta \hat{\omega}_{k}}}{\Lambda_{\omega \hat{\omega}_{k}}^{\zeta \hat{\omega}_{k}}} \zeta_{\hat{\omega}_{k}} \lambda_{k}^{\zeta \hat{\omega}_{k}-1} d \lambda_{k}
$$

To find $H_{\omega \rho}(c)$, we integrate over the arrival of such techniques:

$$
\left.H_{\omega \rho}(c)=\int_{0}^{\infty} \ldots \int_{0}^{\infty} 1\left\{\mathcal{C}_{\omega \rho}\left(\lambda_{l}, \lambda_{\hat{\omega}_{1}}, \ldots, \lambda_{\hat{\omega}_{n}}\right) \leq c\right\}\left(\prod_{k=1}^{n} e^{-\left(\lambda_{k} b_{k} / \Lambda_{\omega \hat{\omega}_{k}}\right.}\right)^{\zeta_{\omega_{k}}} \frac{b_{k}^{\zeta_{\omega_{k}}}}{\Lambda_{\omega \hat{\omega}_{k}}^{\zeta_{\hat{\omega}_{k}}}} \zeta_{\hat{\omega}_{k}} \lambda_{k}^{\zeta_{\hat{\omega}_{k}}-1} d \lambda_{k}\right) \mathcal{B}_{\omega \rho}(d b)
$$

Using the definition of $\lambda_{l}=\frac{t_{l}}{b_{l}}$ and the homogeneity of the cost function, this is

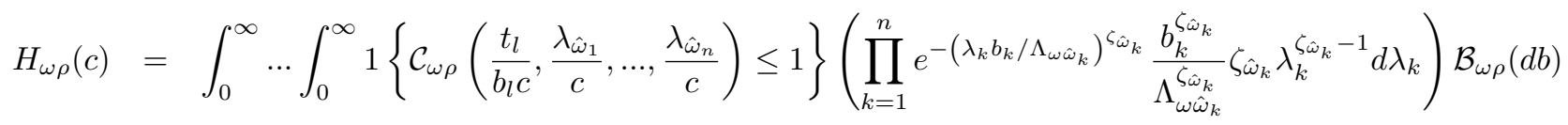

It will be useful to make the changes of variables $v_{k}=\lambda_{k} / c, v_{l}=\frac{t_{l}}{c b_{l}}$, and $m_{j}=\left(\lambda_{l} b_{l} / \Lambda_{\omega \hat{\omega}_{l}}\right)^{\zeta \hat{\omega}_{j}}$ to express $H_{\omega \rho}$ as

$H_{\omega \rho}(c)=\int_{0}^{\infty} \ldots \int_{0}^{\infty} 1\left\{\mathcal{C}_{\omega \rho}\left(v_{l}, v_{1}, \ldots, v_{n}\right) \leq 1\right\} B_{\omega \rho}\left(\frac{t_{l}}{c}\right)^{-\beta_{l}^{\rho}}\left(\prod_{k=1}^{n}\left(\frac{m_{k}^{1 / \zeta_{\omega_{k}}} \Lambda_{\omega \hat{\omega}_{k}}}{c}\right)^{-\beta_{\hat{\omega}_{k}}^{\rho}} e^{-m_{k}} d m_{k}\right) \mathcal{V}_{\omega \rho}(d v)$

or more simply,

$$
H_{\omega \rho}(c)=\tilde{\kappa}_{\omega \rho} B_{\omega \rho} t_{l}^{-\beta_{l}^{\rho}} \Lambda_{\omega \hat{\omega}_{1}}^{-\beta_{\omega_{1}}^{\rho}} \ldots \Lambda_{\omega \hat{\omega}_{n}}^{-\beta_{\omega_{n}}^{\rho}} c^{\gamma}
$$

where

$$
\tilde{\kappa}_{\omega \rho} \equiv \int_{0}^{\infty} \ldots \int_{0}^{\infty} 1\left\{\mathcal{C}_{\omega \rho}\left(v_{l}, v_{1}, \ldots, v_{n}\right) \leq 1\right\} \mathcal{V}_{\omega \rho}(d v) \prod_{k=1}^{n} \int_{0}^{\infty} m_{k}^{-\beta_{\omega_{k}}^{\rho} / \zeta_{\hat{\omega}_{k}}} e^{-m_{k}} d m_{k}
$$

Assumptions 1 and 2e guarantee that $\tilde{\kappa}_{\omega \rho}$ is finite: the first integral is finite because of Lemma 2 , and the subsequent integrals can be written as

$$
\int_{0}^{\infty} m_{\hat{\omega}_{k}}^{-\beta_{\hat{\omega}_{k}}^{\rho} / \zeta_{\hat{\omega}_{k}}} e^{-m_{k}} d m_{k}=\Gamma\left(1-\frac{\beta_{\hat{\omega}_{k}}^{\rho}}{\zeta_{\hat{\omega}_{k}}}\right)
$$


Using the fact that $1-F_{\omega}(c)=\prod_{\rho \in \varrho(\omega)}\left[1-F_{\omega \rho}(c)\right]=\prod_{\rho \in \varrho(\omega)} e^{-H_{\omega \rho}(c)}$, we have

$$
1-F_{\omega}(c)=e^{-\left(c / C_{\omega}\right)^{\gamma}}
$$

where $C_{\omega}$ is defined as

$$
C_{\omega} \equiv\left[\sum_{\rho \in \varrho(\omega)} \tilde{\kappa}_{\omega \rho} B_{\omega \rho} t_{l}^{-\beta_{l}^{\rho}} \Lambda_{\omega \hat{\omega}_{1}}^{-\beta_{\hat{\omega}_{1}}^{\rho}} \ldots \Lambda_{\omega \hat{\omega}_{n}}^{-\beta_{\hat{\omega}_{n}}^{\rho}}\right]^{-1 / \gamma}
$$

To complete the proof, we will derive expressions for $\Lambda_{\omega \hat{\omega}}$ in terms of $C_{\hat{\omega}}$ and substitute into (7). Note first that for each $\hat{\omega} \in \hat{\Omega}^{\rho}$ we have

$$
\begin{aligned}
\int_{0}^{\infty} c^{-\zeta_{\omega}} d F_{\omega}(c) & =\int_{0}^{\infty} c^{-\zeta_{\omega}} C_{\omega}^{-\gamma} \gamma c^{\gamma-1} e^{-\left(c / C_{\omega}\right)^{\gamma}} d c=C_{\omega}^{-\zeta_{\omega}} \int_{0}^{\infty} v^{-\frac{\zeta_{\omega}}{\gamma}} e^{-v} d v \\
& =C_{\omega}^{-\zeta_{\omega}} \Gamma\left(1-\frac{\zeta_{\omega}}{\gamma}\right)
\end{aligned}
$$

therefore Lemma 1 implies

$$
\Lambda_{\omega \tilde{\omega}}=\left\{\begin{array}{cc}
t_{x}^{*} C_{\hat{\omega}} \Gamma\left(1-\frac{\zeta_{R}}{\gamma}\right)^{-1 / \zeta_{R}} & \hat{\omega} \in \hat{\Omega}_{R} \\
C_{\hat{\omega}} \Gamma\left(1-\frac{\zeta_{H}}{\gamma}\right)^{-1 / \zeta_{H}} & \hat{\omega} \in \hat{\Omega}_{H}
\end{array}\right.
$$

Plugging this into (7), defining $\kappa_{\omega \rho} \equiv \tilde{\kappa}_{\omega \rho} \prod_{\hat{\omega} \in \hat{\Omega}^{\rho}} \Gamma\left(1-\frac{\zeta_{\hat{\omega}}}{\gamma}\right)^{\beta_{\hat{\omega}}^{\rho} / \zeta_{\hat{\omega}}}$, and using $\alpha_{\hat{\omega}}^{\rho}=\frac{\beta_{\hat{\omega}}^{\rho}}{\gamma}$ gives the result.

\section{D.2 Factor Shares}

Consider a firm in industry $\omega$. If, in equilibrium, the firm uses a technique of recipe $\rho$ (that uses labor and intermediate inputs $\left.\hat{\Omega}^{\rho}=\left\{\hat{\omega}_{1}, \ldots, \hat{\omega}_{n}\right\}\right)$ with input-augmenting productivities $b=\left\{b_{l}, b_{1}, \ldots, b_{n}\right\}$, effective cost of intermediate inputs $\lambda=\left\{\lambda_{1}, \ldots, \lambda_{n}\right\}$, then its payment to supplier of a relationship-specific input $\hat{\omega}_{i}$ with wedge $t_{\hat{\omega} x}$ is

$$
\begin{aligned}
p_{s} x_{s} & =t_{\hat{\omega}_{i x} x}^{-1} \lambda_{i} \mathcal{C}_{\omega \rho \hat{\omega}_{i}}(\lambda) y_{j}, \quad \omega_{i} \in \Omega_{R}^{\rho} \\
p_{s} x_{s} & =\lambda_{i} \mathcal{C}_{\omega \rho \hat{\omega}_{i}}(\lambda) y_{j}, \quad \omega_{i} \in \Omega_{H}^{\rho} \\
w l & =\lambda_{l} \mathcal{C}_{\omega \rho \hat{\omega}_{i}}\left(\lambda_{l}, \lambda_{1}, \ldots, \lambda_{n}\right) y_{j}+\sum_{\hat{\omega} \in \hat{\Omega}_{R}^{\rho}}\left(1-t_{\hat{\omega}_{i} x}^{-1}\right) \lambda_{i} \mathcal{C}_{\omega \rho \hat{\omega}_{i}}(\lambda) y_{j}
\end{aligned}
$$

where $\mathcal{C}_{\omega \rho l}$ and $\mathcal{C}_{\omega \rho \hat{\omega}}$ denote the partial derivatives of the cost function with respect to the cost of labor and to the cost of input $\hat{\omega}$ respectively.

We characterize average revenue shares of each input in several in several intermediate steps.

\section{Effective Cost Shares}

For any technique of recipe $\rho$ that delivers $\operatorname{cost} c$, let $D_{\omega \rho}(c)$ denote the probability that the technique is actually chosen by the firm. ${ }^{42}$

Lemma 3 Under Assumptions 1 and 2, the average effective cost share of the ith intermediate input and of

\footnotetext{
${ }^{42}$ While it is not relevant for the proof, it turns out that $D_{\omega \rho}(c)=1-F_{\tilde{\omega}}(c)$, the overall probability that a firm's best technique delivers cost $c$.
} 
labor among firms that, in equilibrium, use recipe $\rho$ and have unit cost weakly less than $c_{0}$ are, respectively,

$$
\begin{aligned}
E\left[\frac{\lambda_{\hat{\omega}_{i}} \mathcal{C}_{\omega \rho \hat{\omega}_{i}}(\lambda)}{\mathcal{C}_{\omega \rho}(\lambda)} \mid c \leq c_{0}, \rho\right] & =\frac{\int_{v} \frac{v_{\hat{\omega}_{i}} \mathcal{C}_{\omega \rho} \hat{\omega}_{i}(v)}{\mathcal{C}_{\omega \rho}(v)} 1\left\{\mathcal{C}_{\omega \rho}(v) \leq c_{0}\right\} D_{\omega \rho}\left(\mathcal{C}_{\omega \rho}(v)\right) \mathcal{V}_{\omega \rho}(d v)}{\int_{v} 1\left\{\mathcal{C}_{\omega \rho}(v) \leq c_{0}\right\} D_{\omega \rho}\left(\mathcal{C}_{\omega \rho}(v)\right) \mathcal{V}_{\omega \rho}(d v)} \\
E\left[\frac{\lambda_{l} C_{\omega \rho l}(\lambda)}{\mathcal{C}_{\omega \rho}(\lambda)} \mid c \leq c_{0}, \rho\right] & =\frac{\int_{v} \frac{v_{l} C_{\omega \rho l}(v)}{\mathcal{C}_{\omega \rho}(v)} 1\left\{\mathcal{C}_{\omega \rho}(v) \leq c_{0}\right\} D_{\omega \rho}\left(\mathcal{C}_{\omega \rho}(v)\right) \mathcal{V}_{\omega \rho}(d v)}{\int_{v} 1\left\{\mathcal{C}_{\omega \rho}(v) \leq c_{0}\right\} D_{\omega \rho}\left(\mathcal{C}_{\omega \rho}(v)\right) \mathcal{V}_{\omega \rho}(d v)}
\end{aligned}
$$

Proof. For a firm in industry $\omega$, the measure of the arrival rate of techniques of recipe $\rho$ with $b=$ $\left\{b_{l}, b_{1}, \ldots, b_{n}\right\}$ and $\lambda=\left\{\lambda_{1}, \ldots, \lambda_{n}\right\}$ that deliver cost weakly less than $c_{0}$ is

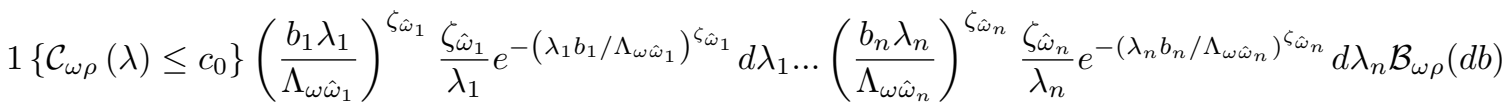

Such a technique is actually used by the firm with probability $D_{\omega \rho}\left(\mathcal{C}_{\omega \rho}(\lambda)\right)$. To find the density of $b$ and $\lambda$ among firms in industry $\omega$ that choose to use a technique of recipe $\rho$ that delivers cost weakly less than $c_{0}$ we simply divide the product of $(10)$ and $D_{\omega \rho}\left(\mathcal{C}_{\omega \rho}(\lambda)\right)$ by the integral over all such combinations of input-augmenting productivities and effective cost, so that the conditional expectation of $\frac{\lambda_{i} \mathcal{C}_{\omega \rho} \hat{\omega}_{i}(\lambda)}{\mathcal{C}_{\omega \rho}(\lambda)}$ is

$$
\begin{aligned}
& \int_{b} \int_{\lambda} \frac{\lambda_{i} C_{\omega \rho} \omega_{i}(\lambda)}{\mathcal{C}_{\omega \rho}(\lambda)} 1\left\{\mathcal{C}_{\omega \rho}(\lambda) \leq c_{0}\right\} D_{\omega \rho}\left(\mathcal{C}_{\omega \rho}(\lambda)\right) \\
& E\left[\frac{\lambda_{i} \mathcal{C}_{\omega \rho \hat{\omega}_{i}}(\lambda)}{\mathcal{C}_{\omega \rho}(\lambda)} \mid c \leq c_{0}, \rho\right]=\frac{\times\left(\frac{b_{1} \lambda_{1}}{\Lambda_{\omega \hat{\omega}_{1}}}\right)^{\zeta_{\hat{\omega}_{1}}} \frac{\zeta_{\hat{\omega}_{1}}}{\lambda_{1}} e^{-\left(\lambda_{1} b_{1} / \Lambda_{\omega \hat{\omega}_{1}}\right)} d \lambda_{1} \ldots\left(\frac{b_{n} \lambda_{n}}{\Lambda_{\omega \omega_{n}}}\right)^{\zeta_{\hat{\omega}_{n}}} \frac{\zeta_{\hat{\omega}_{n}}}{\lambda_{n}} e^{-\left(\lambda_{n} b_{n} / \Lambda_{\omega \omega_{n}}\right)} d \lambda_{n} \mathcal{B}_{\omega \rho}(d b)}{\int_{b} \int_{\lambda} 1\left\{\mathcal{C}_{\omega \rho}(\lambda) \leq c_{0}\right\} D_{\omega \rho}\left(\mathcal{C}_{\omega \rho}(\lambda)\right)} \\
& \times\left(\frac{b_{1} \lambda_{1}}{\Lambda_{\omega \hat{\omega}_{1}}}\right)^{\zeta \hat{\omega}_{1}} \frac{\zeta_{\hat{\omega}_{1}}}{\lambda_{1}} e^{-\left(\lambda_{1} b_{1} / \Lambda_{\omega \hat{\omega}_{1}}\right)} d \lambda_{1} \ldots\left(\frac{b_{n} \lambda_{n}}{\Lambda_{\omega \hat{\omega}_{n}}}\right)^{\zeta_{\hat{\omega}_{n}}} \frac{\zeta_{\hat{\omega}_{n}}}{\lambda_{n}} e^{-\left(\lambda_{n} b_{n} / \Lambda_{\omega \hat{\omega}_{n}}\right)} d \lambda_{n} \mathcal{B}_{\omega \rho}(d b)
\end{aligned}
$$

Making the change of variables of variables $m_{k}=\left(\lambda_{k} b_{k} / \Lambda_{\omega \hat{\omega}_{k}}\right)^{\zeta_{\hat{\omega}_{k}}}$ for each $k$ and using the definition $\lambda_{l}=\frac{t_{l}}{b_{l}}$ gives

$$
\begin{array}{r}
E\left[\frac{\lambda_{i} \mathcal{C}_{\omega \rho \hat{\omega}_{i}}(\lambda)}{\mathcal{C}_{\omega \rho}(\lambda)} \mid c \leq c_{0}, \rho\right]=\frac{\int_{b} \int_{m} \frac{\frac{\Lambda_{\omega \omega_{i}}}{b_{\omega_{i}}} m_{i}{ }^{1 / \zeta_{\omega_{i}}} C_{\omega \rho \omega_{i}}\left(\frac{t_{l}}{b_{l}},\left\{\frac{\Lambda}{b} m^{1 / \zeta}\right\}\right)}{\mathcal{C}_{\omega \rho}\left(\frac{t_{l}}{b_{l}},\left\{\frac{\Lambda}{b} m^{1 / \zeta}\right\}\right)} 1\left\{\mathcal{C}_{\omega \rho}\left(\frac{t_{l}}{b_{l}},\left\{\frac{\Lambda}{b} m^{1 / \zeta}\right\}\right) \leq c_{0}\right\}}{\times D_{\omega \rho}\left(\mathcal{C}_{\omega \rho}\left(\frac{l_{l}}{b_{l}},\left\{\frac{\Lambda}{b} m^{1 / \zeta}\right\}\right)\right) e^{-m_{1}} d m_{1} \ldots e^{-m_{n}} d m_{n} \mathcal{B}_{\omega \rho}(d b)} \\
\int_{b} \int_{m} 1\left\{\mathcal{C}_{\omega \rho}\left(\frac{t_{l}}{b_{l}},\left\{\frac{\Lambda}{b} m^{1 / \zeta}\right\}\right) \leq c_{0}\right\}
\end{array}
$$

where $\mathcal{C}_{\omega \rho}\left(\frac{t_{l}}{b_{l}},\left\{\frac{\Lambda}{b} m^{1 / \zeta}\right\}\right)=\mathcal{C}_{\omega \rho}\left(\frac{t_{l}}{b_{l}}, \frac{\Lambda_{\omega \omega_{i}}}{b_{i}} m_{i}^{1 / \zeta_{\omega_{i}}}, \ldots, \frac{\Lambda_{\omega \omega_{n}}}{b_{n}} m_{n}^{1 / \zeta_{\omega_{n}}}\right)$. A further change of variables $v_{l}=\frac{t_{l}}{b_{l}}$ and $v_{k}=\frac{\Lambda_{\omega \hat{\omega}_{k}}}{b_{k}} m_{k}^{1 / \zeta_{\hat{\omega}_{k}}}$ gives

$$
\begin{aligned}
& \int_{v} \int_{m} \frac{v_{\hat{\omega}_{i}} C_{\omega \rho} \hat{\omega}_{i}(v)}{\mathcal{C}_{\omega \rho}(v)} 1\left\{C_{\omega \rho}(v) \leq c_{0}\right\} D_{\omega \rho}\left(C_{\omega \rho}(v)\right) e^{-m_{1}} d m_{1} \ldots e^{-m_{n}} d m_{n} \\
& E\left[\frac{\lambda_{i} \mathcal{C}_{\omega \rho \hat{\omega}_{i}}(\lambda)}{\mathcal{C}_{\omega \rho}(\lambda)} \mid c \leq c_{0}, \rho\right]=\frac{\times B_{\omega \rho} t_{l}^{-\beta_{l}^{\rho}}\left(\Lambda_{\omega \hat{\omega}_{1}} m_{1}^{1 / \zeta_{\hat{\omega}_{1}}}\right)^{\beta_{\hat{\omega}_{1}}^{\rho}} \ldots\left(\Lambda_{\omega \hat{\omega}_{n}} m_{n}^{1 / \zeta_{\omega_{n}}}\right)^{\beta_{\hat{\omega}_{n}}^{\rho}} \mathcal{V}_{\omega \rho}(d v)}{\int_{v} \int_{m} 1\left\{\mathcal{C}_{\omega \rho}(v) \leq c_{0}\right\} D_{\omega \rho}\left(\mathcal{C}_{\omega \rho}(v)\right) e^{-m_{1}} d m_{1} \ldots e^{-m_{n}} d m_{n}} \\
& \times B_{\omega \rho} t_{l}^{-\beta_{l}^{\rho}}\left(\Lambda_{\omega \hat{\omega}_{1}} m_{1}^{1 / \zeta_{\hat{\omega}_{1}}}\right)^{\beta_{\hat{\omega}_{1}}^{\rho}} \ldots\left(\Lambda_{\omega \hat{\omega}_{n}} m_{n}^{1 / \zeta_{\omega_{n}}}\right)^{\beta_{\hat{\omega}_{n}}^{\rho}} \mathcal{V}_{\omega \rho}(d v)
\end{aligned}
$$

Canceling common terms from the numerator and denominator gives (8). (9) can be derived using identical logic. 


\section{Lemma 4}

$$
\begin{aligned}
& \int_{v} \frac{v_{i} \mathcal{C}_{\omega \rho \hat{\omega}_{i}}(v)}{\mathcal{C}_{\omega \rho}(v)} 1\left\{\mathcal{C}_{\omega \rho}(v) \leq c_{0}\right\} D_{\omega \rho}\left(\mathcal{C}_{\omega \rho}(v)\right) \mathcal{V}_{\omega \rho}(d v)=\beta_{\hat{\omega}_{i}}^{\rho} A_{\omega \rho}\left(c_{0}\right) \\
& \int_{v} \frac{v_{l} C_{\omega \rho l}(v)}{\mathcal{C}_{\omega \rho}(v)} 1\left\{\mathcal{C}_{\omega \rho}(v) \leq c_{0}\right\} D_{\omega \rho}\left(\mathcal{C}_{\omega \rho}(v)\right) \mathcal{V}_{\omega \rho}(d v)=\beta_{L}^{\rho} A_{\omega \rho}\left(c_{0}\right)
\end{aligned}
$$

where $A_{\omega \rho}\left(c_{0}\right)$ is a constant

Proof. For the proof of this lemma we need some additional notation. Define the function $K_{\omega \rho}\left(c ; c_{0}\right)=$ $\int_{c}^{c_{0}} \frac{1}{\tilde{c}} D_{\omega \rho}(\tilde{c}) d \tilde{c}$. Define the function $\psi\left(v_{-i}, c\right)$ to be the solution to $C_{\omega \rho}\left(v_{-i}, \psi\left(v_{-i}, c\right)\right)=c$ if such a solution exists, or take the value of zero no such solution exists, i.e., if the $v_{-i}$ are too large for a solution to exist. Finally, define $\mathcal{V}_{\omega \rho,-i}\left(v_{-i}\right) \equiv v_{l}^{\beta_{l}^{\rho}} \prod_{k \neq i} v_{k}^{\beta_{\hat{\omega}_{k}}^{\rho}}$ and $\mathcal{V}_{\omega \rho, l}\left(v_{-l}\right) \equiv \prod_{k} v_{k}^{\beta_{\hat{\omega}_{k}}^{\rho}}$

We can express the left hand side of (11) as

$$
\begin{aligned}
L H S & =\int_{v} \frac{v_{i} \mathcal{C}_{\omega \rho \hat{\omega}_{i}}(v)}{\mathcal{C}_{\omega \rho}(v)} 1\left\{\mathcal{C}_{\omega \rho}(v) \leq c_{0}\right\} D_{\omega \rho}\left(\mathcal{C}_{\omega \rho}(v)\right) \mathcal{V}_{\omega \rho}(d v) \\
& =\int_{v_{-i}} \int_{v_{i}} \frac{v_{i} C_{\omega \rho \hat{\omega}_{i}}(v)}{\mathcal{C}_{\omega \rho}(v)} 1\left\{C_{\omega \rho}(v) \leq c_{0}\right\} D_{\omega \rho}\left(C_{\omega \rho}(v)\right) \beta_{\hat{\omega}_{i}}^{\rho} v_{i}^{\beta_{\omega_{i}}^{\rho}-1} d v_{i} \mathcal{V}_{\omega \rho,-i}\left(d v_{-i}\right)
\end{aligned}
$$

We can use the definition of $\psi\left(v_{-i}, c\right)$, integrate by parts, and then use the definition of $\psi\left(v_{-i}, c\right)$ again to express the innermost integral as

$$
\begin{aligned}
& \int_{v_{i}} \frac{v_{i} \mathcal{C}_{\omega \rho \hat{\omega}_{i}}(v)}{\mathcal{C}_{\omega \rho}(v)} 1\left\{\mathcal{C}_{\omega \rho}(v) \leq c_{0}\right\} D_{\omega \rho}\left(\mathcal{C}_{\omega \rho}(v)\right) \beta_{\hat{\omega}_{i}}^{\rho} v_{i}^{\beta_{\hat{\omega}_{i}}^{\rho}-1} d v_{i} \\
= & \int_{0}^{\psi\left(v_{-i}, c_{0}\right)} \frac{v_{i} C_{\omega \rho \hat{\omega}_{i}}(v)}{\mathcal{C}_{\omega \rho}(v)} D_{\omega \rho}\left(\mathcal{C}_{\omega \rho}(v)\right) \beta_{\hat{\omega}_{i}}^{\rho} v_{i}^{\beta_{\hat{\omega}_{i}}^{\rho}-1} d v_{i} \\
= & \int_{0}^{\psi\left(v_{-i}, c_{0}\right)} \frac{C_{\omega \rho \hat{\omega}_{i}}(v)}{\mathcal{C}_{\omega \rho}(v)} D_{\omega \rho}\left(\mathcal{C}_{\omega \rho}(v)\right) \beta_{\hat{\omega}_{i}}^{\rho} v_{i}^{\beta_{\hat{\omega}_{i}}^{\rho}} d v_{i} \\
= & -\left.K_{\omega \rho}\left(\mathcal{C}_{\omega \rho}(v) ; c_{0}\right) \beta_{\hat{\omega}_{i}}^{\rho} v_{i}^{\beta_{\hat{\omega}_{i}}^{\rho}}\right|_{0} ^{\psi\left(v_{-i}, c_{0}\right)}+\int_{0}^{\psi\left(v_{-i}, c_{0}\right)} K_{\omega \rho}\left(\mathcal{C}_{\omega \rho}(v) ; c_{0}\right)\left(\beta_{\hat{\omega}_{i}}^{\rho}\right)^{2} v_{i}^{\beta_{\hat{\omega}_{i}}^{\rho}-1} d v_{i} \\
= & \int_{0}^{\psi\left(v_{-i}, c_{0}\right)} K_{\omega \rho}\left(\mathcal{C}_{\omega \rho}(v) ; c_{0}\right)\left(\beta_{\hat{\omega}_{i}}^{\rho}\right)^{2} v_{i}^{\beta_{\hat{\omega}_{i}}^{\rho}-1} d v_{i} \\
= & \beta_{\hat{\omega}_{i}}^{\rho} \int_{v_{i}} 1\left\{C_{\omega \rho}(v) \leq c_{0}\right\} K_{\omega \rho}\left(C_{\omega \rho}(v) ; c_{0}\right) \beta_{\hat{\omega}_{i}}^{\rho} v_{i}^{\beta_{\hat{\omega}_{i}}-1} d v_{i}
\end{aligned}
$$

Plugging this back into (13) gives

$$
L H S=\beta_{\hat{\omega}_{i}}^{\rho} \int_{v} 1\left\{\mathcal{C}_{\omega \rho}(v) \leq c_{0}\right\} K_{\omega \rho}\left(\mathcal{C}_{\omega \rho}(v), c_{0}\right) \mathcal{V}_{\omega \rho}(d v)
$$

The derivation of (12) follows identical logic.

Proposition 7 Under Assumptions 1 and 2, the average effective cost share of the ith intermediate input and of labor among firms that, in equilibrium, use recipe $\rho$ and have unit cost weakly less than $c_{0}$ are, respectively,

$$
\begin{gathered}
E\left[\frac{\lambda_{i} \mathcal{C}_{\omega \rho \hat{\omega}_{i}}(\lambda)}{\mathcal{C}_{\omega \rho}(\lambda)} \mid c \leq c_{0}, \rho\right]=\alpha_{\hat{\omega}_{i}}^{\rho} \\
E\left[\frac{\lambda_{l} C_{\omega \rho l}(\lambda)}{\mathcal{C}_{\omega \rho}(\lambda)} \mid c \leq c_{0}, \rho\right]=\alpha_{L}^{\rho}
\end{gathered}
$$


Proof. Lemma 3 gives

$$
E\left[\frac{\lambda_{i} \mathcal{C}_{\omega \rho \hat{\omega}_{i}}(\lambda)}{\mathcal{C}_{\omega \rho}(\lambda)} \mid c \leq c_{0}, \rho\right]=\frac{\int_{v} \frac{v_{i} \mathcal{C}_{\omega \rho \omega_{i}}(v)}{\mathcal{C}_{\omega \rho}(v)} 1\left\{\mathcal{C}_{\omega \rho}(v) \leq c_{0}\right\} D_{\omega \rho}\left(\mathcal{C}_{\omega \rho}(v)\right) \mathcal{V}_{\omega \rho}(d v)}{\int_{v} 1\left\{\mathcal{C}_{\omega \rho}(v) \leq c_{0}\right\} D_{\omega \rho}\left(\mathcal{C}_{\omega \rho}(v)\right) \mathcal{V}_{\omega \rho}(d v)}
$$

Lemma 4 implies that the numerator equals $\beta_{\omega_{i}}^{\rho} A_{\omega \rho}\left(c_{0}\right)$. The homogeneity of the cost function implies that $1=\frac{v_{l} C_{\omega \rho l}(v)}{C_{\omega \rho}(v)}+\sum_{i} \frac{v_{i} \mathcal{C}_{\omega \rho \hat{\omega}_{i}}(v)}{\mathcal{C}_{\omega \rho}(v)}$, so the denominator equals $\beta_{l}^{\rho} A_{\omega \rho}\left(c_{0}\right)+\sum_{i} \beta_{\hat{\omega}_{i}}^{\rho} A_{\omega \rho}\left(c_{0}\right)=\gamma A_{\omega \rho}\left(c_{0}\right)$. Together these imply that $E\left[\frac{\lambda_{i} \mathcal{C}_{\omega \rho \omega_{i}}(\lambda)}{\mathcal{C}_{\omega \rho}(\lambda)} \mid c \leq c_{0}, \rho\right]=\alpha_{\hat{\omega}_{i}}^{\rho}$. Identical logic implies that $E\left[\frac{\lambda_{l} C_{\omega \rho l}(\lambda)}{\mathcal{C}_{\omega \rho}(\lambda)} \mid c \leq c_{0}, \rho\right]=\alpha_{L}^{\rho}$.

\section{Actual Cost Shares}

Lemma 5 Among firms that produce $\omega$ that, in equilibrium, use a supplier for relationship-specific input $\hat{\omega} \in \Omega_{R}^{\rho}$ that delivers effective cost $\lambda_{\hat{\omega}}$, the harmonic average of the wedge is

$$
\bar{t}_{x}=E\left[t_{x \hat{\omega}}^{-1} \mid \lambda_{\hat{\omega}}\right]^{-1}=\left(\int_{1}^{\infty} t_{x}^{-1} d \tilde{T}\left(t_{x}\right)\right)^{-1}
$$

where $\tilde{T}\left(t_{x}\right) \equiv \frac{\int_{1}^{t_{x}} t^{-\zeta_{R}} d T(t)}{\int_{1}^{\infty} t^{-\zeta_{R}} d T(t)}$.

Proof. Consider all suppliers drawn by $j$ to supply input $\hat{\omega}$ for recipe $\rho$. The effective cost delivered by the supplier is $\lambda=\frac{p_{s}}{t_{x} z}$ where $p_{s}=c_{s}$ is the price charged by the supplier. Given the match-specific productivity $z$ and wedge $t_{x}$, the probability that the supplier's efficiency is high enough to deliver an effective cost lower $\lambda$ is the probability that $c_{s}$ is small enough to so that $\frac{t_{x} c_{s}}{z}<\lambda$, i.e., $c_{s}<\lambda z / t_{x}$, or $1-F_{\hat{\omega}}\left(\lambda z / t_{x}\right)$. Integrating over possible values of $z$ and $t_{x}$, the probability that a supplier delivers effective cost lower than $\lambda$ is $\int_{0}^{\infty} \int_{1}^{\infty}\left[1-F_{\hat{\omega}}(\lambda z / t)\right] d T(t) \zeta_{R} z^{-\zeta_{R}-1} d z$. Second, the probability that a supplier delivers effective cost less than $\lambda$ and the wedge is less than $t_{x}$ is $\int_{0}^{\infty} \int_{1}^{t_{x}}\left[1-F_{\hat{\omega}}(\lambda z / t)\right] d T(t) \zeta_{R} z^{-\zeta_{R}-1} d z$. Together, these imply that, among suppliers who deliver effective cost less than $\lambda$, the probability that the wedge is less than $t_{x}$ is

$$
\begin{aligned}
\operatorname{Pr}\left(t_{x s}<t_{x} \mid \lambda_{s} \leq \lambda\right) & =\frac{\int_{0}^{\infty} \int_{1}^{t_{x}}\left[1-F_{\hat{\omega}}(\lambda z / t)\right] d T(t) z^{-\zeta_{R}-1} d z}{\int_{0}^{\infty} \int_{1}^{\infty}\left[1-F_{\hat{\omega}}(\lambda z / t)\right] d T(t) z^{-\zeta_{R}-1} d z} \\
& =\frac{\int_{0}^{\infty} \int_{1}^{t_{x}}\left[1-F_{\hat{\omega}}(u)\right] \lambda^{\zeta_{R}} t^{-\zeta_{R}} d T(t) u^{-\zeta_{R}-1} d u}{\int_{0}^{\infty} \int_{1}^{\infty}\left[1-F_{\hat{\omega}}(u)\right] \lambda^{\zeta_{R}} t^{-\zeta_{R}} d T(t) u^{-\zeta_{R}-1} d u} \\
& =\frac{\int_{1}^{t_{x}} t^{-\zeta_{R}} d T(t)}{\int_{1}^{\infty} t^{-\zeta_{R}} d T(t)} \\
& =\tilde{T}\left(t_{x}\right)
\end{aligned}
$$

where the second line uses the change of variables $u=\lambda t z$. With this, we have that among suppliers that deliver effective cost weakly greater than $\lambda$, the harmonic average of wedges is

$$
\bar{t}_{x} \equiv E\left[t_{x s}^{-1} \mid \lambda_{s} \leq \lambda\right]^{-1}
$$

Since $\bar{t}_{x}$ does not depend on $\lambda$, the expectation must be the same for each $\lambda$, i.e.,

$$
\bar{t}_{x}=E\left[t_{x s}^{-1} \mid \lambda_{s}\right]^{-1}
$$

Finally, this equation holds regardless of whether $s$ is selected as a supplier. In other words,

$$
E\left[t_{x \hat{\omega}}^{-1} \mid \lambda_{\hat{\omega}}\right]=E\left[t_{x s}^{-1} \mid \lambda_{s}, s \text { selected as supplier }\right]=E\left[t_{x s}^{-1} \mid \lambda_{s}\right]=\bar{t}_{x}^{-1}
$$


Proposition 8 Among firms in industry $\omega$ that, in equilibrium, use recipe $\rho$ and have unit cost $c$ :

- the average share of expenditures spent on input $\hat{\omega} \in \Omega_{R}^{\rho}$ is $\frac{1}{t_{x}} \alpha_{\hat{\omega}}^{\rho}$

- the average share of expenditures spent on input $\hat{\omega} \in \Omega_{H}^{\rho}$ is $\alpha_{\hat{\omega}}^{\rho}$

- the average share of expenditures spent on input $\hat{\omega} \in \Omega_{H}^{\rho}$ is $\alpha_{L}^{\rho}+\left(1-\frac{1}{t_{x}}\right) \alpha_{R}^{\rho}$

Proof. Consider a relationship specific-input $\hat{\omega}$. Note first that the share of $j$ 's expenditures spent on $\hat{\omega}$ is $\frac{1}{t_{\hat{\omega} x}} \frac{\lambda_{\hat{\omega}} \mathcal{C}_{\omega \rho}(\lambda)}{\mathcal{C}_{\omega \rho}(\lambda)}$. Note that conditional on $c, \bar{p}_{j}$ is independent of any feature of the firm's sourcing decision, and conditional on $\lambda_{i}, t_{\hat{\omega} x}$ is independent of any other feature of the firm's sourcing decision. Putting the pieces together, we have, by iterated expectations,

$$
\begin{aligned}
E\left[\frac{1}{t_{\hat{\omega} x}} \frac{\lambda_{\hat{\omega}} \mathcal{C}_{\omega \rho \hat{\omega}}(\lambda)}{\mathcal{C}_{\omega \rho}(\lambda)} \mid c, \rho\right] & =E\left[\frac{1}{t_{x \hat{\omega}}} \frac{\lambda_{\hat{\omega}} \mathcal{C}_{\omega \rho \hat{\omega}}(\lambda)}{\mathcal{C}_{\omega \rho}(\lambda)} \mid c, \rho\right] \\
& =E\left\{E\left[\frac{1}{t_{x \hat{\omega}}} \frac{\lambda_{\hat{\omega}} \mathcal{C}_{\omega \rho \hat{\omega}}(\lambda)}{\mathcal{C}_{\omega \rho}(\lambda)} \mid c, \rho, b, \lambda\right] \mid c, \rho\right\} \\
& =E\left\{E\left[\frac{1}{t_{x \hat{\omega}}} \mid c, \rho, b, \lambda\right] \frac{\lambda_{\hat{\omega}} \mathcal{C}_{\omega \rho \hat{\omega}}(\lambda)}{\mathcal{C}_{\omega \rho}(\lambda)} \mid c, \rho\right\} \\
& =E\left[\frac{1}{t_{x \hat{\omega}}} \mid c, \rho, b, \lambda\right] E\left\{\frac{\lambda_{\hat{\omega}} \mathcal{C}_{\omega \rho \hat{\omega}}(\lambda)}{\mathcal{C}_{\omega \rho}(\lambda)} \mid c, \rho\right\} \\
& =\frac{1}{\bar{t}_{x}} \alpha_{\hat{\omega}}^{\rho}
\end{aligned}
$$

The expression for homogeneous inputs follows directly from Proposition 7. The expression for labor follows from the fact that the cost shares sum to 1 .

Corollary 2 Among firms in industry $\omega$ that, in equilibrium, use recipe $\rho$ :

- the average and aggregate shares of expenditures spent on input $\hat{\omega} \in \Omega_{R}^{\rho}$ are both $\frac{1}{t_{x}} \alpha_{\hat{\omega}}^{\rho}$

- the average and aggregate shares of expenditures spent on input $\hat{\omega} \in \Omega_{H}^{\rho}$ are $\alpha_{\hat{\omega}}^{\rho}$

- the average and aggregate shares of expenditures spent on input $\hat{\omega} \in \Omega_{H}^{\rho}$ are $\alpha_{L}^{\rho}+\left(1-\frac{1}{t_{x}}\right) \alpha_{R}^{\rho}$

Proof. This follows directly from the previous corollary by integrating over realizations of $c$.

We next turn to revenue shares. Let $s_{\omega j \hat{\omega}}$ be the ratio of $j$ 's expenditure on input $\hat{\omega}$ to $j$ 's revenue. Let $\bar{p}_{j}$ be $j$ 's average price across all buyers; $j$ charges a price of $c_{j}$ to other firms and $\frac{\varepsilon}{\varepsilon-1} c_{j}$ to the household.

Proposition 9 Among firms in industry $\omega$ that, in equilibrium, use recipe $\rho$ and have unit cost $c$ :

- the average share of revenue spent on input $\hat{\omega} \in \Omega_{R}^{\rho}$ is $\frac{1}{t_{x}} \alpha_{\hat{\omega}}^{\rho} E\left[\frac{c}{\bar{p}} \mid c, \rho\right]$

- the average share of expenditures spent on input $\hat{\omega} \in \Omega_{H}^{\rho}$ is $\alpha_{\hat{\omega}}^{\rho} E\left[\frac{c}{\bar{p}} \mid c, \rho\right]$

- the average share of expenditures spent on input $\hat{\omega} \in \Omega_{H}^{\rho}$ is $\left(\alpha_{L}^{\rho}+\left(1-\frac{1}{t_{x}}\right) \alpha_{R}^{\rho}\right) E\left[\frac{c}{\bar{p}} \mid c, \rho\right]$

Proof. This proof closely follows the proof of cost shares. Consider a relationship-specific input $\hat{\omega}$ Note first that $j$ 's revenue share of input $\hat{\omega}$ is $\frac{c}{\bar{p}_{j}} \frac{1}{t_{\hat{\omega} x}} \frac{\lambda_{\hat{\omega}} \mathcal{C}_{\omega \rho \hat{\omega}}(\lambda)}{\mathcal{C}_{\omega \rho}(\lambda)}$. Note that conditional on $c, \bar{p}_{j}$ is independent of any feature of the firm's sourcing decision, and conditional on $\lambda_{i}, t_{\hat{\omega} x}$ is independent of any other feature of the 
firm's sourcing decision. Putting the pieces together, we have

$$
\begin{aligned}
E\left[\frac{c}{\bar{p}_{j}} \frac{1}{t_{\hat{\omega} x}} \frac{\lambda_{\hat{\omega}} \mathcal{C}_{\omega \rho \hat{\omega}}(\lambda)}{\mathcal{C}_{\omega \rho}(\lambda)} \mid c, \rho\right] & =E\left[\frac{c}{\bar{p}} \frac{1}{t_{x \hat{\omega}}} \frac{\lambda_{\hat{\omega}} \mathcal{C}_{\omega \rho \hat{\omega}}(\lambda)}{\mathcal{C}_{\omega \rho}(\lambda)} \mid c, \rho\right] \\
& =E\left\{E\left[\frac{c}{\bar{p}} \frac{1}{t_{x \hat{\omega}}} \frac{\lambda_{\hat{\omega}} \mathcal{C}_{\omega \rho \hat{\omega}}(\lambda)}{\mathcal{C}_{\omega \rho}(\lambda)} \mid c, \rho, b, \lambda\right] \mid c, \rho\right\} \\
& =E\left\{E\left[\frac{c}{\bar{p}} \mid c, \rho, b, \lambda\right] E\left[\frac{1}{t_{x \hat{\omega}}} \mid c, \rho, b, \lambda\right] \frac{\lambda_{\hat{\omega}} \mathcal{C}_{\omega \rho \hat{\omega}}(\lambda)}{\mathcal{C}_{\omega \rho}(\lambda)} \mid c, \rho\right\} \\
& =E\left[\frac{c}{\bar{p}} \mid c, \rho, b, \lambda\right] E\left[\frac{1}{t_{x \hat{\omega}}} \mid c, \rho, b, \lambda\right] E\left\{\frac{\lambda_{\hat{\omega}} \mathcal{C}_{\omega \rho \hat{\omega}}(\lambda)}{\mathcal{C}_{\omega \rho}(\lambda)} \mid c, \rho\right\} \\
& =E\left[\frac{c}{\bar{p}} \mid c, \rho\right] \frac{1}{\bar{t}_{x}} \alpha_{\hat{\omega}}^{\rho}
\end{aligned}
$$

The derivation for homogeneous inputs is the same but without the wedge (i.e., setting the wedge to 1). The derivation for labor is similar.

Corollary 3 Among firms in industry $\omega$ that, in equilibrium use recipe $\rho$, the following expressions hold:

$$
\begin{aligned}
& 0=E\left[\frac{s_{j R}}{\left.\frac{\alpha_{R}^{\rho}}{t_{x}}-\frac{s_{j H}}{\alpha_{H}^{\rho}} \mid \rho\right]}\right. \\
& 0=E\left[\frac{s_{j R}+s_{j L}}{\alpha_{R}^{\rho}+\alpha_{L}^{\rho}}-\frac{s_{j H}}{\alpha_{H}^{\rho}} \mid \rho\right]
\end{aligned}
$$

Proof. This follows from rearranging the expressions in the previous proposition and integrating over $c$.

\section{D.3 Counterfactuals}

Given the household's preferences, let $P_{\omega}$ be the ideal price index for the consumption aggregate for industry $\omega$ and let $P$ be the overall ideal price index. These satisfy $P_{\omega} \equiv\left(\int_{0}^{J_{\omega}} p_{j}^{1-\varepsilon} d j\right)^{\frac{1}{1-\varepsilon}}$ and $P=\left(\sum_{\omega} v_{\omega} P_{\omega}^{1-\eta}\right)^{\frac{1}{1-\eta}}$.

Since each firm charges a fixed markup over marginal cost in sales to the household, firm $j$ in industry $\omega$ would charge a price of $p_{j}=\frac{\varepsilon}{\varepsilon-1} c_{j}$. Thus the price index for $\omega$ satisfies

$$
P_{\omega}^{1-\varepsilon}=\int_{0}^{J_{\omega}}\left(\frac{\varepsilon}{\varepsilon-1} c_{j}\right)^{1-\varepsilon} d j=\left(\frac{\varepsilon}{\varepsilon-1}\right)^{1-\varepsilon} J_{\omega} \int_{0}^{\infty} c^{1-\varepsilon} d F_{\omega}(c)
$$

Proposition 1 gives $F_{\omega}(c)=1-e^{-\left(c / C_{\omega}\right)^{\gamma}}$. Integrating yields $\int_{0}^{\infty} c^{1-\varepsilon} d F_{\omega}(c)=\Gamma\left(1-\frac{\varepsilon-1}{\gamma}\right) C_{\omega}^{1-\varepsilon}$, which implies that the industry price index can be expressed as

$$
P_{\omega}=\frac{\varepsilon}{\varepsilon-1} J_{\omega}^{\frac{1}{1-\varepsilon}} \Gamma\left(1-\frac{\varepsilon-1}{\gamma}\right)^{\frac{1}{1-\varepsilon}} C_{\omega}
$$

The overall price index is therefore

$$
P=\frac{\varepsilon}{\varepsilon-1}\left(\sum_{\omega} v_{\omega} J_{\omega}^{\frac{\eta-1}{\varepsilon-1}} \Gamma\left(1-\frac{\varepsilon-1}{\gamma}\right)^{\frac{\eta-1}{\varepsilon-1}} C_{\omega}^{1-\eta}\right)^{\frac{1}{1-\eta}}
$$

To find total profit, note that $j$ 's profit (which comes only from sales to the household because firm-tofirm sales are priced at marginal cost) is $\pi_{\omega j}=u_{\omega j}\left(p_{\omega j}-c_{\omega j}\right)$. Using $u_{\omega j}=U v_{\omega}\left(\frac{P_{\omega}}{P}\right)^{-\eta}\left(\frac{p_{\omega j}}{P_{\omega}}\right)^{-\varepsilon}=$ $U P v_{\omega}\left(\frac{P_{\omega}}{P}\right)^{1-\eta}\left(\frac{p_{\omega j}}{P_{\omega}}\right)^{1-\varepsilon} \frac{1}{p_{j}}$ and $c_{\omega j}=\frac{\varepsilon-1}{\varepsilon} p_{\omega j}$, this is $\pi_{\omega j}=U P v_{\omega}\left(\frac{P_{\omega}}{P}\right)^{1-\eta}\left(\frac{p_{\omega j}}{P_{\omega}}\right)^{1-\varepsilon} \frac{1}{\varepsilon}$. Total profit can be 
found by integrating over all firms

$$
\Pi=\sum_{\omega} \int_{0}^{J_{\omega}} \pi_{\omega j} d j=\sum_{\omega} \int_{0}^{J_{\omega}} U P\left(\frac{v_{\omega} P_{\omega}}{P}\right)^{1-\eta}\left(\frac{p_{\omega j}}{P_{\omega}}\right)^{1-\varepsilon} \frac{1}{\varepsilon} d j=\frac{1}{\varepsilon} U P
$$

Total household income is profit plus wage income, while its expenditure is $U P$, so its budget is $U P=$ $\Pi+w L=\frac{1}{\varepsilon} U P+w L$, or (normalizing the wage to unity)

$$
U=\frac{\varepsilon}{\varepsilon-1} \frac{w}{P} L=\left(\sum_{\omega} v_{\omega} J_{\omega}^{\frac{\eta-1}{\varepsilon-1}} \Gamma\left(1-\frac{\varepsilon-1}{\gamma}\right)^{\frac{\eta-1}{\varepsilon-1}} C_{\omega}^{1-\eta}\right)^{\frac{1}{\eta-1}} L
$$

Proposition 10 A change in the distribution of relationship-specific intermediate input wedges from $T$ to $T^{\prime}$ leads to a change in household utility that can be summarized by

$$
\frac{U^{\prime}}{U}=\left(\sum_{\omega} H H_{\omega}\left(\frac{C_{\omega}^{\prime}}{C_{\omega}}\right)^{1-\eta}\right)^{\frac{1}{\eta-1}}
$$

and the change in industry cost indexes satisfy the following system of equations

$$
\frac{C_{\omega}^{\prime}}{C_{\omega}}=\left[\sum_{\rho \in \varrho(\omega)} R_{\omega \rho}\left(\left(\frac{t_{x}^{* \prime}}{t_{x}^{*}}\right)^{\alpha_{R}^{\rho}} \prod_{\hat{\omega} \in \hat{\Omega}_{\rho}}\left(\frac{C_{\hat{\omega}}^{\prime}}{C_{\hat{\omega}}}\right)^{\alpha_{\hat{\omega}}^{\rho}}\right)^{-\gamma}\right]^{-\frac{1}{\gamma}}
$$

Proof. The share of the household's spending on goods from $\omega$ is

$$
H H_{\omega}=\frac{v_{\omega} P_{\omega}^{1-\eta}}{P^{1-\eta}}=\frac{v_{\omega}\left(\frac{\varepsilon}{\varepsilon-1}\right)^{1-\eta} J_{\omega}^{\frac{1-\eta}{1-\varepsilon}} \Gamma\left(1-\frac{\varepsilon-1}{\gamma}\right)^{\frac{1-\eta}{1-\varepsilon}} C_{\omega}^{1-\eta}}{P^{1-\eta}}
$$

Using $U=\frac{\varepsilon}{\varepsilon-1} L / P$ and rearranging gives

$$
H H_{\omega}=\frac{v_{\omega} J_{\omega}^{\frac{1-\eta}{1-\varepsilon}} \Gamma\left(1-\frac{\varepsilon-1}{\gamma}\right)^{\frac{1-\eta}{1-\varepsilon}} C_{\omega}^{1-\eta}}{(U / L)^{\eta-1}}
$$

Under the counterfactual, we have

$$
\begin{aligned}
\left(U^{\prime} / L\right)^{\eta-1} & =\sum_{\omega} v_{\omega} J_{\omega}^{\frac{\eta-1}{\varepsilon-1}} \Gamma\left(1-\frac{\varepsilon-1}{\gamma}\right)^{\frac{\eta-1}{\varepsilon-1}}\left(C_{\omega}^{\prime}\right)^{1-\eta} \\
& =\sum_{\omega} v_{\omega} J_{\omega}^{\frac{\eta-1}{\varepsilon-1}} \Gamma\left(1-\frac{\varepsilon-1}{\gamma}\right)^{\frac{\eta-1}{\varepsilon-1}} C_{\omega}^{1-\eta}\left(\frac{C_{\omega}^{\prime}}{C_{\omega}}\right)^{1-\eta} \\
& =\sum_{\omega} H H_{\omega}(U / L)^{\eta-1}\left(\frac{C_{\omega}^{\prime}}{C_{\omega}}\right)^{1-\eta}
\end{aligned}
$$

Rearranging gives (14).

We next show that the share of revenue is $R_{\omega \rho}=\kappa_{\omega \rho} B_{\omega \rho}\left(\frac{t_{l}^{\alpha_{L}^{\rho}}\left(t_{x}^{*}\right)^{\alpha_{R}^{\rho}} \prod_{\hat{\omega} \in \Omega^{\rho} \rho} C_{\hat{\omega}}^{\alpha_{\omega}^{\rho}}}{C_{\omega}}\right)^{-\gamma}$, where we define $C_{\omega \rho} \equiv \kappa_{\omega \rho}\left(t_{l}^{\alpha_{L}^{\rho}}\left(t_{x}^{*}\right)^{\alpha_{R}^{\rho}} \prod_{\hat{\omega} \in \hat{\Omega}^{\rho}}\left(Q_{\hat{\omega}}\right)^{\alpha_{\hat{\omega}}^{\rho}}\right)^{\gamma}$, so that $F_{\omega \rho}(q)=e^{-\left(q / Q_{\omega \rho}\right)^{-\gamma}}$. This follows from two facts. First, 
among producers of $\omega$ that have efficiency $q$, the fraction that use recipe $\rho$ is:

$$
\begin{aligned}
\operatorname{Pr}(\rho \mid c, \omega) & =\frac{\left(\prod_{\tilde{\rho} \neq \rho}\left[1-F_{\omega \tilde{\rho}}(c)\right]\right) F_{\omega \rho}^{\prime}(c)}{F_{\omega}^{\prime}(c)}=\frac{F_{\omega \rho}^{\prime}(c) /\left[1-F_{\omega \rho}(c)\right]}{F_{\omega}^{\prime}(c) /\left[1-F_{\omega}(c)\right]} \\
& =\kappa_{\omega \rho} B_{\omega \rho}\left(\frac{t_{l}^{\alpha_{L}^{\rho}}\left(t_{x}^{*}\right)^{\alpha_{R}^{\rho}} \prod_{\hat{\omega} \in \hat{\Omega}^{\rho}} C_{\hat{\omega}}^{\alpha_{\hat{\omega}}^{\rho}}}{C_{\omega}}\right)^{-\gamma}
\end{aligned}
$$

where the last equality follows from $F_{\omega \rho}(c)=1-e^{-\kappa_{\omega \rho} B_{\omega \rho}\left(t_{l}^{\alpha_{L}^{\rho}}\left(t_{x}^{*}\right)^{\alpha_{R}^{\rho}} \prod_{\hat{\omega} \in \hat{\Omega}^{\rho} \rho} C_{\hat{\omega}}^{\alpha_{\hat{\omega}}^{\rho}}\right)^{-\gamma} c^{\gamma}}$ and $F_{\omega}(c)=1-$ $e^{-\left(c / C_{\omega}\right)^{\gamma}}$. The second fact is that, conditional on $c$, revenue is independent of the recipe chosen by a firm or any other feature of the firm's sourcing decisions.

Finally, we have that the counterfactual industry cost indexes $\left\{C_{\omega}^{\prime}\right\}$ satisfy

$$
\begin{aligned}
C_{\omega}^{\prime} & =\left\{\sum_{\rho \in \varrho(\omega)} \kappa_{\omega \rho} B_{\omega \rho}\left(t_{l}^{\alpha_{L}^{\rho}}\left(t_{x}^{* \prime}\right)^{\alpha_{R}^{\rho}} \prod_{\hat{\omega} \in \hat{\Omega}^{\rho}}\left(C_{\hat{\omega}}^{\prime}\right)^{\alpha_{\hat{\omega}}^{\rho}}\right)^{-\gamma}\right\}^{-\frac{1}{\gamma}} \\
& =\left\{\sum_{\rho \in \varrho(\omega)} \kappa_{\omega \rho} B_{\omega \rho}\left(t_{l}^{\alpha_{L}^{\rho}}\left(t_{x}^{*}\right)^{\alpha_{R}^{\rho}} \prod_{\hat{\omega} \in \hat{\Omega}^{\rho}}\left(C_{\hat{\omega}}\right)^{\alpha_{\hat{\omega}}^{\rho}}\right)^{-\gamma}\left(\left(\frac{t_{x}^{* \prime}}{t_{x}^{*}}\right)^{\alpha_{R}^{\rho}} \prod_{\hat{\omega} \in \hat{\Omega}_{\rho}}\left(\frac{C_{\hat{\omega}}^{\prime}}{C_{\hat{\omega}}}\right)^{\alpha_{\hat{\omega}}^{\rho}}\right)^{-\gamma}\right\}^{-\frac{1}{\gamma}} \\
& =\left\{\sum_{\rho \in \varrho(\omega)} R_{\omega \rho} C_{\omega}^{-\gamma}\left(\left(\frac{t_{x}^{* \prime}}{t_{x}^{*}}\right)^{\alpha_{R}^{\rho}} \prod_{\hat{\omega} \in \hat{\Omega}_{\rho}}\left(\frac{C_{\hat{\omega}}^{\prime}}{C_{\hat{\omega}}}\right)^{\alpha_{\hat{\omega}}^{\rho}}\right)^{-\gamma}\right\}^{-\frac{1}{\gamma}}
\end{aligned}
$$

Rearranging yields (15).

\section{D.4 Imperfect Enforcement: Microfoundation}

There are two frictions. Suppliers can deliver defective intermediate inputs that cause the buyer to have to use labor, and workers can shirk.

First, a supplier of a relationship-specific input can sell a good that is defective or imperfectly customized to the buyer. If this happens, the buyer needs to hire extra labor to correct the defect. The supplier can save on production cost by producing defective inputs. If the supplier produces intermediate inputs that are defective enough so that the buyer must use up $\psi^{x}$ efficiency units of labor, the supplier's cost is scaled by a factor of $g^{x}\left(\psi^{x}\right) \leq 1$. Both the buyer and supplier recognize that the supplier will save on cost by producing a defective input, and the price will be $\tilde{p}_{s}\left(\psi^{x}\right)=g^{x}\left(\psi^{x}\right) c_{s}$ where $c_{s}$ is the supplier's unit cost of producing the intermediate input defect-free.

Similarly, a worker that shirks derives value from shirking. Let $\tilde{w}\left(\psi^{l}\right)$ be the wage a firm must pay to attract a worker that shirks enough so that only $\frac{1}{\psi^{l}}$ efficiency units of labor are delivered per unit of raw labor.

The buyer takes as given prices, the defectiveness of the input, and worker's shirking, and minimizes cost. Let $l^{\text {prod }}$ be the mass of labor hired for production and let $l_{\hat{\omega}}^{x}$ be the mass of labor hired to customize the defective inputs. The firm's cost minimization problem can be described as:

$$
\min \tilde{w}\left(\psi^{l}\right)\left(l^{\text {prod }}+\sum_{\hat{\omega} \in \hat{\Omega}_{R}^{\rho}} l_{\hat{\omega}}^{x}\right)+\sum_{\hat{\omega} \in \Omega_{R}^{\rho}} \tilde{p}_{\hat{\omega} s}\left(\psi^{x}\right) x_{\hat{\omega}}+\sum_{\hat{\omega} \in \Omega_{R}^{\rho}} p_{\hat{\omega} s} x_{\hat{\omega}}
$$

subject to

$$
G\left(b_{l} \frac{l^{\text {prod }}}{\psi^{l}},\left\{b_{\hat{\omega}} z_{\hat{\omega}} \min \left\{x_{\hat{\omega}}, \frac{l_{\hat{\omega}}^{x}}{\psi^{l} \psi^{x}}\right\}\right\}_{\hat{\omega} \in \hat{\Omega}_{R}^{\rho}},\left\{b_{\hat{\omega}} z_{\hat{\omega}} x_{\hat{\omega}}\right\}_{\hat{\omega} \in \hat{\Omega}_{H}^{\rho}}\right) \geq y
$$


Weak enforcement means that the court will only enforce claims where the damage is large relative to the size of the transaction. For the defective inputs, the cost to the buyer is $\tilde{w}\left(\psi^{l}\right) l_{\hat{\omega}}^{x}$ and the value of the transaction is $\tilde{p}_{s}\left(\psi^{x}\right) x_{\hat{\omega}}$. It is assumed that the court will not step in unless the damage ratio $\frac{\tilde{w}\left(\psi^{l}\right) l_{\hat{\omega}}^{x}}{\tilde{p}_{s}\left(\psi^{x}\right) x_{\hat{\omega}}}$ is greater than $t_{x \hat{\omega}}-1$. With worker shirking, the cost to the buyer is $\tilde{w}\left(\psi^{l}\right)\left(\psi^{l}-1\right) l$ and the value of the transaction is $\tilde{w}\left(\psi^{l}\right) l$. It is assumed that if the damage ratio $\frac{\tilde{w}\left(\psi^{l}\right)\left(\psi^{l}-1\right) l}{\tilde{w}\left(\psi^{l}\right) l}$ is no greater than $t_{l}-1$ then the court will not step in. The supplier and the worker shirk up to the point of the court stepping in.

In this case, we can use the expressions for $t_{l}, t_{x}$, and $x_{\hat{\omega}}=\frac{l_{\omega}^{x}}{\psi^{l} \psi^{x}}$ to rewrite the cost minimization problem as

$$
\min t_{l} \tilde{w}\left(\psi^{l}\right) \frac{l^{\text {prod }}}{\psi^{l}}+\sum_{\hat{\omega} \in \Omega_{R}^{\rho}}\left(t_{x \hat{\omega}} \tilde{p}_{\hat{\omega} s}\left(\psi^{l}\right) x_{\hat{\omega}}+\sum_{\hat{\omega} \in \Omega_{R}^{\rho}} p_{\hat{\omega} s} x_{\hat{\omega}}\right.
$$

subject to

$$
G\left(b_{l} \frac{l^{\text {prod }}}{\psi^{l}},\left\{b_{\hat{\omega}} z_{\hat{\omega}} x_{\hat{\omega}}\right\}_{\hat{\omega} \in \hat{\Omega}_{R}^{\rho}},\left\{b_{\hat{\omega}} z_{\hat{\omega}} x_{\hat{\omega}}\right\}_{\hat{\omega} \in \hat{\Omega}_{H}^{\rho}}\right) \geq y
$$

Finally, we study the limiting economy as $\tilde{w}\left(\psi^{l}\right) \rightarrow w$ and $p_{s}\left(\psi^{x}\right) \rightarrow c_{s}$. In this limit, the payoff to the worker from shirking or to the supplier from shirking are almost zero, but the cost to the buyer may still be large. In this limit, the buyer's marginal cost is

$$
c=\mathcal{C}\left(\frac{t_{l} w}{b_{l}},\left\{\frac{t_{x \hat{\omega}} p_{s}}{b_{\hat{\omega}} z_{\hat{\omega}}}\right\}_{\hat{\omega} \in \hat{\Omega}_{R}^{\rho}},\left\{\frac{p_{s}}{b_{\hat{\omega}} z_{\hat{\omega}}}\right\}_{\hat{\omega} \in \hat{\Omega}_{H}^{\rho}}\right)
$$

In principle, the contracts can be written to get around this friction. However, the doctrine of expectation damages limits the damages the buyer can collect from the supplier. The damages cannot be more than what is needed so that the buyer's is as well off as she would have been had the contract been honored.

\section{E Empirical Support for Model Assumptions}

\section{E.1 Distortions and Markups}

Table XXIII shows how measured markups, plants ratio of sales to cost vary with the level of distortions. Court congestion should increase distortions for plants in industries that tend to rely on relationship-specific relative to those in industries that tend to rely on homogeneous inputs. The first row of the table indicates that, across all measures, ratios of sales to cost decline with distortions. The second and third column shows that this appears to be the direct impact of the distortions rather than the indirect impact of distortions on size or age. 
Table XXIII Sales over Total Cost

\begin{tabular}{lcccccc}
\hline & \multicolumn{5}{c}{ Dependent variable: Sales/Total Cost } \\
\cline { 2 - 6 } & $(1)$ & $(2)$ & $(3)$ & $(4)$ & $(5)$ & $(6)$ \\
\hline Avg Age Of Civil Cases * Rel. Spec. & $-0.0353^{* *}$ & $-0.0347^{* *}$ & $-0.0345^{* *}$ & $-0.0494^{*}$ & $-0.0496^{*}$ & $-0.0508^{*}$ \\
& $(0.0097)$ & $(0.0094)$ & $(0.0093)$ & $(0.022)$ & $(0.022)$ & $(0.022)$ \\
Plant Age & & $0.000574^{* *}$ & $0.000258^{+}$ & & $0.000575^{* *}$ & $0.000259^{+}$ \\
& & $(0.00014)$ & $(0.00014)$ & $(0.00014)$ & $(0.00014)$ \\
Log Employment & & & $0.0314^{* *}$ & & $0.0314^{* *}$ \\
& & & $(0.0016)$ & & & $(0.0016)$ \\
\hline 5 -digit Industry FE & & & Yes & Yes & Yes & Yes \\
District FE & Yes & Yes & Yes & Yes & Yes & Yes \\
\hline Estimator & Yes & Yes & OLS & IV & IV \\
\hline$R^{2}$ & OLS & OLS & 0.115 & 0.114 & 0.110 & 0.115 \\
Observations & 0.114 & 0.110 & 0.115 & 205109 & 204767 \\
\hline Standard errors in parentheses & 208527 & 205109 & 204767 & 208527 & &
\end{tabular}

Standard errors in parentheses

$+p<0.10,{ }^{*} p<0.05,{ }^{* *} p<0.01$

\section{E.2 Do wedges get paid in another factor?}

We have assumed that when a relationship-specific input is distorted, primary inputs get used up. Primary inputs includes labor, capital, services, and some other inputs. Table XXIV shows regressions of the cost share of labor/capital/services/other inputs in total non-material inputs on the interaction of court quality and relationship-specificity. This might happen if one particular component of primary inputs was used to customize the distorted input, or if the distorted intermediate input were particularly complementary with one particular component. We do not find evidence that the cost share of any particular component of primary inputs is systematically correlated with wedges.

Table XXIV Cost share of factors in equipped labor

\begin{tabular}{|c|c|c|c|c|}
\hline & Labor & Capital & Services & Rest \\
\hline & (1) & $(2)$ & (3) & (4) \\
\hline Avg Age Of Civil Cases * Rel. Spec. & $\begin{array}{c}-0.000504 \\
(0.0054)\end{array}$ & $\begin{array}{l}0.00405 \\
(0.0030)\end{array}$ & $\begin{array}{c}-0.000248 \\
(0.0046)\end{array}$ & $\begin{array}{r}-0.00355 \\
(0.0049)\end{array}$ \\
\hline 5-digit Industry FE & Yes & Yes & Yes & Yes \\
\hline District FE & Yes & Yes & Yes & Yes \\
\hline$R^{2}$ & 0.310 & 0.232 & 0.341 & 0.269 \\
\hline Observations & 208527 & 208527 & 208527 & 208527 \\
\hline
\end{tabular}

\section{E.3 Plant-level substitutability of inputs}

Fact 1 showed that when relationship-specific inputs are more severely distorted, the cost share of those inputs declines. In our model, this happens because the buyer must expend additional primary inputs in order to use the relationship-specific input. An alternative possibility is that the distortion raises the price paid to the supplier. If primary inputs and intermediate inputs were substitutes, the cost share of intermediates would fall. However, we believe the evidence does not support an elasticity of substitution between primary and intermediate inputs that is larger than unity. Indeed, in the model, the average cost share of intermediate 
inputs among plants that use any particular recipe is independent of the cost of intermediate inputs and the cost of labor.

We know of two estimates of long-run plant level elasticities of substitution between materials and primary inputs, Oberfield and Raval (2014) and Appendix B.3 of Atalay (2017). Each find that elasticities slightly less than unity. Further, we can investigate this elasticity in the context of Indian manufacturing plants. Table XXV uses the interaction of court quality with the average dependence on relationship-specific inputs among an industry's upstream industries to stand in for a shifter to the cost of intermediate inputs. The IV coefficient estimates are positive. Thus we do not find support for an assertion that primary and intermediate inputs are substitutes at the plant-level.

Table XXV Plant-level elasticity of substitution

\begin{tabular}{|c|c|c|c|c|}
\hline & \multicolumn{4}{|c|}{ Dependent variable: Materials Expenditure in Total Cost } \\
\hline & (1) & $(2)$ & $(3)$ & (4) \\
\hline Avg Age Of Civil Cases * Rel. Spec. & $\begin{array}{r}-0.0147^{+} \\
(0.0080)\end{array}$ & $\begin{array}{l}-0.0135 \\
(0.0089)\end{array}$ & $\begin{array}{c}-0.0397^{* *} \\
(0.013)\end{array}$ & $\begin{array}{c}-0.0401^{* *} \\
(0.013)\end{array}$ \\
\hline LogGDPC * Rel. Spec. & & $\begin{array}{c}0.0112 \\
(0.0090)\end{array}$ & & $\begin{array}{c}0.00653 \\
(0.0095)\end{array}$ \\
\hline Avg Age Of Civ. Cases * Rel. Spec. of Upstream Sector & $\begin{array}{c}-0.00360 \\
(0.011)\end{array}$ & $\begin{array}{c}0.00268 \\
(0.012)\end{array}$ & $\begin{array}{c}0.0450^{*} \\
(0.019)\end{array}$ & $\begin{array}{c}0.0349^{+} \\
(0.020)\end{array}$ \\
\hline Trust $*$ Rel. Spec. & & $\begin{array}{l}0.0274 \\
(0.038)\end{array}$ & & $\begin{array}{l}0.0342 \\
(0.038)\end{array}$ \\
\hline Language HHI * Rel. Spec. & & $\begin{array}{l}0.0467 \\
(0.032)\end{array}$ & & $\begin{array}{l}0.0501 \\
(0.032)\end{array}$ \\
\hline Caste HHI * Rel. Spec. & & $\begin{array}{c}0.0980^{*} \\
(0.050)\end{array}$ & & $\begin{array}{c}0.0897^{+} \\
(0.050)\end{array}$ \\
\hline 5-digit Industry FE & Yes & Yes & Yes & Yes \\
\hline District FE & Yes & Yes & Yes & Yes \\
\hline Estimator & OLS & OLS & IV & IV \\
\hline$R^{2}$ & 0.480 & 0.484 & 0.480 & 0.484 \\
\hline Observations & 208527 & 196748 & 208527 & 196748 \\
\hline
\end{tabular}

Standard errors in parentheses, clustered at the state $\times$ industry level.

$+p<0.10,{ }^{*} p<0.05,{ }^{* *} p<0.01$

\section{E.4 Distortions are costly}

In our microfoundation, the reason a distortion is costly is that the resource the supplier saves by delivering an imperfect input is smaller than the resources used by the buyer correcting the input. An alternative possibility is that these costs are roughly equal, in which case there would be no resource cost of the distortion despite the fact that the buyer's reduced cost share of relationship-specific inputs. In the extreme, this would mean that despite the impact on cost shares, there loss in productivity would be smaller than suggested by Section 4.2. We argue here that distortions do indeed raise the buyer's cost. Table XXVI shows that when distortions are more likely to be severe - in industries that tend to rely on relationship-specific inputs in states with slower courts - industries tend to have fewer plants. 
Table XXVI Extensive-margin regressions

\begin{tabular}{|c|c|c|c|c|c|c|}
\hline & \multicolumn{6}{|c|}{ Dependent variable: $\log \left|J_{\omega, t}^{d}\right|$} \\
\hline & (1) & $(2)$ & $(3)$ & $(4)$ & $(5)$ & (6) \\
\hline Avg Age Of Civil Cases * Rel. Spec. & $\begin{array}{c}-0.0413^{*} \\
(0.017)\end{array}$ & $\begin{array}{c}-0.0382^{*} \\
(0.017)\end{array}$ & $\begin{array}{c}-0.0259 \\
(0.018)\end{array}$ & $\begin{array}{c}-0.133^{* *} \\
(0.035)\end{array}$ & $\begin{array}{c}-0.107^{* *} \\
(0.035)\end{array}$ & $\begin{array}{c}-0.106^{* *} \\
(0.032)\end{array}$ \\
\hline LogGDPC * Rel. Spec. & & $\begin{array}{c}0.0505^{* *} \\
(0.016)\end{array}$ & $\begin{array}{c}0.0518^{* *} \\
(0.016)\end{array}$ & & $\begin{array}{l}0.0313 \\
(0.019)\end{array}$ & $\begin{array}{c}0.0353^{*} \\
(0.018)\end{array}$ \\
\hline Trust $*$ Rel. Spec. & & & $\begin{array}{c}-0.0482 \\
(0.14)\end{array}$ & & & $\begin{array}{c}0.00793 \\
(0.14)\end{array}$ \\
\hline Language HHI * Rel. Spec. & & & $\begin{array}{l}0.120 \\
(0.15)\end{array}$ & & & $\begin{array}{l}0.121 \\
(0.15)\end{array}$ \\
\hline Caste HHI * Rel. Spec. & & & $\begin{array}{c}0.225^{* *} \\
(0.086)\end{array}$ & & & $\begin{array}{l}0.171^{+} \\
(0.087)\end{array}$ \\
\hline Corruption * Rel. Spec. & & & $\begin{array}{c}0.537^{+} \\
(0.32)\end{array}$ & & & $\begin{array}{l}0.381 \\
(0.33)\end{array}$ \\
\hline 5-digit Industry FE & Yes & Yes & Yes & Yes & Yes & Yes \\
\hline State $\times$ Year FE & Yes & Yes & Yes & Yes & Yes & Yes \\
\hline Estimator & OLS & OLS & OLS & IV & IV & IV \\
\hline$R^{2}$ & 0.410 & 0.417 & 0.423 & 0.410 & 0.417 & 0.423 \\
\hline Observations & 191008 & 183214 & 177075 & 191008 & 183214 & 177075 \\
\hline
\end{tabular}

Standard errors in parentheses, clustered at the state $\times$ industry level.

$+p<0.10,{ }^{*} p<0.05,{ }^{* *} p<0.01$

Note: Dependent variable is the log number of producers of $\omega$ in a state $d$ at time $t$. Multi-product plants are counted once for each product. GDP per capita is the average district GDP per capita within each state.

\section{F Additional Structural Results}

\section{F.1 Counterfactual: Robustness to different parameter values}

Figures 7 and 8 show the results from the welfare counterfactual for different values of $\gamma$ and $\zeta$. 
Figure 7 Welfare counterfactual for different elasticities $\gamma$

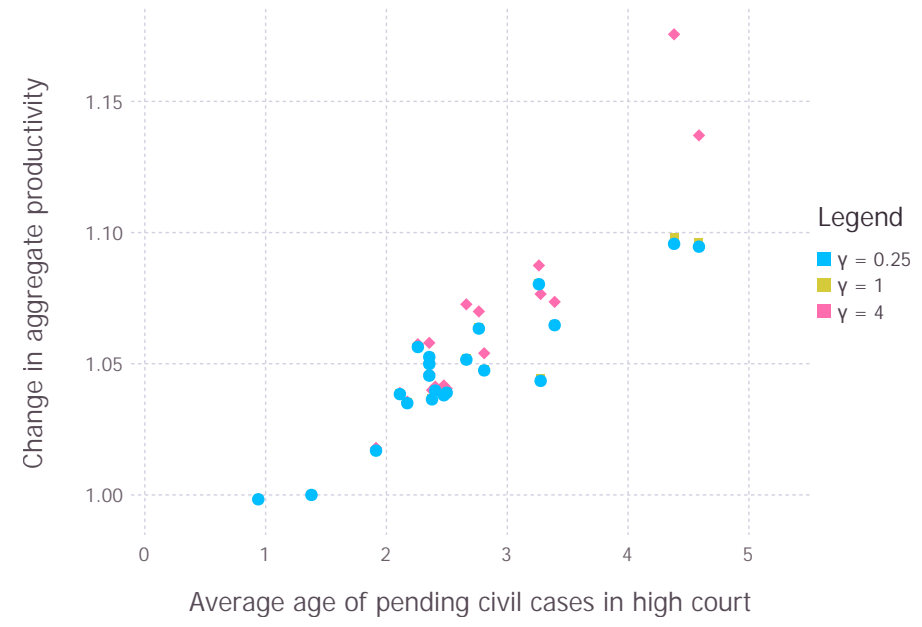

The figure shows the counterfactual increase in $U$ for each state for different values of $\gamma$.

Figure 8 Welfare counterfactual for different elasticities $\zeta$

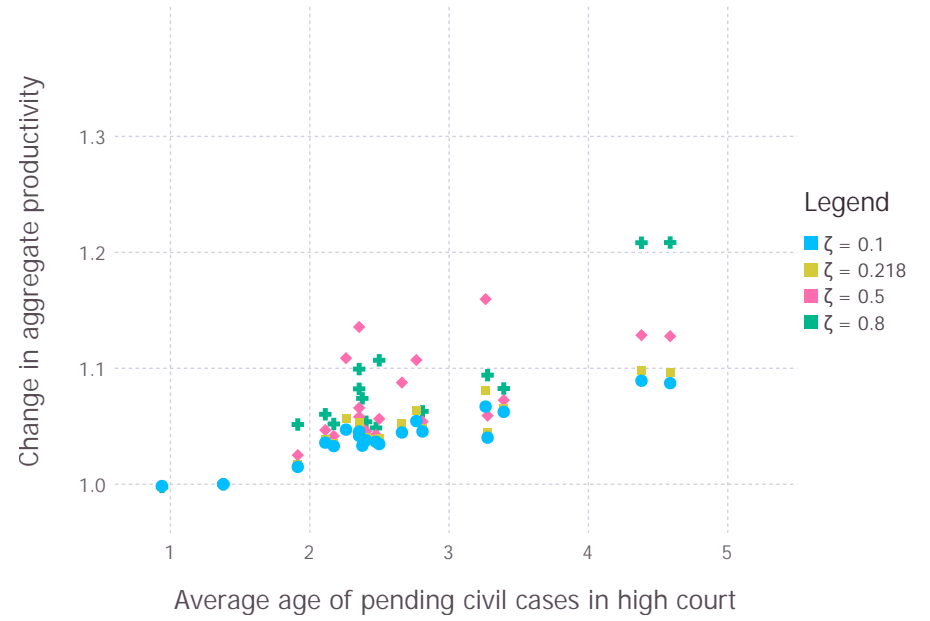

The figure shows the counterfactual increase in $U$ for each state for different values of $\zeta$. 


\section{F.2 Fineness of recipes}

This subsection explores the robustness of our estimates to the choice of how finely to define recipes. In our clustering procedure that defines recipes, we have to choose the number of clusters (recipes) within each product. In the baseline results, we choose $\left\lceil n \log \left((\# \text { observations })_{\omega}\right)\right\rceil$ clusters, where \#observations $\omega_{\omega}$ is the number of single product plant-year observations that produce $\omega$, and set $n=1.5$.

We now explore how much this choice of $n=1.5$ matters. To do so, we run linear regressions that most closely mimic the structural regressions (cf. the GMM moment conditions in Proposition 5):

$$
\log \left(\frac{\bar{s}_{R}^{\rho d}}{\bar{s}_{H}^{\rho d}}\right)=\beta \cdot(\text { Court quality })_{d}+\nu_{\rho}+\varepsilon_{\rho d}
$$

where $\bar{s}_{R}^{\rho d}$ (and $\bar{s}_{H}^{\rho d}$ ) is the weighted average sales share of relationship-specific (homogeneous) inputs of plants that produce using recipe $\rho$ in state $d$ (weights are the probability weights as in the GMM procedure), and $\nu_{\rho}$ is a set of fixed effects. The estimate for $\beta$ has a negative sign: Among plants that use a particular recipe, the sales shares of relationship-specific inputs is low compared to homogeneous inputs when courts are slow (i.e., when the average age of pending cases is high). The same holds when we instrument for court quality with the log age of court.

Figure F.2 shows that the point estimates do not change much with the fineness of our recipe classification. For $n=0$, each product category has only a single recipe, so the total number of recipes equals the number of products (which is 4,530). For $n=3$, each product category has on average 7.3 recipes, resulting in a total of 33,225 recipes. With more recipes, the estimates become more precise: the clustering procedure assigns outliers their own recipe, so that no longer contaminate the within-recipe variation in average sales shares. 


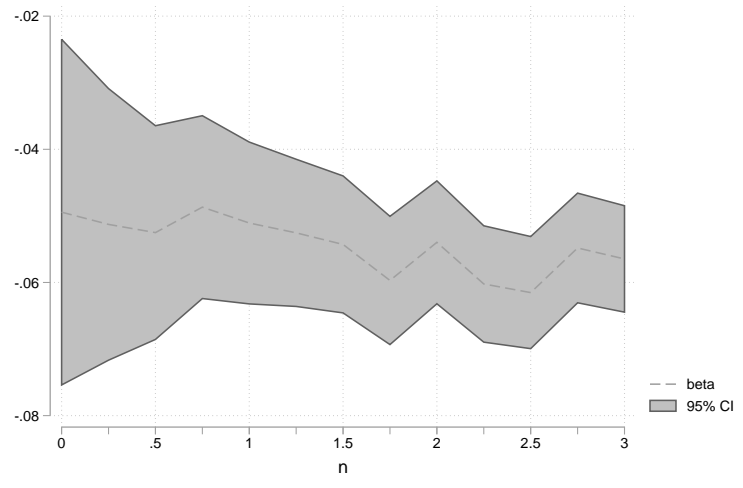

(a) OLS

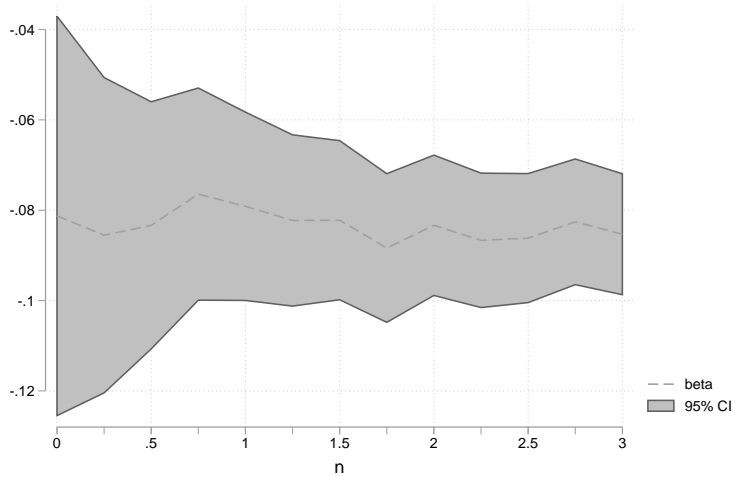

(b) IV

Figure 9 Regression coefficients for different levels of recipe fineness 